\title{
Viviane Rossi Figueiredo
}

\author{
Avaliação dos efeitos pulmonares e \\ sistêmicos agudos em resposta à injeção \\ intrapleural de talco de diferentes tamanhos \\ de partículas
}

Tese apresentada à Faculdade de Medicina da Universidade de São Paulo para obtenção do título de Doutor em Ciências

Área de Concentração: Pneumologia

Orientadora: Profa. Dra. Leila Antonangelo

\section{São Paulo}

2006 
"Sou-lhe grato, principalmente, pelo privilégio que me obteve de poder --- sem demasia das ilusões, mas reverente --- levantar a voz nesse recinto, como um menino que depõe o seu brinquedo na superfície translúcida de uma água, para a qual a serenidade não é a estagnação, e cujo brilho da face viva nada rouba à projeção poderosa da profundidade".

João Guimarães Rosa 


\section{DEDICATÓRIAS}

Ao meu querido Luiz Fernando, meu amigo e companheiro, que trouxe luz para a minha vida e calor para o meu coração;

Aos meus filhos Eduardo e Maria Fernanda, o meu sol e a minha lua;

Aos meus pais, Ruth e Demóstenes, que velaram o meu sono, me embalaram no colo e me amaram profundamente todos esses anos. 


\section{AGRADECIMENTOS}

- À minha orientadora, Profa. Dra. Leila Antonangelo, exemplo de mulher profissional, pela dedicação e perseverança mesmo na adversidade. Agradeço cada minuto de sua atenção, quando seu minuto era tão precioso;

- Ao Prof. Dr. Francisco Vargas Suso, pelo apoio e incentivo, nessa etapa tão importante da minha vida. Agradeço as orientações e principalmente as repreensões, fonte de aprendizado;

- Ao Prof. Dr. Evaldo Marchi e Profa. Dra. Lisete Ribeiro Teixeira, exemplos de dedicação acadêmica, pelo apoio e incentivo e principalmente pelo ombro amigo nas horas de dificuldade;

- Ao Dr. Eduardo Henrique Genofre, pela disponibilização tão gentil e tranqüila das informações. Agradeço imensamente sua generosidade e seu apoio;

- Ao Serviço de Broncoscopia do HCFMUSP, pelo grupo maravilhoso de profissionais (médicos, enfermeiros e funcionários administrativos), que me incentivaram em durante todos esses anos;

- Ao Grupo de Pleura InCor HCFMUSP, que me acolheu com 
amizade e respeito;

- Aos colegas Dra. Milena Marques Pagliarelli Acencio, Carlos Sérgio Rocha Silva e Gabriela Gaspar Carnevale, pelas orientações durante todas as etapas do trabalho;

- Aos profissionais Luiz César Moreira, Tânia Cabral, Antoniete Lamana e Geni Pedroso, pela paciência e dedicação, recebendo minhas amostras mesmo após o horário.

- À Profa Dra. Vera Capelozzi e ao colega Edwin Parra, pela gentileza na análise histológica, fundamental para a finalização do estudo;

- À Comissão de Pós-graduação, pelo apoio, capacidade de orientação e transmissão de informações. 


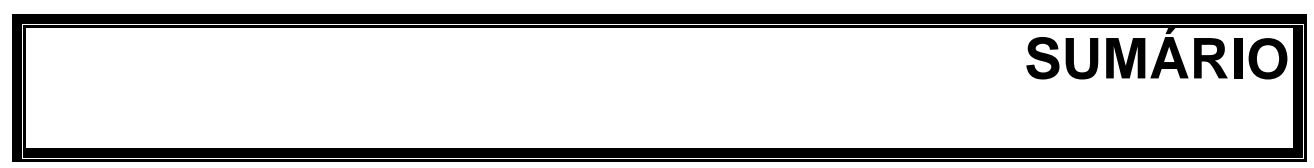




\title{
SUMÁRIO
}

\author{
LISTA DE ABREVIATURAS \\ LISTA DE FIGURAS \\ LISTA DE TABELAS \\ RESUMO \\ SUMMARY
}

INTRODUÇÃO

OBJETIVOS

MATERIAL E MÉTODOS 10

$\begin{array}{ll}\text { Composição dos grupos } & 10\end{array}$

Análise do talco com relação ao tamanho e à composição

elemental das partículas $\quad 12$

Injeção do esclerosante $\quad 15$

Eutanásia $\quad 15$

$\begin{array}{ll}\text { Coleta de sangue } & 16\end{array}$

$\begin{array}{ll}\text { Coleta de lavado broncoalveolar } & 16\end{array}$

$\begin{array}{ll}\text { Coleta dos pulmões para análise histológica } & 17\end{array}$

Fator de correção da diluição do lavado broncoalveolar 17

Citologia global e diferencial do lavado broncoalveolar e do sangue 18

Dosagens bioquímicas e imunológicas no soro e no LBA 19

Análise histológica e contagem de partículas de talco nos pulmões 20

Análise estatística $\quad 21$

RESULTADOS 22

1 - Sangue e lavado broncoalveolar $\quad 22$

1.1 - Leucócitos 22

1.2 - Neutrófilos 24

1.3 - Fator de correção da diluição do lavado broncoalveolar 25

1.4 - Desidrogenase lática $\quad 25$ 
1.5 - Proteína C reativa $\quad 25$

1.6 - Fator de crescimento endotelial vascular 27

1.7 - Interleucina 8

2 - Correlações 37

2.1 - Correlações observadas entre os valores obtidos de IL-8,

VEGF e DHL no LBA e no sangue 37

2.2 - Correlação entre os valores de IL-8, VEGF e DHL obtidos no LBA à direita e à esquerda 38

2.3 - Correlações entre os valores de IL-8, VEGF e DHL no LBA

(direita e esquerda) e sangue. $\quad 40$

3 - Avaliação quantitativas partículas de talco nos pulmões dos animais dos grupos TP, TM e controle

4 - Avaliação histológica do pulmão dos animais dos grupos TP e TM e controle

DISCUSSÃO

CONCLUSÕES

REFERÊNCIAS

63

\section{ANEXOS}

ANEXO A

ANEXO B

ANEXO C 


\section{LISTA DE ABREVIATURAS}

DHL Desidrogenase lática

DTPA Ácido pentético complexado com tecnécio 99m

ELISA Enzyme-linked immunosorbent assay

HE Hematoxilina-eosina

IL Interleucina

IPT Instituto de Pesquisas Tecnológicas da Universidade de São Paulo

LBA Lavado broncoalveolar

MEV Microscopia eletrônica de varredura

PCR Proteína C reativa

SDRA Síndrome do desconforto respiratório agudo

TM Talco de partículas de tamanhos diversos

TNF $\alpha \quad$ Fator de Necrose Tumoral

TP Talco de partículas pequenas

VEGF Fator de crescimento endotelial vascular 


\section{LISTA DE FIGURAS}

Figura 1: Aspecto do talco de partículas pequenas (TP). Microscopia Eletrônica de Varredura (2,0 KX).

Figura 2: Aspecto do talco misto de partículas de tamanhos diversos (TM). Microscopia Eletrônica de Varredura (3,5 KX).

Figura 3: Evolução temporal dos níveis séricos de PCR (mg/L) de coelhos submetidos à injeção intrapleural de TP e TM.

Figura 4: Evolução temporal dos níveis séricos de VEGF $(\mathrm{pg} / \mathrm{mL})$ de coelhos submetidos à injeção intrapleural de TP e TM.

Figura 5: Evolução temporal dos níveis de VEGF no LBA à direita e à esquerda de coelhos submetidos à injeção intrapleural de TP e TM.

Figura 6: Evolução temporal dos níveis séricos de IL-8 $(\mathrm{pg} / \mathrm{mL})$ de coelhos submetidos à injeção intrapleural de TP e TM.

Figura 7: Evolução temporal dos níveis de IL-8 no LBA à direita e à esquerda de coelhos submetidos à injeção de TP e TM intrapleural.

Figura 8: Correlação entre os níveis de VEGF $(\mathrm{pg} / \mathrm{mL})$ do sangue e do LBA à direita e à esquerda no grupo de coelhos submetidos à injeção intrapleural de TP.

Figura 9: Correlação entre os níveis de VEGF $(\mathrm{pg} / \mathrm{mL})$ do sangue e do LBA à direita e à esquerda no grupo de coelhos submetidos à injeção intrapleural de TM. 
Figura 10: Correlação entre os níveis de IL-8 (pg/mL) no lavado broncoalveolar à direita e no lavado broncoalveolar à esquerda.

Figura 11: Correlação entre os níveis de VEGF no LBA à direita e à esquerda.

Figura 12: Correlação entre os níveis de DHL no LBA à direita e à esquerda (grupo TP).

Figura 13: Correlação entre os níveis de IL-8 e de VEGF no LBA à direita e à esquerda dos animais submetidos à injeção intrapleural de TP.

Figura 14: Fotomicrografia de parênquima pulmonar de coelho submetido à injeção intrapleural de TM. Presença de partículas de talco. HE com luz polarizada, aumento de 400X.

Figura 15: Fotomicrografia de parênquima pulmonar de coelho submetido à injeção intrapleural de TP. Presença de partículas de talco. HE com luz polarizada, HE aumento de 400X.

Figura 16: Fotomicrografia de parênquima pulmonar de coelho submetido à injeção intrapleural de TP. Presença de capilarite (C) e macrófagos (M). HE aumento de 400X.

Figura 17: Fotomicrografia de parênquima pulmonar de coelho submetido à injeção intrapleural de TM. Presença de macrófagos (setas). HE, aumento de 400X.

Figura 18: Fotomicrografia de parênquima pulmonar de coelho submetido à injeção intrapleural de TP. Presença de trombo. HE, aumento de 400X. 
Figura 19: Fotomicrografia de parênquima pulmonar de coelho submetido à injeção intrapleural de TM. Presença de infiltrado linfomononuclear (setas). HE, aumento de 400X. 


\section{LISTA DE TABELAS}




\section{LISTA DE TABELAS}

Tabela 1: Total de leucócitos $/ \mathrm{mm}^{3}$ no LBA de coelhos submetidos à injeção intrapleural de TP ou TM. Comparação entre os grupos TP e TM.

Tabela 2: Total de leucócitos $/ \mathrm{mm}^{3}$ no LBA de coelhos submetidos à injeção intrapleural de TP ou TM. Comparação entre os lados direito e esquerdo.

Tabela 3: Níveis séricos de PCR $(\mathrm{mg} / \mathrm{dL})$ de coelhos submetidos à injeção intrapleural de TP ou TM. Comparação com grupo controle.

Tabela 4: Níveis séricos de PCR $(\mathrm{mg} / \mathrm{dL})$ de coelhos submetidos à injeção intrapleural de TP ou TM. Comparação entre os grupos TP e TM.

Tabela 5: Níveis de VEGF ( $\mathrm{pg} / \mathrm{mL}$ ) no sangue de coelhos submetidos à injeção intrapleural de TP e TM. Comparação com grupo controle.

Tabela 6: Níveis de VEGF (pg/mL) no LBA de coelhos submetidos à injeção intrapleural de TP ou TM. Comparação com grupo controle.

Tabela 7: Níveis de VEGF (pg/mL) no LBA de coelhos submetidos à injeção intrapleural de TP ou TM. Comparação entre os lados direito e esquerdo.

Tabela 8: Níveis de IL-8 (pg/mL) no sangue de coelhos submetidos à injeção intrapleural de TP ou TM. Comparação com 
Tabela 9: Níveis de IL-8 (pg/mL) no LBA de coelhos submetidos à injeção intrapleural de TP ou de TM. Comparação com grupo controle.

Tabela 10: Níveis séricos de IL-8 $(\mathrm{pg} / \mathrm{mL})$ de coelhos submetidos à injeção intrapleural de TP ou TM. Comparação entre os grupos TP e TM.

Tabela 11: Níveis de IL-8 (pg/mL) no LBA de coelhos submetidos à injeção intrapleural de TP ou de TM. Comparação entre os grupos TP e TM.

Tabela 12: Níveis de IL-8 (pg/mL) no LBA de coelhos submetidos à injeção intrapleural de TP e TM. Comparação entre os lados direito e esquerdo.

Tabela 13: Avaliação da celularidade nos pulmões direito e esquerdo de coelhos submetidos à injeção intrapleural de TP ou de TM (escore de 0 a 3). Comparação com grupo controle.

Tabela 14: Avaliação da capilarite nos pulmões direito e esquerdo de coelhos submetidos à injeção intrapleural de TP ou de TM (escore de 0 a 3). Comparação com grupo controle.

Tabela 15: Avaliação da presença de infiltrado linfomononuclear nos pulmões direito e esquerdo de coelhos submetidos à injeção intrapleural de TP ou de TM (escore de 0 a 3). Comparação com grupo controle.

Tabela 16: Avaliação da presença de macrófagos nos pulmões direito e esquerdo de coelhos submetidos à injeção intrapleural de 
TP ou de TM (escore de 0 a 3). Comparação com grupo controle.

Tabela 17: Avaliação da celularidade nos pulmões direito e esquerdo de coelhos submetidos à injeção intrapleural de TP ou de TM (escore de 0 a 3). Comparação entre os grupos TP e TM.

Tabela 18: Avaliação da presença de infiltrado linfomononuclear nos pulmões direito e esquerdo de coelhos submetidos à injeção intrapleural de TP ou de TM (escore de 0 a 3). Comparação entre os grupos TP e TM.

Tabela 19: Avaliação da celularidade nos pulmões direito e esquerdo de coelhos submetidos à injeção intrapleural de TP ou de TM (escore de 0 a 3). Comparação entre os lados direito e esquerdo.

Tabela 20: Avaliação da presença de capilarite nos pulmões direito e esquerdo de coelhos submetidos à injeção intrapleural de TP ou de TM (escore de 0 a 3). Comparação entre os lados direito e esquerdo.

Tabela 21: Avaliação da presença de infiltrado linfomononuclear nos pulmões direito e esquerdo de coelhos submetidos à injeção intrapleural de TP ou de TM (escore de 0 a 3). Comparação entre os lados direito e esquerdo. 
Figueiredo VR. Avaliação dos efeitos pulmonares e sistêmicos agudos em resposta à injeção intrapleural de talco de diferentes tamanhos de partículas [tese]. São Paulo: Faculdade de Medicina, Universidade de São Paulo; 2006. 68p.

Pacientes com comprometimento pleural por neoplasias malignas freqüentemente apresentam derrame pleural recidivante. Nestes casos, a sínfise das membranas pleurais (pleurodese) com a finalidade de evitar o acúmulo de líquido no espaço pleural deve ser considerada. O talco é o agente mais utilizado indicado para essa finalidade. Entretanto, seu uso terapêutico continua controverso devido aos efeitos deletérios que podem advir de sua utilização. O mais grave entre todos é a insuficiência respiratória aguda, que pode evoluir para a síndrome do desconforto respiratório agudo (SDRA). Essa complicação pode estar relacionada com a composição, com o tamanho das partículas de talco e com a resposta inflamatória desencadeada pelas mesmas. O objetivo deste estudo foi avaliar os efeitos pulmonares e sistêmicos em resposta à injeção intrapleural (IIP) de talco de partículas pequenas (TP) e de partículas de tamanhos diversos (TM). Cem coelhos foram submetidos à IIP com talco. Metade dos animais foi injetada com TP (diâmetro médio= 6,41 $\mu \mathrm{m}$ ) e outra metade com TM (diâmetro médio $=21,15 \mu \mathrm{m}$ ), que é o talco usado na prática clínica. Quinze coelhos compuseram o grupo controle. Foram avaliados a celularidade, os níveis de desidrogenase lática ( $\mathrm{DHL})$, proteína C reativa (PCR), interleucina-8 (IL-8) e fator de crescimento endotelial vascular (VEGF) no sangue e no lavado broncoalveolar (LBA) às 6, 24, 48, 72 e 96 horas após a IIP. Realizou-se também a quantificação de partículas 
de talco e a análise histológica dos pulmões. Utilizamos o teste t e Anova na análise estatística, considerando $p<0,05$ como significância estatística. A maioria dos parâmetros avaliados apresentou níveis mais elevados no sangue e no LBA dos animais injetados com TP ou TM quando comparados ao grupo controle, sugerindo uma resposta sistêmica e pulmonar à IIP de talco. Com relação aos grupos de talco, os níveis de PCR e de IL-8 apresentaram-se mais elevados no sangue e no LBA dos animais injetados com TP. Partículas de talco foram observadas em todas as lâminas examinadas, sem diferenças significativas entre os grupos. Os pulmões dos animais injetados com TP apresentaram infiltrado linfomononuclear mais exuberante que no grupo TM. A resposta inflamatória pulmonar antecedeu (24 h) a resposta sistêmica (48 h), sugerindo que o pulmão é o principal órgão da resposta sistêmica aguda. Estes achados estudo nos permitem concluir que o talco calibrado com partículas maiores deva ser utilizado na prática clínica, objetivando uma pleurodese mais segura.

Descritores: $\quad$ 1. Pleurodese, 2. Talco/administração \& dosagem,

3. Mediadores da inflamação/uso diagnóstico,

4. Coelhos, 5. Pneumonia/induzido quimicamente,

6. Lavagem broncoalveolar 
Figueiredo VR. Pulmonary and systemic response following intrapleural instillation of talc with different particle size [thesis]. São Paulo: "Faculdade de Medicina, Universidade de São Paulo"; 2006. $68 p$.

Talc has been the pleurodesis agent of choice for the local treatment of recurrent pleural diseases. However, serious concerns exist about its safety. The acute respiratory failure is considered its most serious complication. The physiopathologic mechanisms involved are still unclear. It has been attributed to the systemic dissemination of small talc particles, to the composition of talc and to the inflammatory response. The purpose of this study was to evaluate the systemic and pulmonary response following intrapleural instillation of small particles talc (ST) and mixed particles talc (MT). One hundred rabbits received intrapleural instillation of talc as follows: fifty rabbits were instilled with ST (mean diameter=6,41 mírons), and 50 rabbits with MT (mean diameter= 21,15 mcrons). As control (without talc instillation) were used 15 animals. We studied the pulmonary and systemic inflammatory response (total cell count and differential, levels of lactate dehydrogenase (LD), C-reactive protein (PCR), interleukin-8 (IL-8) and human vascular endothelial growth factor (VEGF) in serum and bronchoalveolar lavage (BAL). Histologic analysis of both lungs and quantitation of talc particles were done at 6, 24, 48, 72 and 96h. ST group showed higher pulmonary and systemic inflammatory response than did the MT group. PCR and IL-8 concentrations were higher in serum and BAL of ST group than the MT group. Many talc particles were observed in the 
pulmonary tissue of both talc groups, but without statistical significance. We also observed a predominance of cellular infiltrates (lymphomononuclear cells) in the lungs of ST group. The pulmonary inflammatory response (increased IL-8 in BAL) was earlier (24h) than the systemic inflammatory response $(48 \mathrm{~h})$. These observations suggest that the main organ in the systemic inflammatory acute response is lung. So, we recommend the clinical use of mixed talc without small particles to induce safety pleurodesis.

Descriptors: $\quad$ 1. Pleurodesis, 2. Bronchoalveolar lavage,

3. Inflammation mediators/diagnostic use,

4. Talc/administration \& dosage, 5. Rabbits,

6. Pneumonia/chemically induced. 


\section{INTRODUÇÃO}

Pacientes com comprometimento pleural por neoplasias malignas freqüentemente apresentam derrame pleural recidivante. Estes derrames, pelo tamanho e pela rapidez de recorrência, não invariavelmente conduzem a quadros de grande desconforto respiratório $(1,2)$. Nestes casos, a sínfise das membranas pleurais (pleurodese) com a finalidade de evitar o re-acúmulo de líquido no espaço pleural é uma das formas de abordagem terapêutica a ser considerada. Estima-se que somente nos Estados Unidos da América, 100.000 pacientes sejam submetidos à pleurodese por ano (3).

A pleurodese minimamente invasiva, realizada através da colocação intrapleural de dreno de fino calibre, tem sido cada vez mais utilizada e representa, no momento, a melhor abordagem para a indução da pleurodese (4). Nesta técnica, após o esvaziamento da cavidade pleural, introduz-se o agente esclerosante promovendo a sínfise das duas membranas pleurais e conseqüentemente, a obliteração do espaço pleural. Por ser realizada com dreno de fino calibre, prescinde da utilização de anestesia geral, o que possibilita sua realização ambulatorialmente (4).

Muitos agentes esclerosantes têm sido utilizados na indução da pleurodese, dentre eles o talco (5-7), o nitrato de prata $(8,9)$, a tetraciclina (8), a bleomicina $(7,10-12)$ e o Corynebacterium parvum $(8,13)$. A efetividade destes agentes varia segundo os dados de literatura. Para o talco, estima-se em até $95 \%$ de taxa de sucesso; $76 \%$ para o Corynebacterium parvum; $67 \%$ para a tetraciclina; $54 \%$ para a bleomicina e 
$90 \%$ para o nitrato de prata $(14,15)$. Por conseguinte, a escolha do esclerosante geralmente recai sobre sua taxa de eficácia, facilidade de obtenção e custo de mercado.

O talco livre de asbestos é o agente mais universalmente utilizado na indução de pleurodese (aproximadamente 68\% das indicações na prática clínica) (4) por apresentar grande disponibilidade, baixo custo e alto índice de efetividade (70 a 95\%, segundo vários autores) (6, 16-18). Quanto à forma de utilização, a instilação do talco pode ser realizada na forma de polvilhamento ("poudrage") durante toracoscopia ou na forma de suspensão ("slurry") via dreno torácico $(18,19)$.

Entretanto, o uso terapêutico do talco continua controverso na prática médica devido aos efeitos deletérios que podem advir de sua utilização. Estes efeitos colaterais podem variar desde complicações menores como febre, discreta hipoxemia, dispnéia, hipotensão e infecção local a complicações maiores que incluem a arritmia, a trombose venosa, a embolia pulmonar e a insuficiência respiratória aguda, que em alguns casos pode evoluir para a síndrome do desconforto respiratório agudo (SDRA) $(6,18,20-29)$

Trabalho recente desenvolvido sob a forma de questionário com médicos que utilizam talco como agente esclerosante seletivo, relata que 70\% destes já observaram insuficiência respiratória como complicação da pleurodese. (4).

Em recente revisão de literatura são mencionados pelo menos 42 casos de SDRA após a administração intrapleural de talco, sendo que em 11 desses casos, os pacientes evoluíram para óbito (30). No quadro 1 
sumarizamos vários estudos de pleurodese induzida com talco desenvolvidos em centros médicos de diversos países $(6,7,9,11,12,18$, 20-29, 31-41).

Conforme se pode notar, há diversidade no relato das doses utilizadas de talco, bem como nas vias de administração. Nem todos os trabalhos relatam os efeitos colaterais advindos da administração deste agente bem como, se houveram ou não exames laboratoriais complementares que comprovassem a evolução desfavorável do paciente. Nos casos que evoluíram para insuficiência respiratória $(6,18,20-22,24$, 26-29), observa-se que o início dos sintomas foi precoce (entre 2 e 96 horas da indução) sugerindo que o quadro é agudo. Alguns pacientes pioraram gradativamente e, a despeito da intubação traqueal e ventilação mecânica, evoluíram para óbito, enquanto que outros apresentaram melhora gradual e recuperação lenta, com evolução clínica satisfatória. Assim, qualquer investigação a respeito do mecanismo de ação do talco na insuficiência respiratória deve enfocar as primeiras 96 horas.

Nestes casos mais graves (incidência de 1 a $9 \%$ ), cuja taxa de mortalidade é alta (35 a 65\%) (16, 18, 22, 26), o mecanismo fisiopatológico envolvido com a lesão pulmonar aguda não é totalmente conhecido. O termo síndrome do desconforto respiratório agudo (SDRA) se refere a quadro clínico com dispnéia, taquipnéia e cianose e cuja radiografia de tórax evidencia infiltrado alveolar difuso. Os achados histológicos incluem dano alveolar difuso com infiltração celular por neutrófilos, macrófagos e eritrócitos; membrana hialina e edema rico em proteína nos espaços alveolares, além de danos no capilar e no epitélio alveolar (42). 
QUADRO 1 - Relação de estudos clínicos de pleurodese por talco, de 1983 a 2006, em diversos países do mundo

\begin{tabular}{|c|c|c|c|c|c|c|c|c|c|c|c|}
\hline Autor & Ano & País & $n$ & indicação & dose & \begin{tabular}{|l|} 
forma de \\
administração
\end{tabular} & $\begin{array}{l}\text { diâmetro das } \\
\text { partículas }\end{array}$ & $\operatorname{IRA}(\mathrm{n})$ & \begin{tabular}{|l|} 
Início dos \\
sintomas
\end{tabular} & Morte & Talco \\
\hline Rinaldo JE & 1983 & EUA & 3 & DPM & $10 \mathrm{~g}$ & suspensão & $\mathrm{NI}$ & 3 & $6-72 \mathrm{hs}$ & 1 & $\mathrm{NI}$ \\
\hline Bouchama A & 1984 & França & 1 & DPM & $2 \mathrm{~g}$ & suspensão & $\mathrm{NI}$ & 1 & $3 \mathrm{hs}$ & 0 & + LBA \\
\hline Almind $\mathrm{M}$ & 1989 & Dinamarca & 96 & PTX & $5 g$ & suspensão & $\mathrm{NI}$ & 0 & ausentes & 0 & $\mathrm{NI}$ \\
\hline Webb WR & 1992 & EUA & 34 & DPM B & $5 \mathrm{~g}$ & suspensão & $\mathrm{NI}$ & 0 & ausentes & 0 & $\mathrm{NI}$ \\
\hline Weissberg D & 1993 & Israel & 360 & todos & $2 g$ & susp / insuf & $\mathrm{NI}$ & 0 & ausentes & 0 & $\mathrm{NI}$ \\
\hline Kennedy L & 1994 & EUA & 75 & $90 \% \mathrm{M}$ & $10 \mathrm{~g}$ & suspensão & $\mathrm{NI}$ & $3(4 \%)$ & 72 hs & 0 & $\mathrm{NI}$ \\
\hline Yim APC & 1996 & China & 46 & DPM B & $5 g$ & insuflação & $\mathrm{NI}$ & 0 & ausentes & 0 & $\mathrm{NI}$ \\
\hline Viallat & 1996 & França & 360 & DPM & $3-4,5 \mathrm{~g}$ & insuflação & $\mathrm{NI}$ & 0 & ausentes & 0 & $\mathrm{NI}$ \\
\hline Campos JRM & 1997 & Brasil & 338 & DPM B & $2 g$ & insuflação & $\mathrm{NI}$ & 4 & 24-48hs & 0 & LBA + necro + \\
\hline Noppen M & 1997 & Bélgica & 28 & PTX & $2 g$ & insuflação & $\mathrm{NI}$ & 0 & ausentes & 0 & $\mathrm{NI}$ \\
\hline Zimmer PW & 1997 & EUA & 19 & DPM & $5 g$ & suspensão & $\mathrm{NI}$ & 0 & ausentes & 0 & $\mathrm{NI}$ \\
\hline Danby CA & 1998 & EUA & 24 & DPM & $3-8 g$ & insuflação & $\mathrm{NI}$ & 0 & ausentes & 0 & $\mathrm{NI}$ \\
\hline Aelony $\mathrm{Y}$ & 1998 & EUA & 25 & DPM & $2,5-5 g$ & insuflação & $\mathrm{NI}$ & 0 & ausentes & 0 & $\mathrm{NI}$ \\
\hline Rehse D & 1999 & EUA & 89 & todos & $5 g$ & suspensão & $\mathrm{NI}$ & $9 \%$ & ausentes & 0 & $\mathrm{NI}$ \\
\hline Marom EM & 1999 & Inglaterra & 32 & DPM & $5-10 \mathrm{~g}$ & insuflação & $\mathrm{NI}$ & 0 & ausentes & 0 & $\mathrm{NI}$ \\
\hline Diacon AH & 2000 & Suiça & 15 & DPM & $5 \mathrm{~g}$ & insuflação & $\mathrm{NI}$ & 0 & ausentes & 0 & $\mathrm{NI}$ \\
\hline Brant A & 2001 & N. Zelândia & 33 & 86\%DPM & $2,5 / 3 \mathrm{~g}$ & suspensão & $\mathrm{NI}$ & 1 & 2 - 20hs & 1 & $\mathrm{NI}$ \\
\hline Campos JRM & 2001 & Brasil & 614 & todos & $2 g$ & insuflação & $5 \ll 70$ & $7(1,3 \%)$ & 12 hs & 3 & +LBA +necro \\
\hline Cardillo G & 2002 & Itália & 611 & DPM & $5 g$ & insuflação & $\mathrm{NI}$ & 0 & ausentes & 0 & $\mathrm{NI}$ \\
\hline Gill AJ & 2004 & Austrália & 1 & DPB & alta & insuflação & $\mathrm{NI}$ & 1 & 18hs & 1 & ausente na necro \\
\hline Aelony $\mathrm{Y}$ & 2004 & EUA & 295 & todos & $7,5-10 \mathrm{~g}$ & insuflação & $\mathrm{NI}$ & 1 & 96 hs & 0 & $\mathrm{NI}$ \\
\hline Dresler CM & 2005 & EUA & 482 & DPM & $4-5 g$ & susp / insuf & $\mathrm{NI}$ & $8 \% 1 ; 4 \% S$ & $\mathrm{NI}$ & $6 \mathrm{6I} ; 5 \mathrm{~S}$ & $\mathrm{NI}$ \\
\hline Pachoalini M & 2005 & Brasil & 25 & DPM & $5 g$ & suspensão & $6,4 \ll 50,5$ & 0 & ausentes & 0 & $\mathrm{NI}$ \\
\hline Kolschmann S & 2005 & Alemanha & 102 & DPM & $8 \mathrm{~g}$ & insuflação & $\mathrm{NI}$ & 0 & ausentes & 0 & $\mathrm{NI}$ \\
\hline Aelony $\mathrm{Y}$ & 2005 & EUA & 26 & $M$ & $2 g-5 g$ & insuflação & 5,5 & 0 & ausentes & 0 & $\mathrm{NI}$ \\
\hline Gasparri R & 2006 & Itália & 71 & PTX & $8 \mathrm{~g}$ & insuflação & $\mathrm{NI}$ & 0 & ausentes & 0 & $\mathrm{NI}$ \\
\hline Froudarakis ME & 2006 & Grécia & 18 & todos & $2 g-4 g$ & susp / insuf & $\mathrm{NI}$ & 0 & ausentes & 0 & $\mathrm{NI}$ \\
\hline Cardillo G & 2006 & Itália & 816 & PTX & $2 \mathrm{~g}$ & insuflação & $<50$ & 0 & ausentes & 0 & $\mathrm{NI}$ \\
\hline
\end{tabular}

IRA - insuficiência respiratória aguda, $\mathrm{n}$ - número de casos, DPM - derrame pleural maligno, PTX - pneumotórax, DPB - derrame pleural benigno, $\mathrm{M}$-mesotelioma, NI - não informado 
Embora a literatura cite casos de insuficiência respiratória após a utilização de talco na indução de pleurodese e estes às vezes serem descritos como SDRA devido ao padrão clínico similar, falta na maioria dos trabalhos, a descrição do substrato anatômico das lesões pulmonares que caracterizariam a lesão como síndrome do desconforto respiratório agudo (43).

No princípio, a maior parte destas complicações foi atribuída ao grau de impureza nas preparações de talco, mais especificamente à contaminação com asbestos e aos problemas relacionados com as técnicas de esterilização. Atualmente, os talcos utilizados na indução de pleurodese são livres de asbestos e passam por rigoroso controle de esterilização.

A prevalência variável de quadros de insuficiência respiratória após a injeção intrapleural com diferentes tipos de talco objetivando pleurodese sugere que essa complicação poderia estar relacionada com a composição ou com o tamanho das partículas de talco. Embora o talco seja um silicato hidratado de magnésio, existe uma grande diversidade de elementos químicos na sua composição quando são analisadas as preparações provenientes dos diferentes países (44). Da mesma maneira, a análise das partículas de talco demonstrou diferenças significativas no tamanho das mesmas. É interessante ressaltar que o talco que apresenta partículas predominantemente pequenas é proveniente de países onde a prevalência relatada de insuficiência respiratória aguda, após a pleurodese, é mais alta (44). A análise das partículas através de microscopia eletrônica por varredura (MEV) demonstra variedade no espectro morfológico das 
partículas dos diferentes tipos de talco avaliados, relacionando estes achados com o desenvolvimento da SDRA (45).

A hipótese de que a insuficiência respiratória ocorra pela disseminação pulmonar das partículas de talco é reforçada pelo fato de que pacientes com essa complicação apresentavam estas partículas em amostras do lavado broncoalveolar $(\operatorname{LBA})(18,21,26)$ e na análise histológica do pulmão $(18,26)$. Tais achados não foram observados nos pacientes que evoluíram sem insuficiência respiratória (16). Para alguns autores, o tamanho das partículas de talco seria o fator determinante para a distribuição das mesmas. Assim, as partículas menores, por apresentarem maior facilidade de migração pelos capilares pleurais, estariam relacionadas a uma maior disseminação pulmonar e sistêmica ocasionando, portanto, os efeitos colaterais descritos (44).

Trabalhos na literatura têm relatado e demonstrado a migração de partículas de talco para órgãos distantes do local instilado, como o pulmão contralateral, o cérebro, o fígado, o baço e o rim, tanto em estudos experimentais $(46,47)$ como em estudos realizados em necrópsias de pacientes que fizeram uso desse agente (26).

A literatura menciona um relato de caso recente cujo paciente evoluiu para quadro de insuficiência respiratória fatal após pleurodese com talco. Entretanto, a necrópsia do paciente não demonstrou a disseminação sistêmica das partículas (28). Esse fato levanta a possibilidade de especularmos que, independentemente da disseminação sistêmica das partículas de talco, a reação inflamatória local desencadeada por este agente poderia contribuir para o desfecho sistêmico desfavorável. 
Apesar das especulações, permanece desconhecido o mecanismo pelo qual o talco se dissemina dentro e fora da cavidade torácica. Takada e cols (48) sugerem que as partículas de talco alcançam o parênquima pulmonar através da quebra da barreira mesotelial, em conseqüência do processo inflamatório local. Outras hipóteses propõem como mecanismo de disseminação, a migração das partículas pelos estomas da pleura parietal e destes para os linfáticos (49) ou, a migração direta por invaginação da junção intercelular do mesotélio $(44,48,50)$.

Igualmente desconhecemos a atuação do talco (e somente dele) na produção de inflamação pulmonar e sistêmica. Vários mediadores inflamatórios elevados no soro e no LBA têm sido relacionados ao mecanismo fisiopatológico e ao prognóstico de pacientes com SDRA de outras etiologias. Dentre eles, as interleucinas (IL) IL-1 $1 \beta$, IL-6, IL-8, IL-10 e o fator de necrose tumoral (TNF- $\alpha$ ) têm sido descritos como integrantes no desencadeamento e desenvolvimento do quadro de SDRA (51-54).

Embora alguns trabalhos relacionem o achado de partículas de talco no LBA de animais submetidos à pleurodese com talco (46), não se conhece até o momento, estudos experimentais ou em humanos onde estes mediadores inflamatórios foram avaliados no LBA.

A pleurodese quimicamente induzida em modelos experimentais permite a avaliação da pleura, do parênquima pulmonar e dos órgãos à distância. O modelo em coelhos, em especial, é bastante utilizado, pois as cavidades pleurais direita e esquerda são independentes, permitindo a avaliação da pleura, do parênquima pulmonar homolateral e contralateral à injeção do agente esclerosante e dos respectivos lavados broncoalveolares 
(55-61).

Existem referências na literatura que avaliam a resposta inflamatória sistêmica desencadeada após a pleurodese induzida com talco em animais de experimentação (60). Os resultados demonstram resposta inflamatória sistêmica exacerbada com valores elevados de leucócitos e de neutrófilos no sangue e níveis séricos elevados de IL-8 e fator de crescimento endotelial vascular (VEGF) $(60,61)$. Levando-se em consideração que o lavado broncoalveolar é espelho do que acontece no alvéolo pulmonar, a análise celular e de mediadores inflamatórios, como a IL-8 e o VEGF são importantes na avaliação da resposta inflamatória pulmonar aguda à injeção intrapleural de talco. Da mesma forma, a comparação dos níveis de IL-8 e VEGF no LBA de ambos os pulmões traz informações sobre o comportamento do pulmão contralateral à administração do talco intrapleural.

Considerando que no Brasil existe uma série de casos de pacientes que apresentaram SDRA com evolução para óbito após esta abordagem terapêutica (18), julgamos relevante estudar as alterações pulmonares e sistêmicas em resposta à instilação intrapleural de talco usado em prática clínica com partículas de tamanhos diversos e outro calibrado com partículas menores em modelo experimental. 
OBJETIVOS 


\section{OBJETIVOS}

Estudar os efeitos pulmonares e sistêmicos agudos em resposta à injeção intrapleural de talco de partículas pequenas e de partículas de tamanhos variados.

O estudo compreenderá:

-A avaliação da celularidade, dos níveis de desidrogenase lática $(\mathrm{DHL})$, proteína $\mathrm{C}$ reativa $(\mathrm{PCR})$, interleucina-8 (IL-8) e fator de crescimento endotelial vascular (VEGF) no sangue e no LBA;

-A avaliação da presença de partículas de talco nos pulmões direito e esquerdo;

-A avaliação histológica dos pulmões quanto à presença de danos alveolares difusos. 


\section{MATERIAL E MÉTODOS}

Este estudo foi aprovado pelo Comitê de Ética do Hospital das Clínicas da Faculdade de Medicina da Universidade de São Paulo, conforme parecer $n^{0}$ 004/06.

Os animais foram eutanasiados seguindo a resolução № 714 , de 20 de junho de 2002 do Conselho Federal de Medicina Veterinária.

\section{Composição dos grupos}

Foram utilizados 115 coelhos New Zealand, pesando entre 2 e $3 \mathrm{Kg}$. Cem animais foram submetidos à injeção intrapleural com talco em suspensão (slurry). Em metade dos animais foi utilizado talco de partículas de tamanho pequeno (TP) e nos outros cinqüenta animais foi utilizado talco misto, composto por partículas de tamanhos diversos (TM) semelhante ao usado na prática clínica. Adicionalmente, foram utilizados 15 coelhos como grupo controle, conforme distribuição abaixo:

1. Cinco animais utilizados como controle, sem injeção intrapleural de talco ou solução fisiológica e submetidos a LBA;

2. Cinco animais como controle Sham, submetidos à injeção intrapleural de solução fisiológica e a LBA;

3. Cinco animais utilizados como controle para a análise histológica dos pulmões, sem injeção intrapleural de talco ou solução fisiológica e não submetidos a LBA;

4. Vinte e cinco animais com injeção intrapleural de TP com coleta 
de LBA;

5. Vinte e cinco animais com injeção intrapleural de TP com análise histológica dos pulmões (sem LBA);

6. Vinte e cinco animais com injeção intrapleural de TM com coleta de LBA;

7. Vinte e cinco animais com injeção intrapleural de TM com análise histológica dos pulmões (sem LBA.)

\section{SÍNTESE DOS GRUPOS DE ESTUDO}

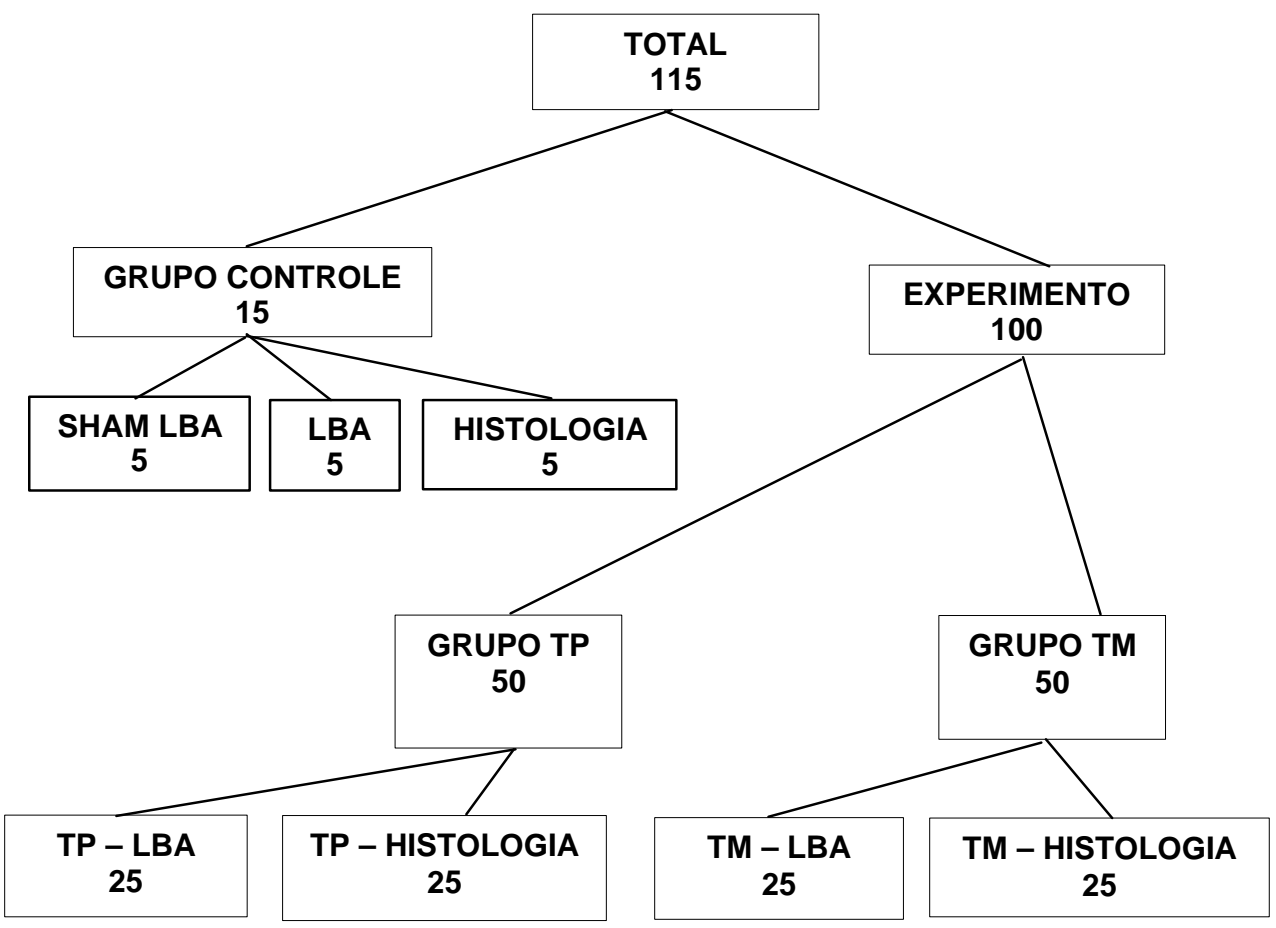


Os animais foram eutanasiados após $6,24,48,72$ ou 96 horas da injeção intrapleural (5 animais para cada tempo).

Como medida de precaução para evitar a contaminação dos materiais, os experimentos foram realizados com luvas e em ambiente livres de talco, sempre pelo mesmo pesquisador.

\section{Análise do talco com relação ao tamanho e à composição elemental das partículas}

No experimento foram utilizados talcos de dois padrões. O primeiro, talco calibrado, fornecido pela empresa Sigma Aldrich (Steinheim, Germany) $\left(3 \mathrm{MgO}_{4} \mathrm{SiO}_{2} \cdot \mathrm{H}_{2} \mathrm{O}\right)$, é referido pelo fabricante como composto predominantemente por partículas com tamanho inferior a $10 \mu \mathrm{m}$ (TP). O segundo, fornecido pela empresa Magnesita (Bahia, Brasil) é o talco utilizado para a indução de pleurodese em humanos no InCor e no HCFMUSP, sendo referido como talco misto (TM), ou seja, com partículas de diferentes tamanhos (a maioria $>10 \mu \mathrm{m}$ ).

Considerando que o objetivo do trabalho é avaliar os efeitos pulmonares e sistêmicos relacionados com uma possível disseminação de partículas de talco, o tamanho das partículas dos dois tipos de talco foi confirmado através de análise granulométrica por difração a laser (Malvern Instruments Ltda - Malvern UK) no Instituto de Pesquisas Tecnológicas da Universidade de São Paulo (IPT). A análise do tamanho das partículas de talco demonstrou que o talco de partículas pequenas (TP) apresentou D50 de $6,41 \mu \mathrm{m}$ (50\% das partículas são menores que $6,41 \mu \mathrm{m})$, D10 de 2,19 
$\mu \mathrm{m}$ (10\% das partículas com diâmetro menor que $2,19 \mu \mathrm{m})$ e D90 de 17,82 $\mu \mathrm{m}(90 \%$ das partículas com diâmetro menor que $17,82 \mu \mathrm{m})$. O talco de partículas de tamanhos diversos (TM) apresentou D50 de 21,15 $\mu \mathrm{m}, \mathrm{D} 10$ de $6,66 \mu \mathrm{m}$ e $\mathrm{D} 90$ de $52,56 \mu \mathrm{m}$.

A composição química das partículas de talco foi analisada no Laboratório de Poluição da Faculdade de Medicina da Universidade de São Paulo, através de espectometria de fluorescência por Raios X (Quadro 3).

Ambas as partículas de talco foram fotografadas por Microscopia Eletrônica de Varredura no Instituto de Pesquisas Tecnológicas da Universidade de São Paulo (IPT) para visualização de sua conformação espacial e estão representadas nas figuras 1 e 2 .

Quadro 2: Tamanho de partículas em $\mu \mathrm{m}$.

\begin{tabular}{|c|c|c|c|}
\hline Talco & D10 $(\mu \mathrm{m})$ & $\mathrm{D} 50(\mu \mathrm{m})$ & $\mathrm{D} 90(\mu \mathrm{m})$ \\
\hline TP & 2,19 & 6,41 & 17,82 \\
\hline TM & 6,66 & 21,15 & 52,56 \\
\hline
\end{tabular}

TP - Talco de partículas pequenas, TM - talco de partículas de tamanhos diversos, D10 - 10\% das partículas abaixo desse diâmetro, D50 - 50\% das partículas abaixo desse diâmetro, D90 - 90\% das partículas abaixo desse diâmetro.

Quadro 3: Composição elemental dos diferentes tipos de talco.

\begin{tabular}{|c|c|c|c|c|c|c|}
\hline Talco & $\mathrm{Si} \%$ & $\mathrm{Mg} \%$ & $\mathrm{Fe} \%$ & $\mathrm{Al} \%$ & $\mathrm{Ca} \%$ & $\mathrm{Cl} \%$ \\
\hline TP & 64,754 & 26,799 & 5,823 & 2,137 & 0,487 & --- \\
\hline TM & 69,746 & 26,801 & 0,687 & 2,229 & --- & 0,536 \\
\hline
\end{tabular}

TP - Talco de partículas pequenas, TM - talco de partículas de tamanhos diversos, Si - silício, Mg - magnésio, $\mathrm{Fe}$ - ferro, $\mathrm{Al}$ - alumínio, $\mathrm{Ca}$ - cálcio, $\mathrm{Cl}$ - cloro. 


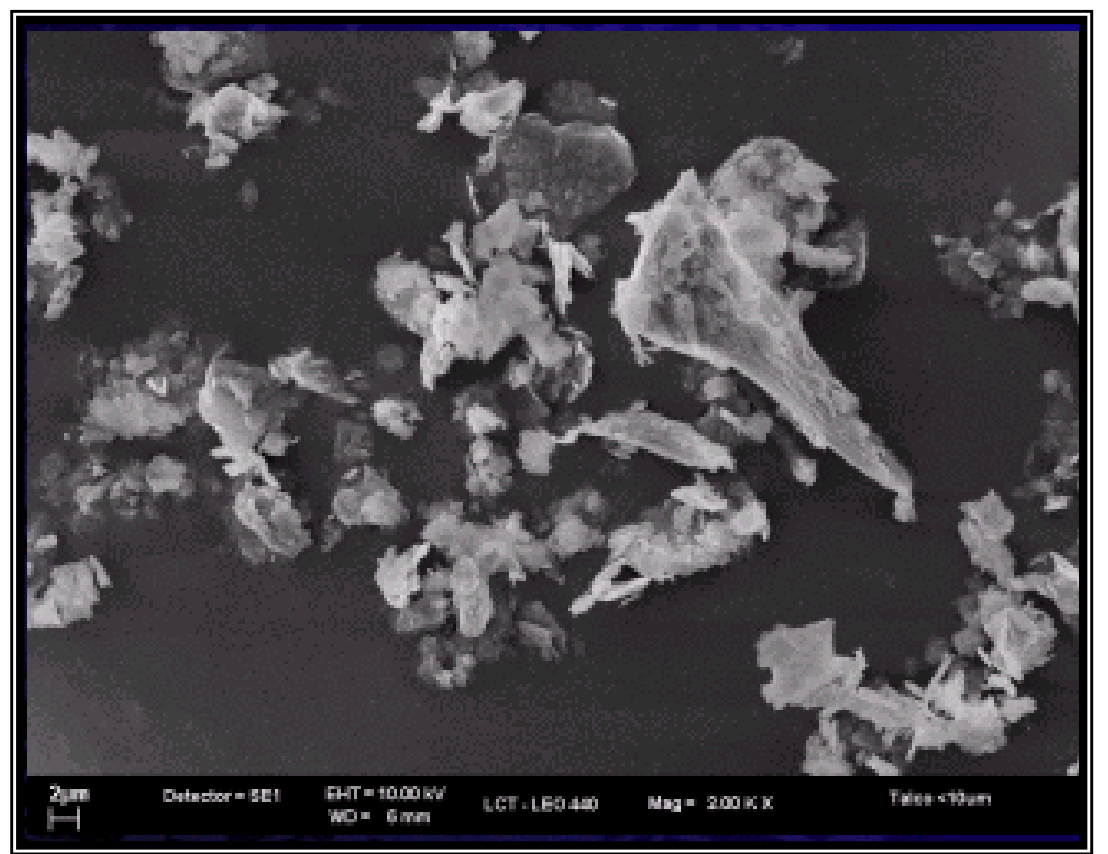

Figura 1: Aspecto do talco de partículas pequenas (TP). Microscopia Eletrônica de Varredura (2,0 KX).

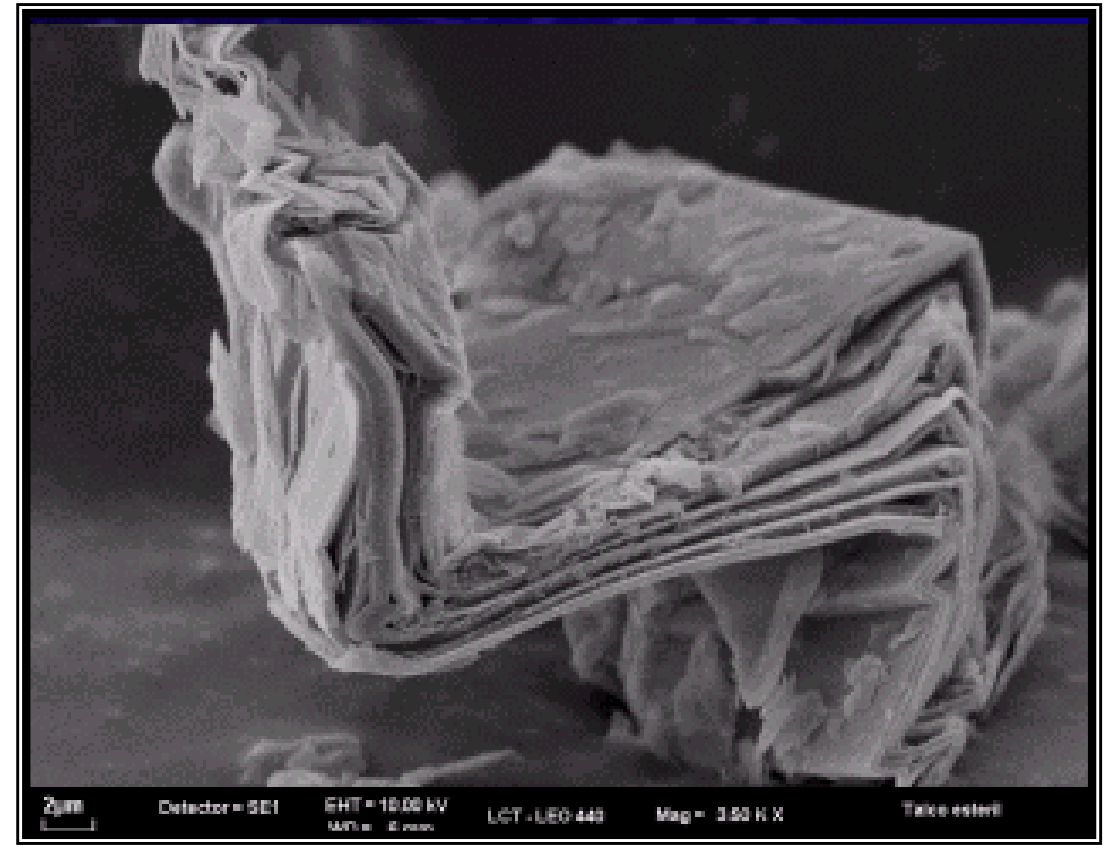

Figura 2: Aspecto do talco misto de partículas de tamanhos diversos (TM). Microscopia Eletrônica de Varredura (3,5 KX). 


\section{Injeção do esclerosante}

Os animais foram anestesiados com a associação de $35 \mathrm{mg} / \mathrm{kg}$ de cloridrato de cetamina (Cristália; São Paulo, Brasil) e $5 \mathrm{mg} / \mathrm{kg}$ de cloridrato de xylasina (Bayer; São Paulo, Brasil), administrados por via intramuscular. Após a anestesia, os animais foram posicionados sobre a mesa cirúrgica e realizada a antissepsia com solução iodada no hemitórax direito (Riodeíne, Rioquímica, São Paulo). A seguir, após a identificação dos espaços intercostais, foi introduzida agulha calibre 21F (Becton-Dickson; Paraná, Brasil) acoplada a uma seringa sem êmbolo, com $4 \mathrm{~mL}$ de talco em suspensão na dose de $400 \mathrm{mg} / \mathrm{kg}$. O volume total da solução foi instilado por força da pressão negativa intrapleural. $\mathrm{O}$ pH das soluções de talco foi previamente medido, não havendo diferença nas soluções preparadas $(\mathrm{pH}=8,4)$. Após a instilação, todo o sistema foi retirado evitando-se, desta maneira, a entrada de ar inadvertidamente na cavidade pleural.

Após a injeção intrapleural do talco, os animais foram monitorados para evidências clínicas de dor (vocalização, taquipnéia ou agitação). Injeções de dipirona (Ariston; São Paulo, Brasil) foram disponibilizadas para o controle da dor.

Eutanásia

Os animais foram eutanasiados com injeção letal de pentobarbital (60 mg/kg) pela veia marginal da orelha nos tempos pré-determinados de $6,24,48,72$ ou 96 horas. 


\section{Coleta do sangue}

Imediatamente após os animais serem eutanasiados, a cavidade abdominal foi aberta e procedeu-se a coleta de sangue da veia cava inferior para a realização de hemograma, uréia, DHL, PCR e dosagem de citocinas (IL-8 e VEGF).

\section{Coleta do lavado broncoalveolar (LBA)}

A coleta do lavado broncoalveolar foi realizada após a eutanásia, iniciando-se a dissecção pela traquéia cervical. O hemitórax esquerdo do animal foi aberto e a traquéia dissecada até a carina principal. Todo o procedimento foi realizado com atenção especial em manter o hemitórax direito fechado para não haver contaminação do campo cirúrgico com o talco da pleurodese. Foi realizado reparo cirúrgico do brônquio fonte esquerdo e direito sob visualização direta. A seguir, foi realizada abertura da traquéia para colocação de catéter de oxigênio número 8 no brônquio fonte esquerdo, enquanto o brônquio fonte direito era mantido fechado pela tração do fio de reparo. Este cateter foi introduzido até o lobo inferior esquerdo sendo tracionado o fio de reparo cirúrgico para isolamento do brônquio fonte esquerdo (prevenindo-se vazamentos). Foram então instilados $20 \mathrm{~mL}$ de SF a 0,9\%, observando-se o enchimento gradual de todo o pulmão esquerdo durante a instilação. Após a instilação total do volume, iniciou-se a recuperação manual do lavado broncoalveolar, com pressão menor que $80 \mathrm{mmHg}$. Considerou-se satisfatório, o lavado 
broncoalveolar que recuperou pelo menos $50 \%$ do volume administrado. Os primeiros $5 \mathrm{~mL}$ de líquido recuperado foram desprezados, visando garantir a não contaminação da amostra com muco ou células de vias aéreas proximais superiores. O mesmo procedimento foi realizado no brônquio fonte direito, procedendo-se o fechamento do brônquio fonte esquerdo.

No lavado broncoalveolar recuperado foram realizadas:

Citologia quantitativa (global e diferencial);

Dosagens bioquímicas: DHL e uréia e

Dosagens Imunológicas: citocinas inflamatórias (IL-8 e VEGF) e PCR.

\section{Coleta dos pulmões para análise histológica}

Os subgrupos de animais que não foram submetidos a lavado broncoalveolar, tiveram o tórax retirado em bloco. Através da traquéia foi injetada formalina a $10 \%$ para evitar o colapso pulmonar e possibilitar a obtenção de amostras teciduais ideais para a análise histológica.

\section{Fator de correção da diluição do lavado broncoalveolar}

Para estabelecer a metologia do procedimento de coleta do lavado broncoalveolar, foi realizado treinamento em alguns animais. Observou-se maior dificuldade de retorno do lavado broncoalveolar do pulmão direito. Devido à segmentação mais precoce à direita (brônquio do lobo superior à 
direita é mais proximal que à esquerda) houve dificuldade para avançar o cateter em posição mais distal. Como resultado, as análises bioquímicas no lavado broncoalvolar à direita se mostraram mais concentradas que à esquerda. Para corrigir a concentração do lavado broncoalveolar à direita e à esquerda, foi calculado um fator de correção de diluição baseado na relação da uréia sérica e do lavado broncoalveolar. Sabendo-se que não há produção de uréia no pulmão, as dosagens de uréia no soro e no fluído que recobre o alvéolo devem ser semelhantes. Assim, utilizando o fator de correção de diluição (61-65), procuramos minimizar a interferência da diluição com solução fisiológica nas análises laboratoriais.

\section{Citologia global e diferencial do lavado broncoalveolar e do sangue}

As amostras de LBA foram coletadas em tubo cônico plástico, e as amostras de sangue foram coletadas em tubos com anticoagulante EDTA.

A contagem global de células no lavado broncoalveolar foi realizada em câmaras de contagem (tipo Neubauer) e o resultado expresso em quantidade de células nucleadas por $\mathrm{mm}^{3}$. Em seguida, as amostras foram centrifugadas e do sedimento obtido, foram preparadas e coradas as lâminas (coloração panóptica de Leishman) utilizadas para a citologia diferencial quantitativa. O líquido sobrenadante recuperado foi armazenado para as dosagens bioquímicas $\left(-20^{\circ} \mathrm{C}\right)$ e imunológicas $\left(-80^{\circ} \mathrm{C}\right)$. Um total de 200 células foi contado e a proporção de leucócitos (com diferencial), macrófagos e células epiteliais foram expressas em porcentagem. O hemograma dos animais foi realizado em equipamento automatizado ( $A B X$, 
Horiba, Micro's CRP Japão).

Dosagens bioquímicas e imunológicas no soro e no LBA

As amostras séricas para a dosagem da DHL, PCR, uréia, IL-8 e VEGF foram coletadas em tubo seco e centrifugadas a $1500 \mathrm{rpm}$ por 15 minutos a $4^{\circ} \mathrm{C}$. As amostras de LBA foram colhidas em tubos cônicos de plástico. O sobrenadante obtido foi utilizado para a dosagem da enzima e da uréia através de método cinético UV semi-automatizado e colorimétrico, respectivamente (Wiener Lab, Rosário, Argentina) (Anexo A).

Parte do sobrenadante das amostras foi separada, aliquotada e armazenada em freezer a $-80^{\circ} \mathrm{C}$ para dosagem posterior das citocinas e da PCR.

A PCR foi quantificada pelo método de imunoaglutinação (Wiener Lab, Rosário, Argentina). Neste método, as amostras positivas são tituladas realizando-se diluições seriadas e a concentração ( $\mathrm{mg} / \mathrm{dL})$ é calculada multiplicando-se o maior título obtido pela sensibilidade da reação $(6 \mathrm{mg} / \mathrm{L})$.

As citocinas IL-8 (OptEIA, rabbit IL-8 set; Pharmingen; San Diego, CA, USA) e VEGF (R\&D Systems; Minneapolis, MN, USA) foram quantificadas pelo método de ELISA (Enzyme-Linked Immunosorbent Assay) de acordo com o protocolo sugerido nos manuais dos fabricantes, com leitura em filtro de $450 \mathrm{~nm}$ (Tabela A - Anexo B). Uma curva padrão com 7 pontos, um branco da reação e um padrão de concentração conhecida foram utilizados em cada placa de leitura. Os resultados das citocinas foram expressos em $\mathrm{pg} / \mathrm{mL}$. 
Os limites de detecção para a IL-8 variaram de 6,25 a $400 \mathrm{pg} / \mathrm{mL}$ e para o VEGF, de 15,6 a $2.000 \mathrm{pg} / \mathrm{mL}$. Quando os valores excediam os limites de detecção, as amostras eram diluídas e dosadas novamente.

\section{Análise histológica e contagem das partículas de talco nos pulmões}

Para a análise histológica e contagem das partículas de talco nos pulmões foram utilizados os animais do experimento que se submeteram à injeção intrapleural de TP e TM, porém não submetidos à realização do LBA. Após 48 horas da fixação dos pulmões (lobo médio à direita e lingular à esquerda) em solução de formol os espécimes foram retirados e incluídos em parafina. Os blocos de parafina foram submetidos à corte histológico de $3 \mu \mathrm{m}$ e corados por hematoxilina-eosina (HE) para análise por microscopia óptica.

Para a avaliação do parênquima pulmonar, considerou-se a celularidade, a presença de edema, capilarite, hemorragia, trombos, infiltrado celular e macrófagos, que são parâmetros histológicos associados ao dano pulmonar relacionado ao talco. A análise foi realizada em 10 campos sob aumento de 400 vezes e o resultado expresso em escore (de 0 a 3) de acordo com a extensão e o grau do comprometimento pulmonar (56).

As partículas de talco foram quantificadas em sistema de análise de imagens. Foram analisados 5 campos por lâmina em aumento de 400X em microscopia óptica de luz polarizada. Foi realizada a contagem do número de partículas de talco e contabilizada a área total analisada. O limite de 
detecção do tamanho de partícula em microscopia óptica é de 1 a $2 \mu \mathrm{m}$. Os resultados foram expressos em número de partículas por centímetro quadrado de área pulmonar analisada (as tabelas apresentam os resultados em número de partículas por 100 centímetros quadrados de parênquima).

\section{Análise estatística}

A análise estatística foi realizada utilizando-se o programa de computador SigmaStat (SPSS Inc.; San Raphael, CA, USA).

Os dados foram expressos em mediana e intervalo de confiança (25 e $75 \%$ ) ou média e desvio padrão.

Para a comparação entre os tipos de talco para as variáveis estudadas foi utilizado o test t-Student (variáveis com distribuição normal) ou o teste de Man-Withney (variáveis com distribuição não-normal). Para comparação entre os achados no pulmão direito e esquerdo foi utilizado o test t-pareado (distribuição normal) ou Wilcoxon (distribuição não-normal).

A análise dos diversos tempos de cada variável, tanto no soro como no lavado broncoalveolar foi realizada utilizando-se o teste de análise de variância (ANOVA). Quando eram detectadas diferenças significativas, os testes foram complementados pelos testes de comparações múltiplas de Tukey ou Dunn.

Foi considerada diferença significativa quando $p<0,05$. 


\section{RESULTADOS}

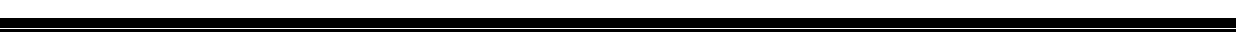




\section{RESULTADOS}

No grupo Sham foi realizada injeção intrapleural de solução salina em 5 animais. No grupo controle (sem injeção intrapleural de talco ou de salina) também foram avaliados 5 animais. Os dois grupos (Sham e controle) não apresentaram diferenças significativas entre si, para todas as variáveis estudadas. Para efeito de comparação com os grupos experimentos, no texto estão apresentadas as tabelas e gráficos referentes em comparação ao grupo controle sem injeção intrapleural de talco. Os resultados do controle Sham estão demonstrados na tabela B do Anexo C.

\section{1 - Sangue e Lavado broncoalveolar}

\section{1 - Leucócitos}

O número de leucócitos no sangue periférico e no LBA não mostrou diferenças significativas entre os dois tipos de talco e o grupo controle (Anexo C - Tabelas C e D). Na comparação entre os dois tipos de talco, a análise do número de leucócitos no sangue periférico não mostrou diferença para nenhum dos tempos avaliados (Anexo C - Tabela E). O número de leucócitos no LBA à direita dos animais injetados com TP apresentou-se mais elevado que no grupo TM, na maioria dos tempos avaliados, com significância estatística às 24 horas (Tabela 1). Semelhante comportamento, embora sem significância estatística, ocorreu no LBA à esquerda. 
Tabela 1: Total de leucócitos $/ \mathrm{mm}^{3}$ no LBA de coelhos submetidos à injeção intrapleural de TP ou TM. Comparação entre os grupos TP e TM.

\begin{tabular}{lccc}
\hline \hline \multicolumn{4}{c}{ Lavado Broncoalveolar à Direita } \\
\hline \hline
\end{tabular}

A leucometria tendeu a ser maior no LBA à direita quando comparado ao esquerdo para ambos os grupo (TP e TM), com significância estatística no grupo TP em 48 horas e no grupo TM em 96 horas (Tabela 2).

Tabela 2: Total de leucócitos $/ \mathrm{mm}^{3}$ no LBA de coelhos submetidos à injeção intrapleural de TP ou TM. Comparação entre os lados direito e esquerdo.

\begin{tabular}{|c|c|c|c|}
\hline \multicolumn{4}{|c|}{ Talco Pequeno } \\
\hline & LBAD & LBAE & $p$ \\
\hline $\begin{array}{l}6 \text { horas } \\
24 \text { horas } \\
48 \text { horas } \\
72 \text { horas } \\
96 \text { horas }\end{array}$ & $\begin{array}{c}10,4(6,8-18,1) \\
4,8(2,2-15,4) \\
1,0(0,8-38,6) \\
14,0(8,0-42,3) \\
3,0(1,8-21,0)\end{array}$ & $\begin{array}{c}5,2(4,1-7,8) \\
5,6(2,1-7,7) \\
1,4(0,5-7,2) \\
4,8(2,4-5,3) \\
5,9(2,0-22,5)\end{array}$ & $\begin{array}{l}0,117 \\
0,183 \\
0,043 \\
0,100 \\
0,053\end{array}$ \\
\hline \multicolumn{4}{|c|}{ Talco Misto } \\
\hline & LBAD & LBAE & $p$ \\
\hline $\begin{array}{l}6 \text { horas } \\
24 \text { horas } \\
48 \text { horas } \\
72 \text { horas } \\
96 \text { horas }\end{array}$ & $\begin{array}{c}4,0(2,1-5,3) \\
0,3(0,2-1,0) \\
4,4(3,3-45,0) \\
0,4(0,4-6,8) \\
0,2(0,2-2,6)\end{array}$ & $\begin{array}{l}3,0(1,1-9,8) \\
1,7(0,2-6,4) \\
2,1(1,6-2,9) \\
0,3(0,2-2,1) \\
0,2(0,2-0,6)\end{array}$ & $\begin{array}{l}0,100 \\
0,059 \\
0,066 \\
0,356 \\
0,025\end{array}$ \\
\hline
\end{tabular}




\section{2 - Neutrófilos}

A exemplo dos leucócitos, o número total de neutrófilos no sangue não apresentou diferenças estatisticamente significantes entre os dois grupos de talco em relação ao controle (Anexo C - Tabela F). A baixa leucometria observada no LBA não permitiu a avaliação deste parâmetro.

Quando comparamos os dois grupos de talco, o percentual dos neutrófilos no sangue tendeu a ser discretamente mais elevado no grupo TP, na maioria dos tempos, mas sem significância estatística, com exceção do tempo de 72 horas que demonstrou uma elevação significativa no grupo TM (Anexo C - Tabela G).

\section{3 - Fator de Correção de Diluição do Lavado Broncoalveolar}

A partir do valor médio da uréia sérica e da uréia obtida no LBA, estabeleceu-se o fator de correção para ser aplicado às dosagens realizadas no LBA. Este fator correspondeu a 11,01 para o LBA à direita e 13,04 para o LBA à esquerda (Anexo C-Tabela H).

\section{4 - Desidrogenase Lática}

Os níveis séricos de DHL e no LBA não apresentaram diferenças estatisticamente significantes entre os grupos de talco e o grupo controle, assim como entre os grupos TP e TM e os lados direito e esquerdo (Anexo C - Tabelas I, J, L, M, N). 


\section{5 - Proteína C Reativa}

Os níveis séricos de PCR elevaram-se já nas primeiras 6 horas em ambos os grupos de estudo, mantendo-se mais elevados que o controle em todos os tempos, com significância estatística (Tabela 3). Observou-se pico sérico de PCR em 24 horas, para ambos os grupos (Figura 3). Na comparação entre os tipos de talco, os níveis de PCR §éricos foram significantemente maiores no grupo TP nas primeiras 24 horas, com significância estatística $(p=0,029)$ (Tabela 4).

Os níveis de PCR no LBA foram abaixo do nível de detecção para o método empregado, em ambos os grupos estudados.

Tabela 3: Níveis séricos de PCR $(\mathrm{mg} / \mathrm{dL})$ de coelhos submetidos à injeção intrapleural de TP ou TM. Comparação com grupo controle.

\begin{tabular}{lcc}
\hline \hline Controle & $12,0(12,0-12,0)$ & \\
\hline \hline & $\mathrm{TP}$ & $\mathrm{p}$ \\
\hline \hline 6 horas & $48,0(24,0-48,0)$ & 0,015 \\
24 horas & $96,0(96,0-102,0)$ & 0,036 \\
48 horas & $48,0(42,0-48,0)$ & 0,008 \\
72 horas & $48,0(30,0-48,0)$ & 0,025 \\
96 horas & $24,0(24,0-30,0)$ & 0,036 \\
\hline \hline & TM & 0,033 \\
\hline \hline 6 horas & $24,0(24,0-48,0)$ & 0,013 \\
4 horas & $48,0(48,0-96,0)$ & 0,037 \\
72 horas & $48,0(24,0-48,0)$ & 0,036 \\
96 horas & $24,0(24,0-30,0)$ & 0,229 \\
\hline \hline TP - talco de partículas pequenas, TM - talco de partículas de tamanhos diversos, PCR - Proteína C reativa
\end{tabular}


Tabela 4: Níveis séricos de PCR $(\mathrm{mg} / \mathrm{dL})$ de coelhos submetidos à injeção intrapleural de TP ou TM. Comparação entre os grupos TP eTM.

\begin{tabular}{lccc}
\hline \hline & TP & TM & $\mathrm{p}$ \\
\hline \hline 6 horas & $48,0(24,0-48,0)$ & $24,0(24,0-48,0)$ & 0,580 \\
24 horas & $96,0(96,0-102,0)$ & $48,0(48,0-96,0)$ & 0,029 \\
48 horas & $48,0(42,0-48,0)$ & $48,0(24,0-48,0)$ & 0,690 \\
72 horas & $48,0(30,0-48,0)$ & $24,0(24,0-30,0)$ & 0,244 \\
96 horas & $24,0(24,0-30,0)$ & $24,0(24,0-24,0)$ & 0,730 \\
\hline \hline
\end{tabular}

TP - talco de partículas pequenas, TM - talco de partículas de tamanhos diversos, PCR - Proteína C reativa

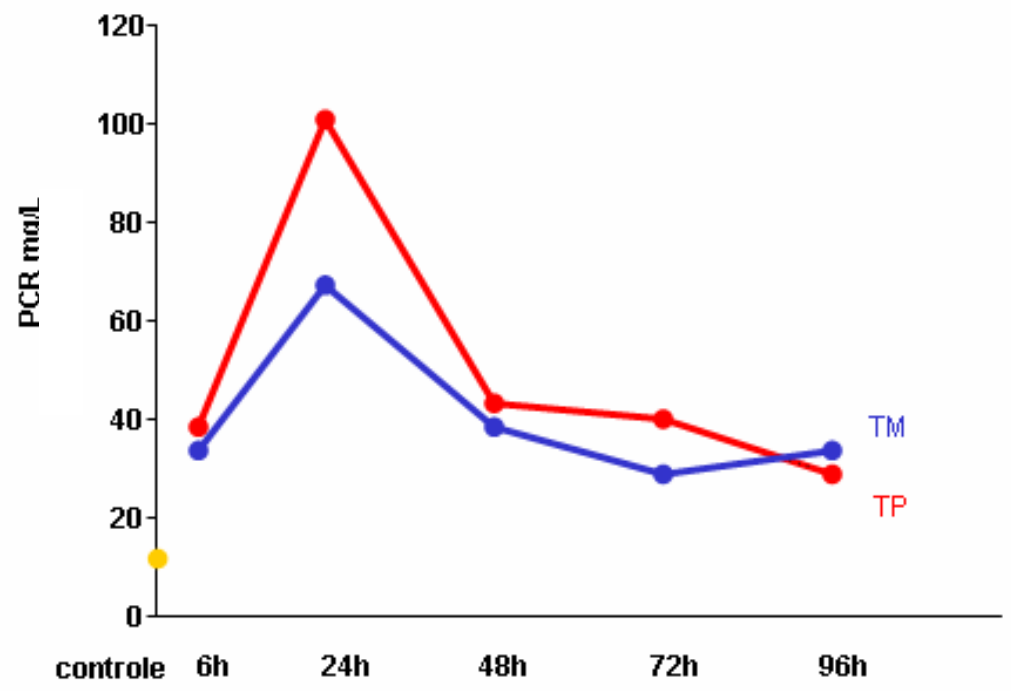

Figura 3: Evolução temporal dos níveis séricos de PCR (mg/L) de coelhos submetidos à injeção intrapleural de TP e TM.

ANOVA TP- $p<0,001 \quad$ ANOVA TM- $p=0,015$

PCR - Proteína C reativa, TP - talco de partículas pequenas, TM - talco de partículas de tamanhos diversos. 


\section{6 - Fator de Crescimento Endotelial Vascular}

Os níveis séricos de VEGF, assim como no LBA, elevaram-se já nas primeiras 6 horas, e mantiveram-se significativamente elevados na maioria dos tempos, em ambos os grupos estudados quando comparados ao grupo controle (Tabela 5 e 6). Entretanto, não observamos diferenças estatisticamente significantes na comparação entre os grupos TP e TM, tanto no LBA quanto no sangue (Anexo C Tabela O e P).

Tabela 5: Níveis de VEGF ( $\mathrm{pg} / \mathrm{mL})$ no sangue de coelhos submetidos à injeção intrapleural de TP e TM. Comparação com grupo controle.

\begin{tabular}{lcc}
\hline \hline Controle & $31,3(31,3-33,3)$ & \\
\hline \hline & $\mathrm{TP}$ & $\mathrm{p}$ \\
\hline \hline 6 horas & $36,3(34,4-42,6)$ & 0,211 \\
4 horas & $63,7(47,6-79,0)$ & 0,051 \\
72 horas & $58,6(49,9-63,4)$ & 0,012 \\
96 horas & $58,3(55,5-71,0)$ & 0,003 \\
\hline \hline & $47,0(41,2-66,1)$ & 0,049 \\
\hline \hline 6 horas & $\mathrm{TM}$ & $\mathrm{p}$ \\
24 horas & $38,9(35,3-44,6)$ & 0,143 \\
48 horas & $54,3(52,3-57,5)$ & 0,001 \\
72 horas & $71,2(45,3-85,2)$ & 0,041 \\
96 horas & $53,2(44,6-57,6)$ & 0,023 \\
\hline \hline
\end{tabular}

TP - talco de partículas pequenas, TM - talco de partículas de tamanhos diversos, VEGF - Fator de crescimento endotelial vascular. 
Tabela 6: Níveis de VEGF (pg/mL) no LBA de coelhos submetidos à injeção intrapleural de TP ou TM. Comparação com grupo controle.

\begin{tabular}{|c|c|c|}
\hline \multicolumn{3}{|c|}{ Lavado Broncoalveolar à Direita } \\
\hline \multicolumn{3}{|c|}{$560,0(439,7-639,1)$} \\
\hline & $\overline{\mathrm{TP}}$ & $\bar{p}$ \\
\hline 6 horas & $1984,6(917,9-2143,9)$ & 0,038 \\
\hline 24 horas & $3627,0(3184,9-6601,8)$ & 0,052 \\
\hline 48 horas & $4245,1(3798,1-6543,2)$ & 0,036 \\
\hline 72 horas & $2218,1(1649,1-3228,8)$ & 0,036 \\
\hline \multirow[t]{2}{*}{96 horas } & $1620,6(1001,1-3225,6)$ & 0,064 \\
\hline & TM & $\mathrm{p}$ \\
\hline 6 horas & 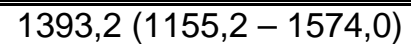 & 0,013 \\
\hline 24 horas & $2763,3(1914,5-4683,7)$ & 0,042 \\
\hline 48 horas & $5256,1(4885,2-6745,1)$ & $<0,001$ \\
\hline 72 horas & $2836,7(1922,2-3373,2)$ & 0,019 \\
\hline 96 horas & $1852,0(1536,2-2143,3)$ & 0,011 \\
\hline \multicolumn{3}{|c|}{ Lavado Broncoalveolar à Esquerda } \\
\hline \multirow[t]{2}{*}{ Controle } & $523,7(232,8-698,0)$ & \\
\hline & $\overline{\mathrm{TP}}$ & $\bar{p}$ \\
\hline 6 horas & $1277,4(727,0-1870,2)$ & 0,099 \\
\hline 24 horas & $3047,3(1987,4-4786,8)$ & 0,025 \\
\hline 48 horas & $3807,2(3333,2-5859,1)$ & 0,036 \\
\hline 72 horas & $1464,9(1004,9-2156,9)$ & 0,184 \\
\hline \multirow[t]{2}{*}{96 horas } & $1156,2(999,2-1413,4)$ & 0,076 \\
\hline & $\overline{T M}$ & $\bar{p}$ \\
\hline 6 horas & $853,9(738,2-1282,2)$ & 0,077 \\
\hline 24 horas & $1645,9(1252,4-2374,3)$ & 0,073 \\
\hline 48 horas & $1645,9(1252,4-2374,3)$ & 0,011 \\
\hline 72 horas & $3711,5(2715,8-4931,5)$ & 0,101 \\
\hline 96 horas & $1645,9(711,4-2450,9)$ & 0,029 \\
\hline
\end{tabular}

TP - talco de partículas pequenas, TM - talco de partículas de tamanhos diversos, VEGF - Fator de crescimento endotelial vascular, LBA - Lavado broncoalveolar.

Na comparação entre o lado pulmonar direito e esquerdo, o LBA apresentou níveis mais elevados de VEGF à direita em todos os tempos, com significância estatística às 6, 24 e 72 horas para o grupo TP e às 48 horas para o grupo TM (Tabela 7). 
Tabela 7: Níveis de VEGF ( $\mathrm{pg} / \mathrm{mL})$ no LBA de coelhos submetidos à injeção intrapleural de TP ou TM. Comparação entre os lados direito e esquerdo.

\begin{tabular}{|c|c|c|c|}
\hline \multicolumn{4}{|c|}{ Talco Pequeno } \\
\hline & LBAD & LBAE & $p$ \\
\hline 6 horas & $\overline{1984,6(917,9-2143,9)}$ & $1277,4(727,0-1870,2)$ & 0,021 \\
\hline $24 \mathrm{r}$ & $3184,9-6601,8)$ & $30047,3(1987,4-4786,8)$ & 0,016 \\
\hline $48 \mathrm{~h}$ & $4245,1(3798,1-6543,2)$ & $3807,2(3333,2-5859,1)$ & 0,249 \\
\hline 72 ho & $2218,1(1649,1-3228,8)$ & $1464,9(1004,9-2156,9)$ & 0,005 \\
\hline 96 horas & $1620,6(1001,1-3225,6)$ & $1156,2(999,2-1413,4)$ & 0,094 \\
\hline \multicolumn{4}{|c|}{ Talco Misto } \\
\hline & LBAD & LBAE & $\bar{p}$ \\
\hline 6 horas & 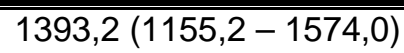 & $853,9(738,2-128$ & 0,183 \\
\hline 24 ho & $2763,3(1914,5-4683,7)$ & $1645,9(1252,4-2374,3)$ & 0,079 \\
\hline $48 \mathrm{~h}$ & $5256,1(4885,2-6745,1)$ & $1645,9(1252,4-2374,3)$ & 0,035 \\
\hline 72 ho & $2836,7(1922,2-3373,2)$ & $3711,5(2715,8-4931,5)$ & 0,069 \\
\hline 96 horas & $1852,0(1536,2-2143,3)$ & $1645,9(711,4-2450,9)$ & 0,990 \\
\hline
\end{tabular}

TP - talco de partículas pequenas, TM - talco de partículas de tamanhos diversos, VEGF - Fator de crescimento endotelial vascular, LBA - Lavado broncoalveolar

Os níveis de VEGF no sangue e no LBA variaram significativamente com o tempo, conforme mostram as figuras 4 e 5 . Os níveis séricos de VEGF para o grupo TP alcançaram pico em 24 horas, enquanto que no LBA, para ambos os grupos e lados direito e esquerdo, o pico ocorreu em 48 horas. 


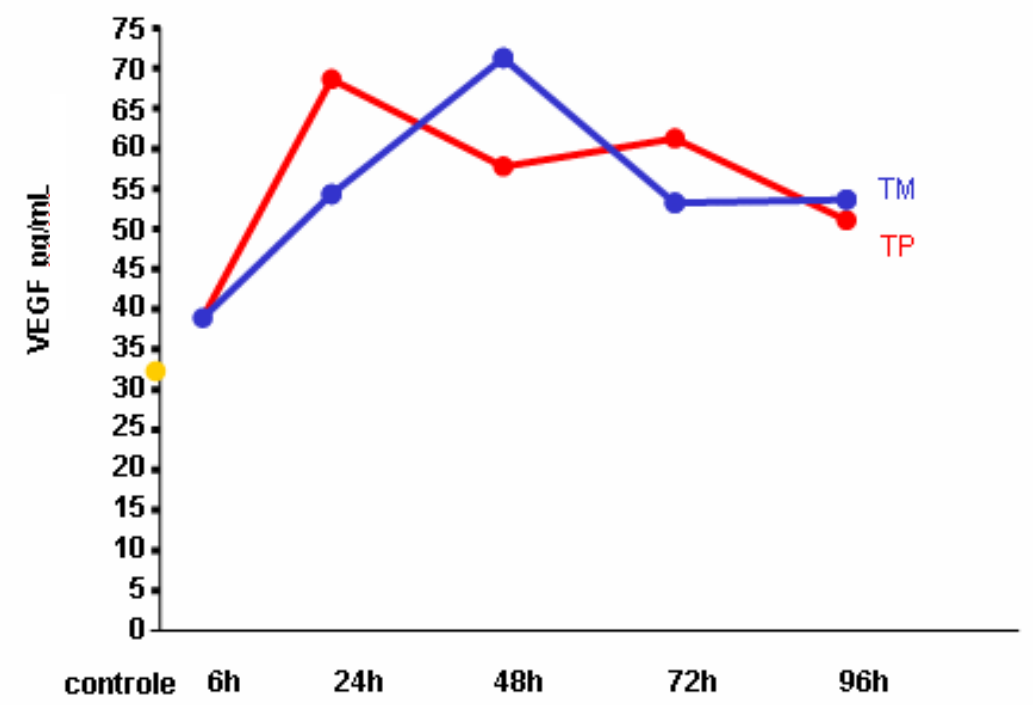

Figura 4: Evolução temporal dos níveis séricos de VEGF $(\mathrm{pg} / \mathrm{mL})$ de coelhos submetidos à injeção intrapleural de TP e TM.
ANOVA TP: $\mathrm{p}=0,05$
ANOVA TM: $p=0,101$

TP - talco de partículas pequenas, TM - talco de partículas de tamanhos diversos, VEGF - Fator de crescimento endotelial vascular.
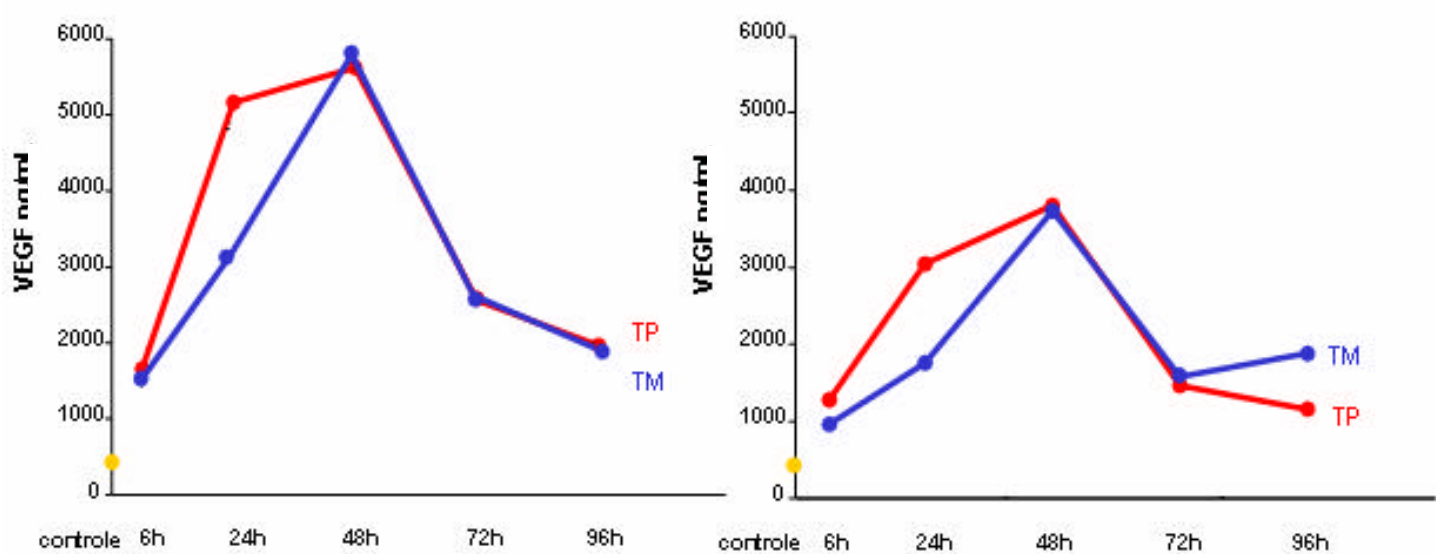

DIREITA

ESQUERDA

Figura 5: Evolução temporal dos níveis de VEGF no LBA à direita e à esquerda de coelhos submetidos à injeção intrapleural de TP e TM.

ANOVA TP à direita- $p=0,024$

ANOVA TM à direita $p<0,001$

ANOVA TP à esquerda- $p=0,004$

ANOVA TM à esquerda $p=0,003$

TP - talco de partículas pequenas, TM - talco de partículas de tamanhos diversos, VEGF - Fator de crescimento endotelial vascular, LBA - Lavado broncoalveolar 


\section{7 - Interleucina 8}

Os níveis de IL-8 no LBA e no sangue foram significantemente mais elevados nos grupos TP e TM quando comparados ao grupo controle (Tabelas 8 e 9).

Tabela 8: Níveis de IL-8 ( $\mathrm{pg} / \mathrm{mL})$ no sangue de coelhos submetidos à injeção intrapleural de TP ou TM. Comparação com grupo controle.

\begin{tabular}{lcc}
\hline \hline Controle & $43,6(33,2-78,2)$ & \\
\hline \hline & $\mathrm{TP}$ & $\mathrm{p}$ \\
\hline \hline 6 horas & $819,7(795,0-950,1)$ & $<0,001$ \\
24 horas & $1008,6(323,9-1219,5)$ & 0,033 \\
48 horas & $1828,7(1746,5-2006,6)$ & $<0,001$ \\
72 horas & $1003,7(891,6-1098,9)$ & $<0,001$ \\
96 horas & $1128,1(927,4-1317,6)$ & $<0,001$ \\
\hline \hline & $\mathrm{TM}$ & 0,004 \\
\hline \hline 6 horas & $558,8(445,1-756,8)$ & 0,028 \\
24 horas & $805,7(517,2-1542,1)$ & $<0,001$ \\
48 horas & $1210,9(1010,1-1312,3)$ & $<0,001$ \\
72 horas & $819,7(623,8-1231,3)$ & 0,032 \\
96 horas & $663,2(596,1-831,7)$ & $\mathrm{p}$ \\
\hline \hline
\end{tabular}

TP - talco de partículas pequenas, TM - talco de partículas de tamanhos diversos, IL-8 - Interleucina - 8. 
Tabela 9: Níveis de IL-8 (pg/mL) no LBA de coelhos submetidos à injeção intrapleural de TP ou de TM. Comparação com grupo controle.

\begin{tabular}{|c|c|c|}
\hline \multicolumn{3}{|c|}{ Lavado Broncoalveolar à Direita } \\
\hline \multirow[t]{2}{*}{ Controle } & $309,3(241,0-391,0)$ & \\
\hline & TP & $p$ \\
\hline 6 horas & $2193,8(1719,5-2457,2)$ & 0,008 \\
\hline 24 horas & $2566,2(1675,3-2987,2)$ & 0,010 \\
\hline 48 horas & $1855,2(1060,3-2327,1)$ & 0,019 \\
\hline 72 horas & $1162,2(873,6-1231,5)$ & 0,001 \\
\hline \multirow[t]{2}{*}{96 horas } & $1539,5(1130,2-1830,3)$ & 0,013 \\
\hline & $\overline{\mathrm{TTM}}$ & $p$ \\
\hline 6 horas & $905,8(811,8-2335,2)$ & 0,071 \\
\hline 24 horas & $2094,5(841,3-2668,0)$ & 0,037 \\
\hline 48 horas & $1065,9(856,1-1090,6)$ & 0,009 \\
\hline 72 horas & $641,8(561,3-687,2)$ & 0,005 \\
\hline 96 horas & $751,8(511,1-897,5)$ & 0,032 \\
\hline \multicolumn{3}{|c|}{ Lavado Broncoalveolar à Esquerda } \\
\hline \multirow[t]{2}{*}{ Controle } & $311,8(251,8-315,9)$ & \\
\hline & TP & $p$ \\
\hline 6 horas & $1253,8(587,4-1870,1)$ & 0,060 \\
\hline 24 horas & $1775,0(1549,3-2095,5)$ & $<0,001$ \\
\hline 48 horas & $1322,3(908,9-1827,8)$ & 0,022 \\
\hline 72 horas & $875,7(585,7-989,9)$ & 0,008 \\
\hline \multirow[t]{2}{*}{96 horas } & $1183,5(621,9-1758,8)$ & 0,024 \\
\hline & $\overline{\mathrm{TM}}$ & $\mathrm{p}$ \\
\hline 6 horas & $868,9(567,0-1583,9)$ & 0,063 \\
\hline 24 horas & $907,7(656,2-1479,3)$ & 0,031 \\
\hline 48 horas & $553,8(433,3-771,7)$ & 0,069 \\
\hline 72 horas & $466,3(293,8-795,1)$ & 0,291 \\
\hline 96 horas & $419,8(107,8-494,6)$ & 0,757 \\
\hline
\end{tabular}

TP - talco de partículas pequenas, TM - talco de partículas de tamanhos diversos, IL-8 - Interleucina - 8, LBA Lavado broncoalveolar

Na comparação entre os grupos TP e TM, observaram-se níveis significativamente mais elevados de IL-8 no grupo TP que no grupo TM, tanto no sangue como no LBA (Tabelas 10 e 11). 
Tabela 10: Níveis séricos de IL-8 $(\mathrm{pg} / \mathrm{mL})$ de coelhos submetidos à injeção intrapleural de TP ou TM. Comparação entre os grupos TP eTM.

\begin{tabular}{lccc}
\hline \hline & TP & TM & $\mathrm{p}$ \\
\hline \hline 6 horas & $819,7(795,0-950,1)$ & $558,8(445,1-756,8)$ & 0,029 \\
24 horas & $1008,6(323,9-1219,5)$ & $805,7(517,2-1542,1)$ & 0,638 \\
48 horas & $1828,7(1746,5-2006,6)$ & $1210,9(1010,1-1312,3)$ & 0,002 \\
72 horas & $1003,7(891,6-1098,9)$ & $819,7(623,8-1231,3)$ & 0,244 \\
96 horas & $1128,1(927,4-1317,6)$ & $663,2(596,1-831,7)$ & 0,003 \\
\hline \hline
\end{tabular}

TP - talco de partículas pequenas, TM - talco de partículas de tamanhos diversos, IL-8 - Interleucina - 8.

Tabela 11: Níveis de IL-8 (pg/mL) no LBA de coelhos submetidos à injeção intrapleural de TP ou de TM. Comparação entre os grupos TP e TM.

\begin{tabular}{|c|c|c|c|}
\hline \multicolumn{4}{|c|}{ Lavado Broncoalveolar à Direita } \\
\hline & TP & TM & $\mathrm{p}$ \\
\hline $\begin{array}{l}6 \text { horas } \\
24 \text { horas } \\
48 \text { horas } \\
72 \text { horas } \\
96 \text { horas } \\
\end{array}$ & $\begin{array}{c}2193,8(1719,5-2457,2) \\
2566,2(1675,3-2987,2) \\
1855,2(1060,3-2327,1) \\
1162,2(873,6-1231,5) \\
1539,5(1130,2-1830,3)\end{array}$ & $\begin{array}{c}905,8(811,8-2335,2) \\
2094,5(841,3-2668,0) \\
1065,9(856,1-1090,6) \\
641,8(561,3-687,2) \\
751,8(511,1-897,5) \\
\end{array}$ & $\begin{array}{l}0,323 \\
0,257 \\
0,063 \\
0,003 \\
0,027\end{array}$ \\
\hline \multicolumn{4}{|c|}{ Lavado Broncoalveolar à Esquerda } \\
\hline & $\overline{\overline{T P}}$ & $\overline{\overline{T M}}$ & $\overline{\mathrm{p}}$ \\
\hline $\begin{array}{l}6 \text { horas } \\
24 \text { horas } \\
\end{array}$ & $\begin{array}{c}1253,8(587,4-1870,1) \\
1775,0(1549,3-2095,5) \\
\end{array}$ & $\begin{array}{l}868,9(567,0-1583,9) \\
907,7(656,2-1479,3) \\
\end{array}$ & $\begin{array}{l}0,605 \\
0,017 \\
\end{array}$ \\
\hline $\begin{array}{l}48 \text { horas } \\
72 \text { horas } \\
96 \text { horas }\end{array}$ & $\begin{array}{c}1322,3(908,9-1827,8) \\
875,7(585,7-989,9) \\
1183,5(621,9-1758,8)\end{array}$ & $\begin{array}{l}553,8(433,3-771,7) \\
466,3(293,8-795,1) \\
419,8(107,8-494,6)\end{array}$ & $\begin{array}{l}0,028 \\
0,127 \\
0,030\end{array}$ \\
\hline
\end{tabular}

Comparando-se o lado pulmonar direito e esquerdo, o LBA apresentou níveis mais elevados de IL-8 à direita em todos os tempos com significância estatística às 48 horas para o grupo TP e às 96 horas para o grupo TM (Tabela 12). 
Tabela 12: Níveis de IL-8 $(\mathrm{pg} / \mathrm{mL})$ no LBA de coelhos submetidos à injeção intrapleural de TP e TM. Comparação entre os lados direito e esquerdo.

\begin{tabular}{|c|c|c|c|}
\hline \multicolumn{4}{|c|}{ Talco Pequeno } \\
\hline & LBAD & LBAE & $p$ \\
\hline 6 horas & $\begin{array}{l}2193,8(1719,5-2457,2) \\
\end{array}$ & $1253,8(587,4-1870,1)$ & 0,117 \\
\hline $24 \mathrm{~h}$ & $2566,2(1675,3-2987,2)$ & $1775,0(1549,3-2095,5)$ & 0,183 \\
\hline 48 horas & $1855,2(1060,3-2327,1)$ & $1322,3(908,9-1827,8)$ & 0,043 \\
\hline 72 horas & $1162,2(873,6-1231,5)$ & $875,7(585,7-989,9)$ & 0,100 \\
\hline 96 horas & $1539,5(1130,2-1830,3)$ & $1183,5(621,9-1758,8)$ & 0,053 \\
\hline \multicolumn{4}{|c|}{ Talco Misto } \\
\hline & LBAD & LBAE & $\bar{p}$ \\
\hline 6 horas & $905,8(811,8-2335,2)$ & $868,9(567,0-1583,9)$ & 0,100 \\
\hline 24 horas & $2094,5(841,3-2668,0)$ & $907,7(656,2-1479,3)$ & 0,059 \\
\hline $48 \mathrm{ho}$ & $1065,9(856,1-1090,6)$ & $553,8(433,3-771,7)$ & 0,066 \\
\hline 72 horas & $641,8(561,3-687,2)$ & $466,3(293,8-795,1)$ & 0,356 \\
\hline 96 horas & $751,8(511,1-897,5)$ & $419,8(107,8-494,6)$ & 0,025 \\
\hline
\end{tabular}

TP - talco de partículas pequenas, TM - talco de partículas de tamanhos diversos, IL-8 - Interleucina - 8, LBA Lavado broncoalveolar.

Os níveis séricos de IL-8 no grupo TP elevaram-se significantemente às $48 \mathrm{~h}$ em relação aos demais tempos. O mesmo comportamento foi observado no grupo TM, entretanto, sem diferença significativa (Figura 6).

No grupo TP, os níveis de IL-8 no LBA à direita elevaram-se significantemente em $24 \mathrm{~h}$ em relação aos demais tempos. O mesmo comportamento foi observado à esquerda, entretanto, sem siginificância estatística. No grupo injetado com TM, os níveis de IL-8 também se elevaram significantemente em $24 \mathrm{~h}$ em relação aos demais tempos à direita; à esquerda observou-se queda dos níveis a partir das $24 \mathrm{~h}$ até às $96 \mathrm{~h}(\mathrm{p}=0,031)$ (Figura 7). 


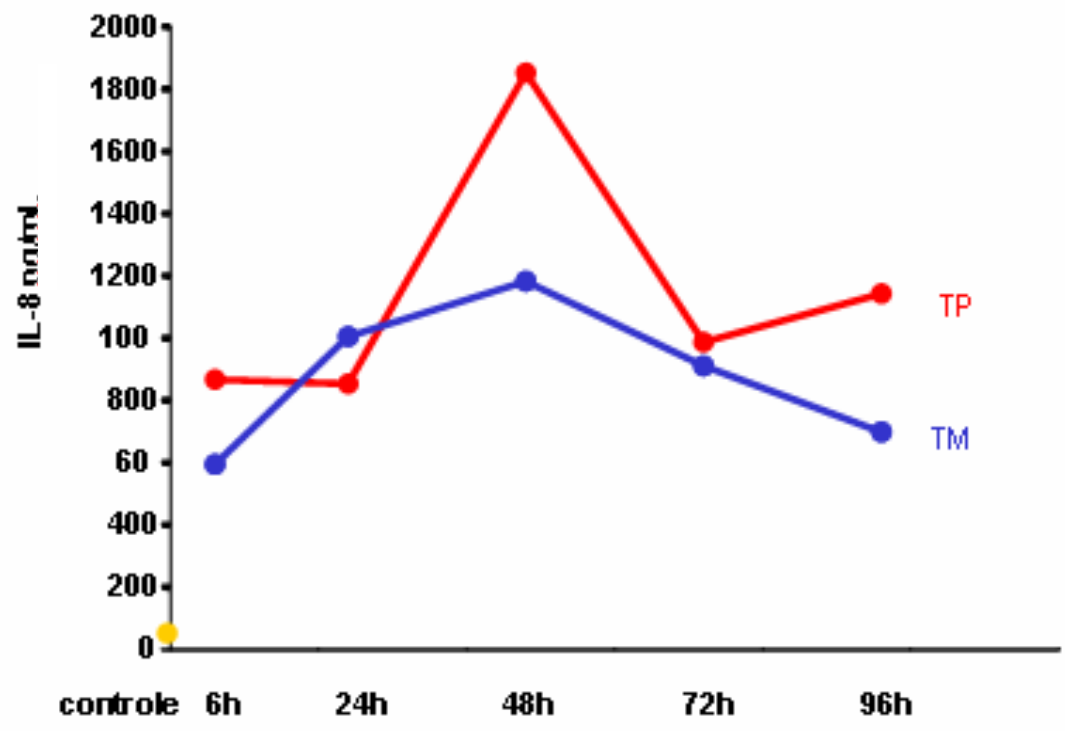

Figura 6: Evolução temporal dos níveis séricos de $\mathrm{IL}-8(\mathrm{pg} / \mathrm{mL})$ de coelhos submetidos à injeção intrapleural de TP e TM.

ANOVA TP- $p<0,001 \quad$ ANOVA TM- $p=0,137$

TP - talco de partículas pequenas, TM - talco de partículas de tamanhos diversos, IL-8 - Interleucina - 8
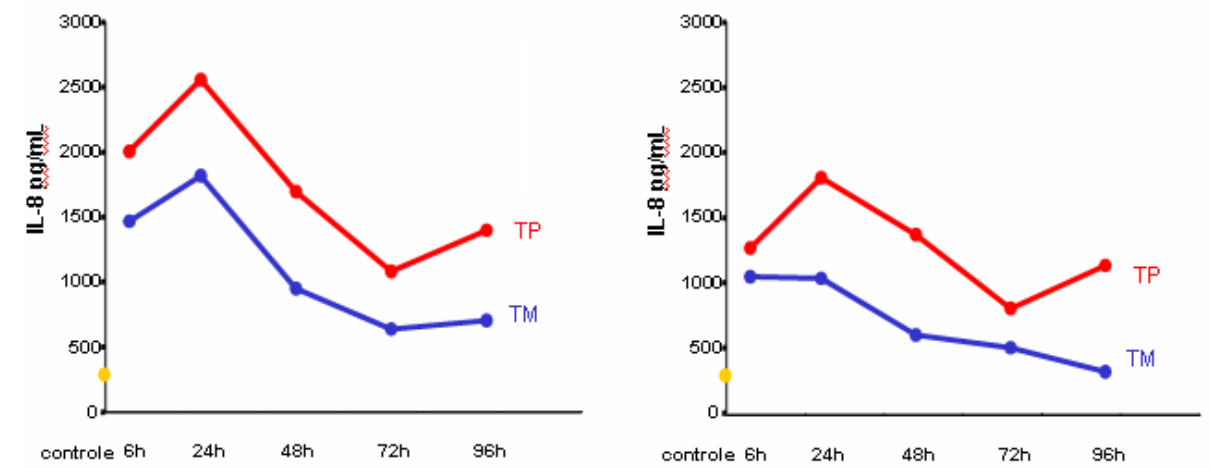

Figura 7: Evolução temporal dos níveis de IL-8 no LBA à direita e à esquerda de coelhos submetidos à injeção de TP e TM intrapleural.

ANOVA TP à direita- $p=0,026$

ANOVA TP à esquerda- $p=0,063$

ANOVA TM à direita $p=0,022$

ANOVA TM à esquerda $p=0,022$

TP - talco de partículas pequenas, TM - talco de partículas de tamanhos diversos, IL-8 - Interleucina - 8, LBA Lavado broncoalveolar. 


\section{2 - Correlações}

\section{1 - Correlações observadas entre os valores obtidos de IL-8, VEGF e}

DHL no LBA e no sangue

Em ambos os grupos de estudo (TP e TM), observamos correlações positivas e significantes entre os níveis de VEGF no sangue e no LBA (Figuras 8 e 9). Para os demais parâmetros (IL-8 e DHL) não observamos correlações significantes entre o lavado broncoalveolar e o sangue.

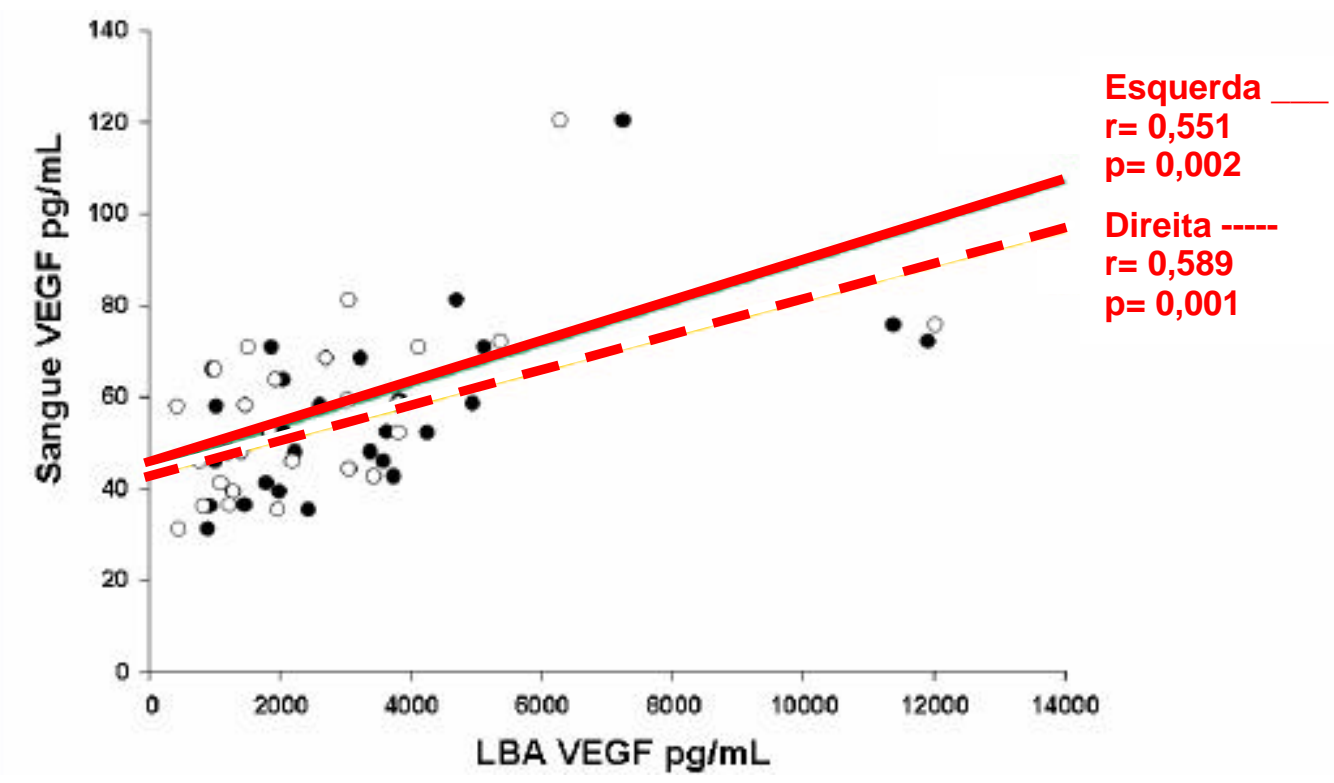

Figura 8: Correlação entre os níveis de VEGF $(\mathrm{pg} / \mathrm{mL})$ do sangue e do LBA à direita e à esquerda no grupo de coelhos submetidos à injeção intrapleural de TP.

TP - talco de partículas pequenas, VEGF - Fator de crescimento do endotélio vascular, LBA - Lavado broncoalveolar 


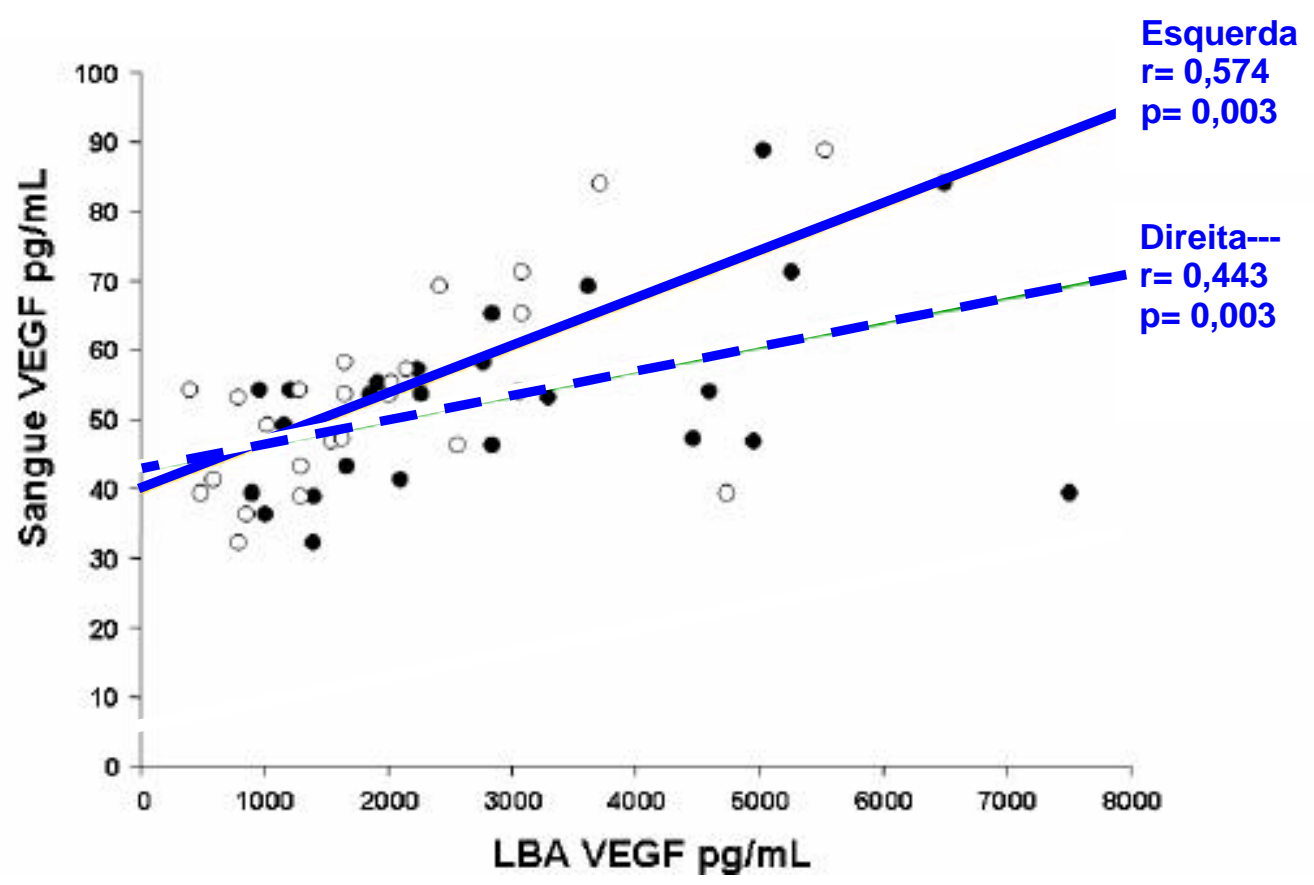

Figura 9: Correlação entre os níveis de VEGF (pg/mL) do sangue e do LBA à direita e à esquerda no grupo de coelhos submetidos à injeção intrapleural de TM.

TM - talco de partículas de tamanhos diversos, VEGF - Fator de crescimento do endotélio vascular, LBA Lavado broncoalveolar

\section{2 - Correlação entre os valores de IL-8, VEGF e DHL obtidos no}

\section{LBA à direita e à esquerda.}

No estudo comparativo entre o LBA à direita e à esquerda observamos correlações positivas e significativas $(p<0,001)$ entre os níveis de IL-8 em ambos os grupos TP e TM ( $r=0,643$ e $r=0,648$ respectivamente) (Figura 10). O mesmo comportamento foi observado quanto ao VEGF $(r=0,929, r=0,779$ e $p<0,001$, respectivamente)(Figura 11). Com relação ao DHL, seus níveis se correlacionaram significantemente $(r=0,627 ; p<0,001)$ entre o LBA à direita e à esquerda no grupo TP (Figura 12). Não foi observada correlação significativa para este parâmetro no grupo TM $(r=0,051 ; p=0,456)$. 


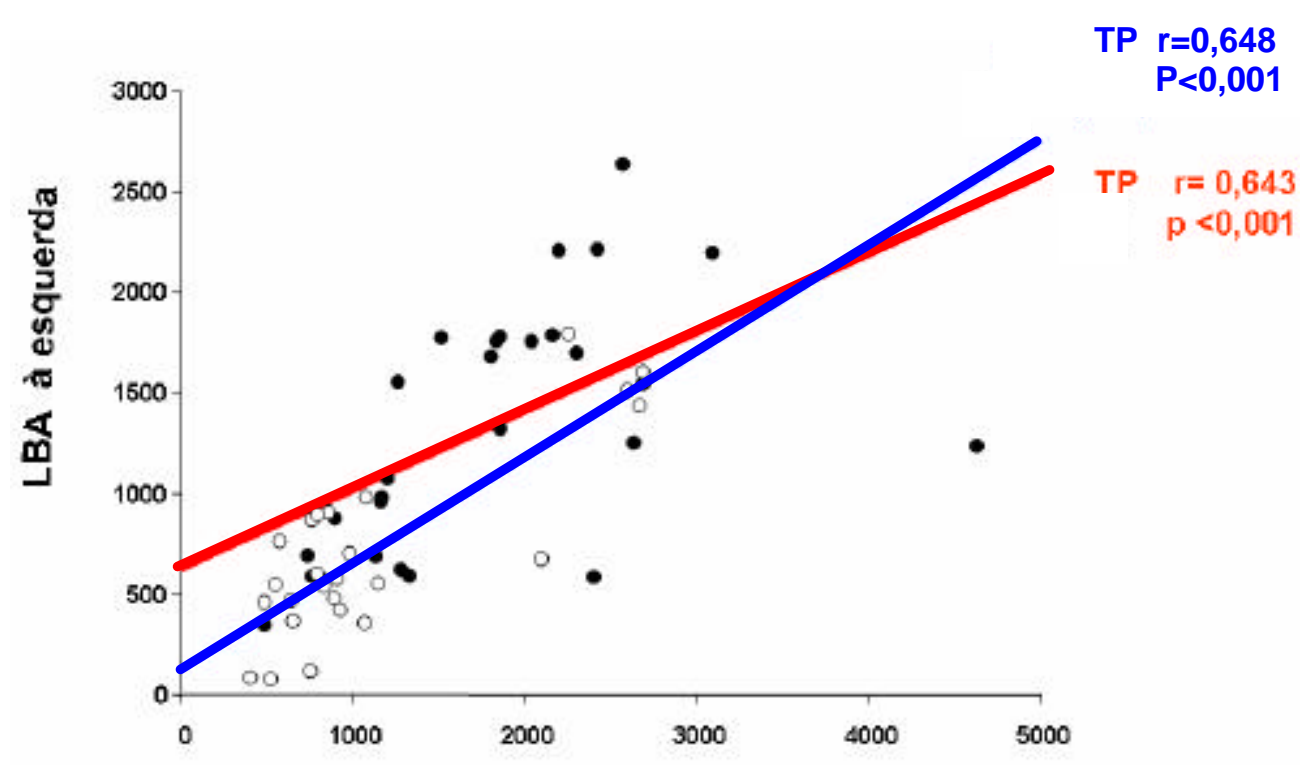

LBA à direita

Figura 10: Correlação entre os níveis de $\mathrm{IL}-8(\mathrm{pg} / \mathrm{mL})$ no lavado broncoalveolar à direita e no lavado broncoalveolar à esquerda

TP - talco de partículas pequenas, TM - talco de partículas de tamanhos diversos, IL-8 - Interleucina -8, LBA - Lavado broncoalveolar.

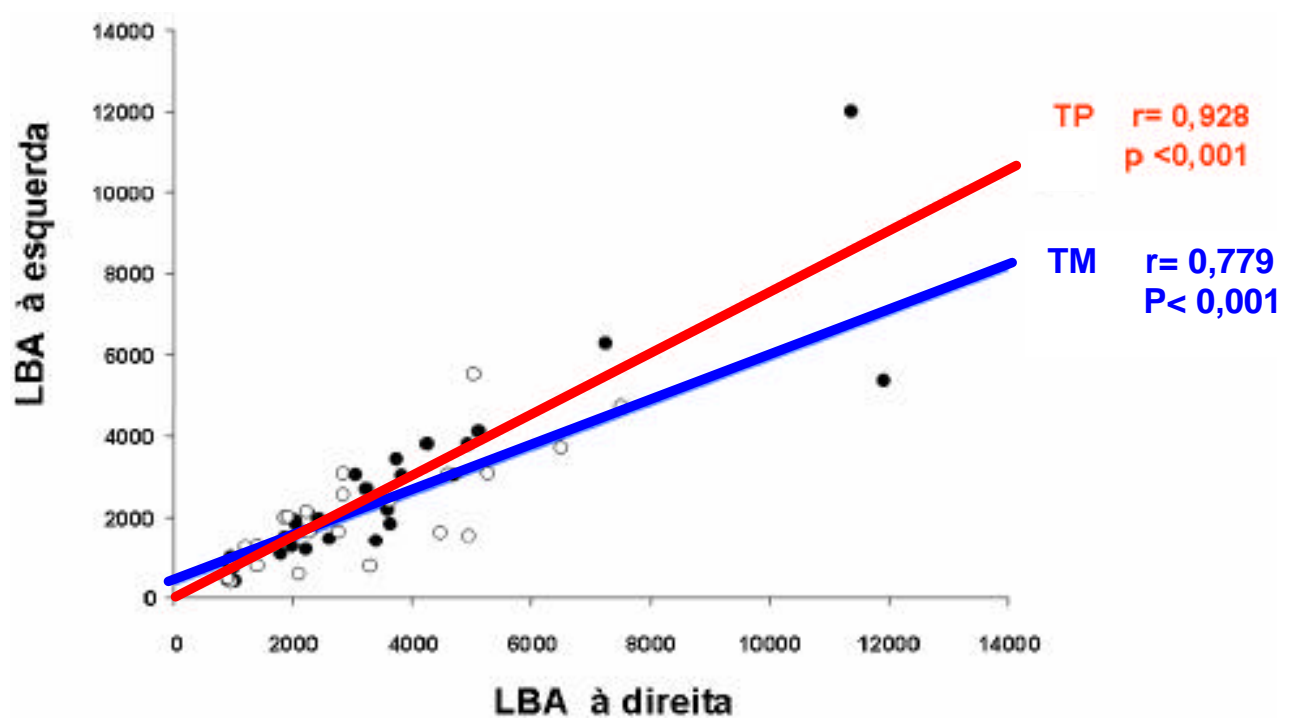

Figura 11: Correlação entre os níveis de VEGF no LBA à direita e à esquerda

TP - talco de partículas pequenas, TM - talco de partículas de tamanhos diversos, VEGF - Fator de crescimento endotelial vascular, LBA - Lavado broncoalveolar. 


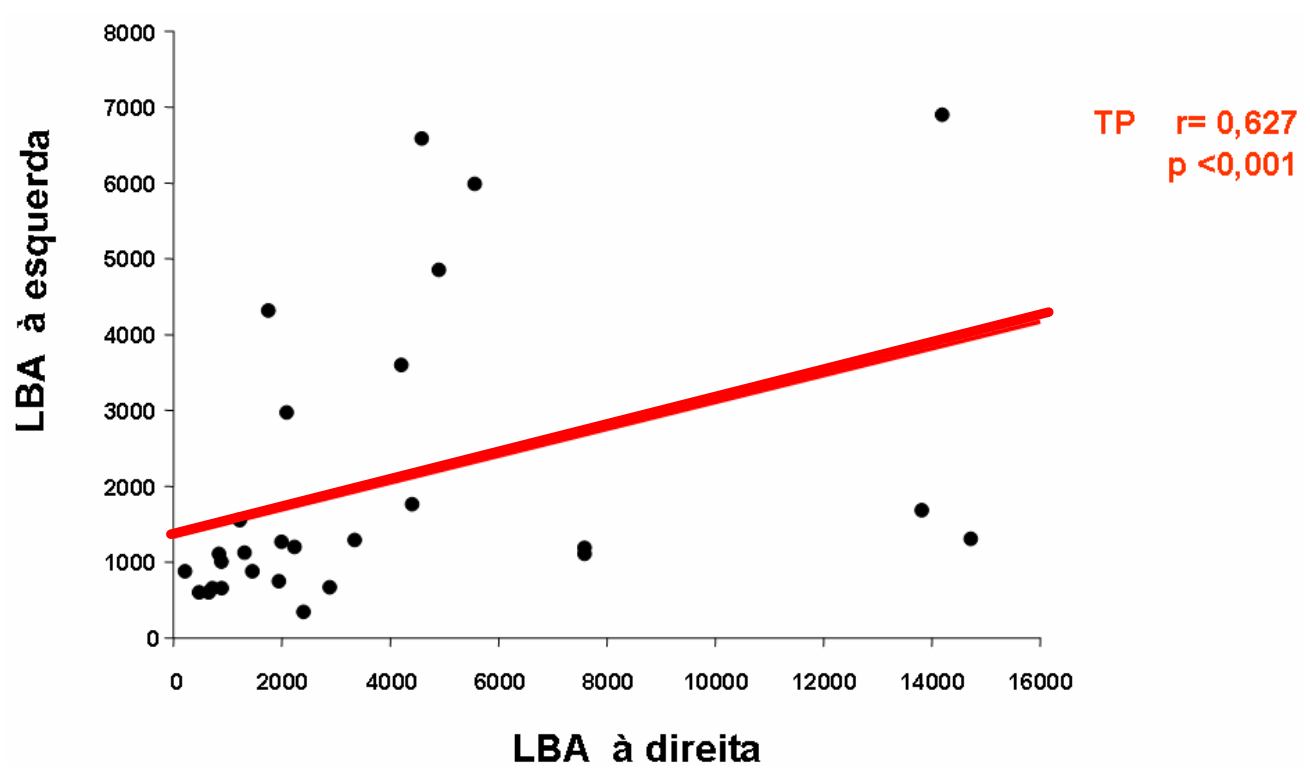

Figura 12: Correlação entre os níveis de DHL no LBA à direita e à esquerda (grupo TP).

TP - talco de partículas pequenas, DHL - Desidrogenase lática, LBA - Lavado broncoalveolar.

\section{3 - Correlações entre os valores de IL-8, VEGF e DHL no LBA} (direita e esquerda) e sangue.

Observou-se correlação positiva e significante entre os níveis de IL-8 e VEGF no lavado broncoalveolar à esquerda dos animais injetados com TP. Embora estes parâmetros tenham se correlacionado à direita $(r=0,348)$ não houve significância estatística $(p=0,0689)$ (Figura 13). $O$ mesmo comportamento não foi observado para o grupo TM que não apresentou correlações significativas. Da mesma maneira, não foram observadas correlações significativas entre VEGF, IL-8 e DHL no LBA (direita e esquerda) e no sangue. 


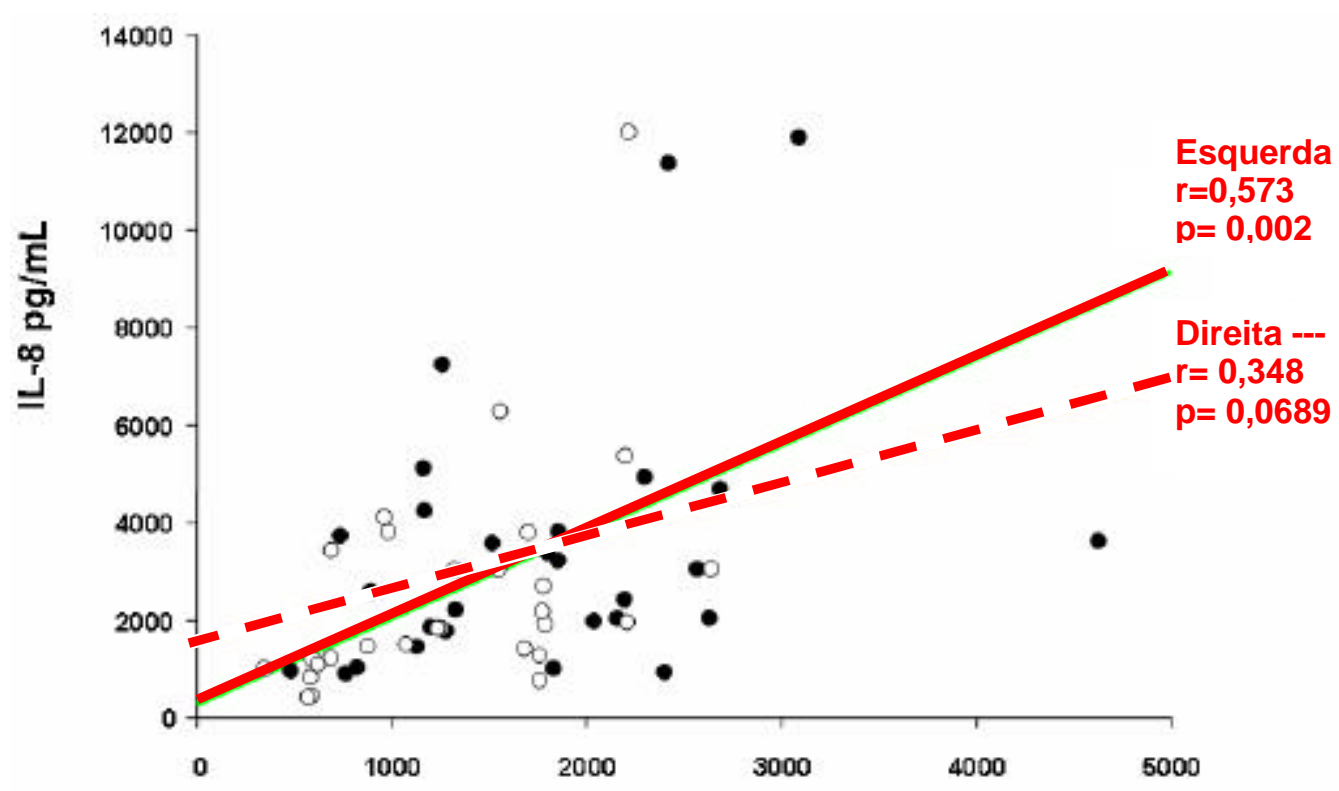

VEGF pg/mL

Figura 13: Correlação entre os níveis de IL-8 e de VEGF no LBA à direita e à esquerda dos animais submetidos à injeção intrapleural de TP.

TP - talco de partículas pequenas, IL-8 - Interleucina -8, VEGF - Fator de crescimento endotelial vascular, LBA - Lavado broncoalveolar

3 - Avaliação quantitativas partículas de talco nos pulmões dos animais dos grupos TP, TM e controle

Não observamos diferenças significativas no número de partículas de talco entre os grupos TP e TM e entre os lados direito e esquerdo (Figura 14 e 15; Anexo C - Tabela Q e R). 


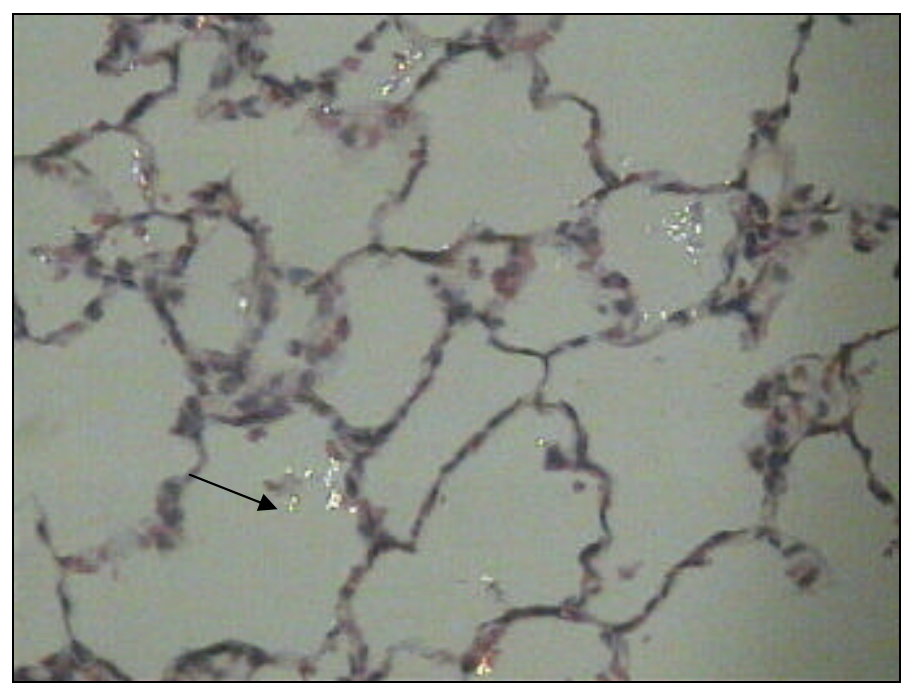

Figura 14: Fotomicrografia de parênquima pulmonar de coelho submetido à injeção intrapleural de TM. Presença de partículas de talco. HE com luz polarizada, aumento de 400X.

TM - talco de partículas de tamanhos diversos

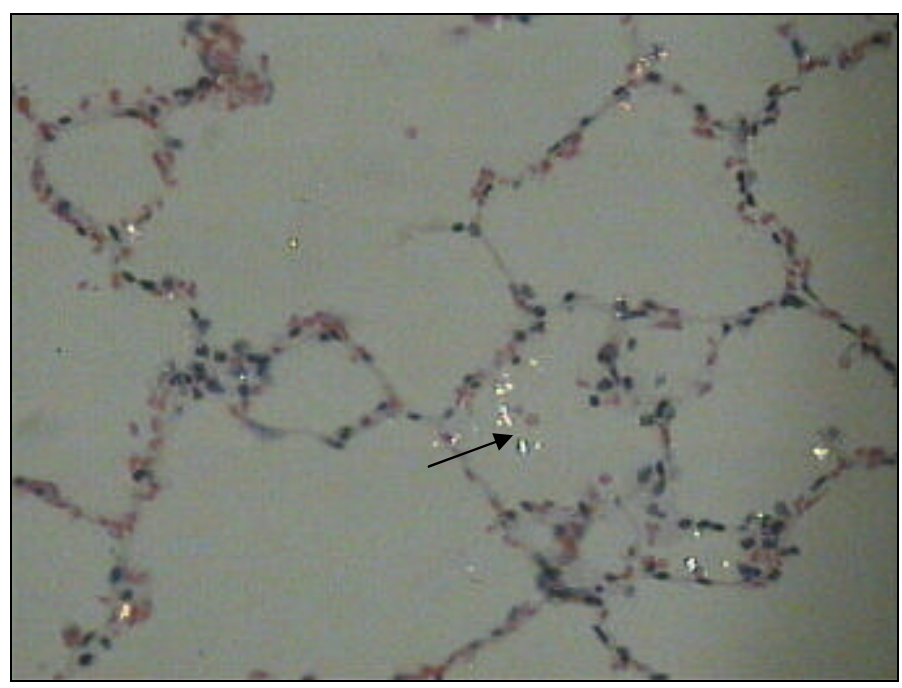

Figura 15: Fotomicrografia de parênquima pulmonar de coelho submetido à injeção intrapleural de TP. Presença de partículas de talco. HE com luz polarizada, aumento de 400X.

TP - talco de partículas pequenas 
4 - Avaliação histológica do pulmão dos animais dos grupos TP e TM e controle

Para a avaliação do parênquima pulmonar considerou-se a celularidade, a presença de edema, capilarite, hemorragia, trombos, infiltrado linfomononuclear e macrófagos (Figura 16 a 18).

Para todos os parâmetros avaliados, os animais dos grupos TP e TM apresentaram variáveis graus de alterações quando comparados ao grupo controle, com significância estatística na avaliação de celularidade, capilarite, infiltrado linfomononuclear e macrófagos em alguns tempos (Tabela 13 a 16). Para os demais parâmetros (presença de trombos, hemorragia e edema) não foram observadas diferenças entre os grupos TP e TM e o controle (Anexo C - Tabelas S a U).

$\mathrm{Na}$ comparação entre os grupos TP e TM, observamos maior celularidade global representada preferencialmente por células linfomononucleares no grupo TP quando comparado ao TM. As diferenças observadas com relação aos tempos estão demonstradas nas Tabelas 17 e 18. Na avaliação dos demais parâmetros não observamos significância estatística entre os grupos e nos vários tempos (Anexo C - Tabela V a BB).

Na comparação entre os pulmões direito e esquerdo, foi observada apenas prevalência discreta do pulmão direito quando avaliamos a celularidade global, a presença de capilarite e de infiltrado linfomononuclear (Tabela 19 -21). Os demais parâmetros não apresentaram diferenças estatisticamente siginificantes entre os grupos ou entre os lados (Anexo C -Tabelas CC a EE) 
Tabela 13: Avaliação da celularidade nos pulmões direito e esquerdo de coelhos submetidos à injeção intrapleural de TP ou de TM (escore de 0 a 3). Comparação com grupo controle.

\begin{tabular}{lcc}
\hline \hline & Pulmão Direito & \\
\hline \hline Controle & $0,0(0,0-0,0)$ & $\mathrm{p}$ \\
\hline \hline & TP & 0,413 \\
\hline 6 horas & $0,0(0,0-1,3)$ & 0,413 \\
48 horas & $0,0(0,0-1,3)$ & 0,016 \\
72 horas & $2,0(2,0-2,3)$ & 0,003 \\
96 horas & $2,5(1,5-3,0)$ & 0,029 \\
\hline \hline & $2,0(2,0-2,5)$ & $\mathrm{p}$ \\
\hline \hline 6 horas & TM & 0,343 \\
24 horas & $1,0(0,0-2,0)$ & 1,000 \\
48 horas & $0,0(0,0-0,0)$ & 0,063 \\
72 horas & $1,0(0,8-2,0)$ & 1,000 \\
96 horas & $0,0(0,0-0,0)$ & 0,057 \\
\hline \hline & $3,0(2,3-3,0)$ & $\mathrm{p}$ \\
\hline \hline Controle & Pulmão Esquerdo & 0,190 \\
\hline \hline & $0,0(0,0-0,0)$ & 0,413 \\
\hline \hline 6 horas & TP & 0,016 \\
24 horas & $1,0(0,0-2,0)$ & 0,114 \\
48 horas & $0,0(0,0-1,3)$ & 0,029 \\
\hline 6 horas & $2,0(1,8-2,3)$ & 0,730 \\
\hline \hline & $1,0(0,5-1,5)$ & 0,629 \\
\hline \hline 6 horas & $1,0(1,0-1,0)$ & 1,000 \\
\hline \hline & $0,0(0,0-0,5)$ & \\
\hline & $0,0(0,0-0,0)$ & $(0,0-0,3)$ \\
\hline
\end{tabular}

TP - talco de partículas pequenas, TM - talco de partículas de tamanhos diversos. 
Tabela 14: Avaliação da capilarite nos pulmões direito e esquerdo de coelhos submetidos à injeção intrapleural de TP ou de TM (escore de $0 \mathrm{a}$ 3). Comparação com grupo controle.

\begin{tabular}{|c|c|c|}
\hline \multicolumn{3}{|c|}{ Pulmão Direito } \\
\hline Controle & $0,0(0,0-0,0)$ & \\
\hline & $\begin{array}{cc}\mathrm{TP} \\
\end{array}$ & $\bar{p}$ \\
\hline $\begin{array}{l}6 \text { horas } \\
24 \text { horas } \\
48 \text { horas } \\
72 \text { horas } \\
96 \text { horas }\end{array}$ & $\begin{array}{l}0,0(0,0-1,3) \\
0,0(0,0-1,3) \\
2,0(1,0-2,0) \\
1,0(0,5-2,0) \\
1,0(1,0-1,5)\end{array}$ & $\begin{array}{l}0,413 \\
0,413 \\
0,016 \\
0,114 \\
0,029\end{array}$ \\
\hline 96 horas & TM & $p$ \\
\hline $\begin{array}{l}6 \text { horas } \\
24 \text { horas } \\
48 \text { horas } \\
72 \text { horas } \\
96 \text { horas } \\
\end{array}$ & $\begin{array}{l}0,5(0,0-1,0) \\
0,0(0,0-0,0) \\
1,0(0,8-2,0) \\
0,0(0,0-0,0) \\
1,0(1,0-2,5)\end{array}$ & $\begin{array}{l}0,343 \\
1,000 \\
0,063 \\
1,000 \\
0,057\end{array}$ \\
\hline \multicolumn{3}{|c|}{ Pulmão Esquerdo } \\
\hline \multirow[t]{2}{*}{ Controle } & $0,0(0,0-0,0)$ & \\
\hline & $\overline{T P}$ & $p$ \\
\hline $\begin{array}{l}6 \text { horas } \\
24 \text { horas } \\
48 \text { horas } \\
72 \text { horas } \\
96 \text { horas }\end{array}$ & $\begin{array}{l}1,0(0,0-2,0) \\
0,0(0,0-1,3) \\
1,0(0,8-2,0) \\
1,0(0,5-1,5) \\
1,0(1,0-1,0)\end{array}$ & $\begin{array}{l}0,190 \\
0,413 \\
0,063 \\
0,114 \\
0,029\end{array}$ \\
\hline 96 horas & $\overline{\mathrm{TTM}}$ & $p$ \\
\hline $\begin{array}{l}6 \text { horas } \\
24 \text { horas } \\
48 \text { horas } \\
72 \text { horas } \\
96 \text { horas }\end{array}$ & $\begin{array}{l}0,0(0,0-0,5) \\
0,0(0,0-0,0) \\
0,0(0,0-0,3) \\
0,0(0,0-0,8) \\
0,0(0,0-0,0)\end{array}$ & $\begin{array}{l}0,686 \\
1,000 \\
0,730 \\
0,629 \\
1,000\end{array}$ \\
\hline
\end{tabular}

TP - talco de partículas pequenas, TM - talco de partículas de tamanhos diversos. 


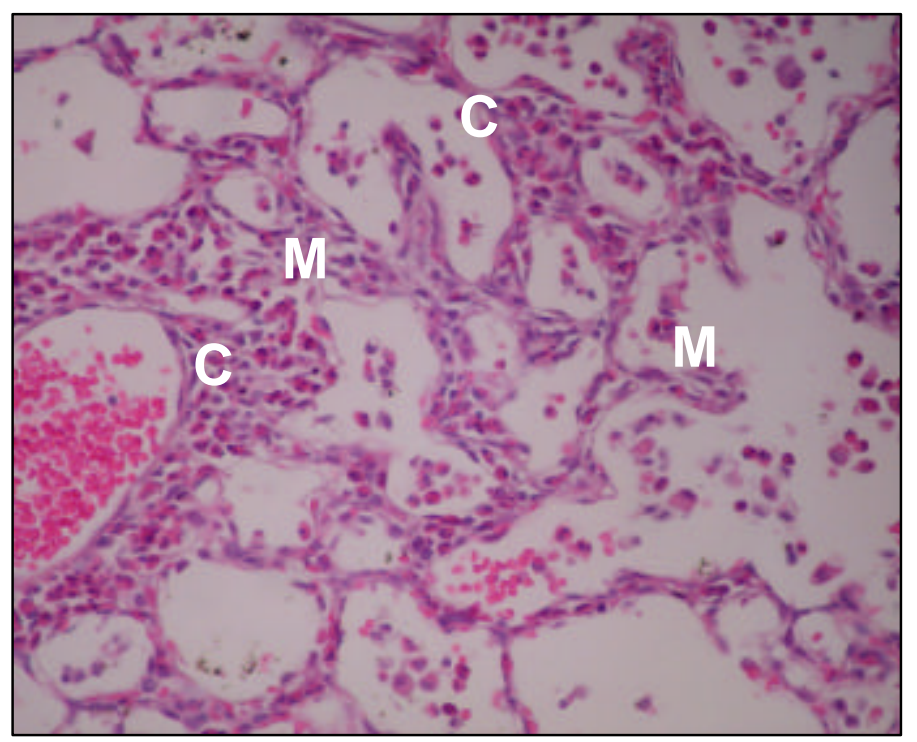

Figura 16: Fotomicrografia de parênquima pulmonar de coelho submetido à injeção intrapleural de TP. Presença de capilarite (C) e macrófagos (M). HE, aumento de 400X.

TM - talco de partículas de tamanhos diversos

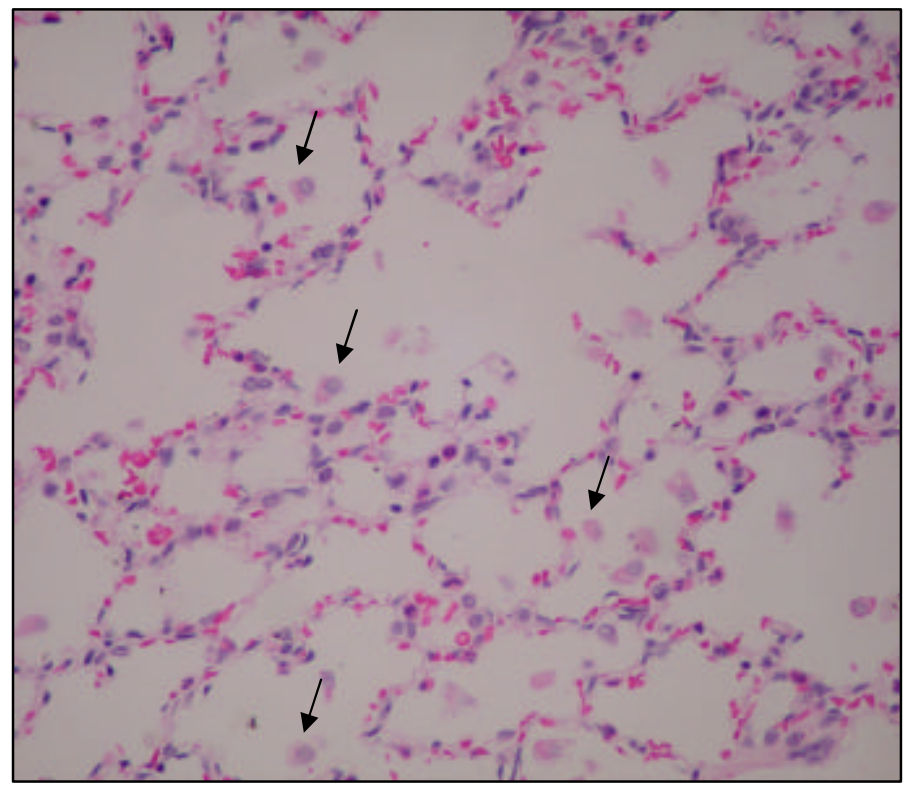

Figura 17: Fotomicrografia de parênquima pulmonar de coelho submetido à injeção intrapleural de TM. Presença de macrófagos (setas). HE, aumento de 400X.

TM - talco de partículas de tamanhos diversos 


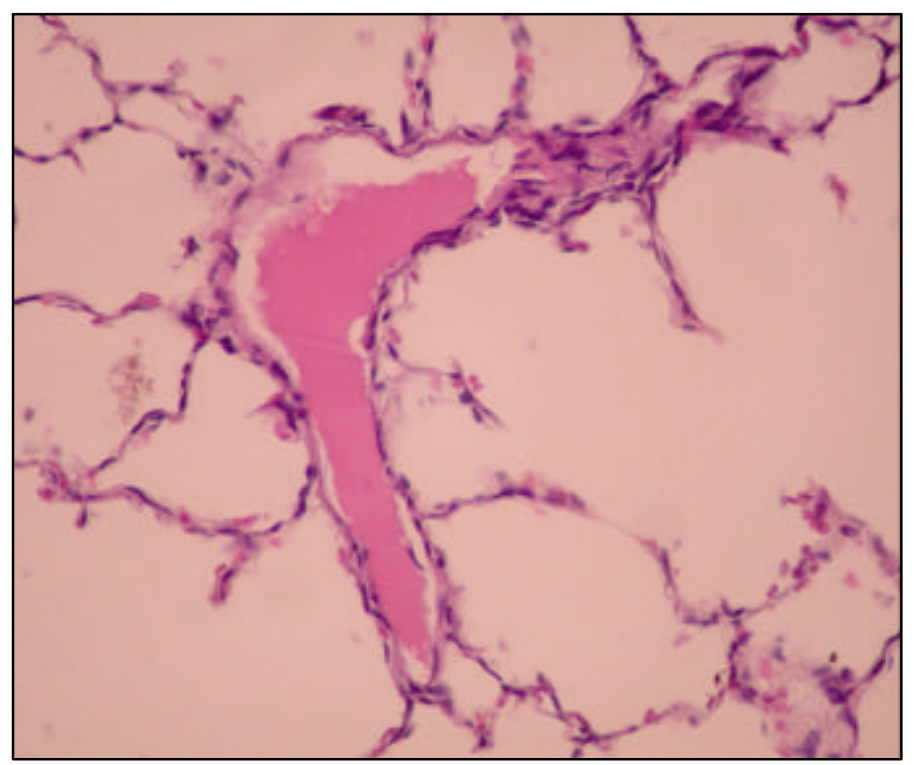

Figura 18: Fotomicrografia de parênquima pulmonar de coelho submetido à injeção intrapleural de TP. Presença de trombo. HE, aumento de 400X.

TM - talco de partículas de tamanhos diversos

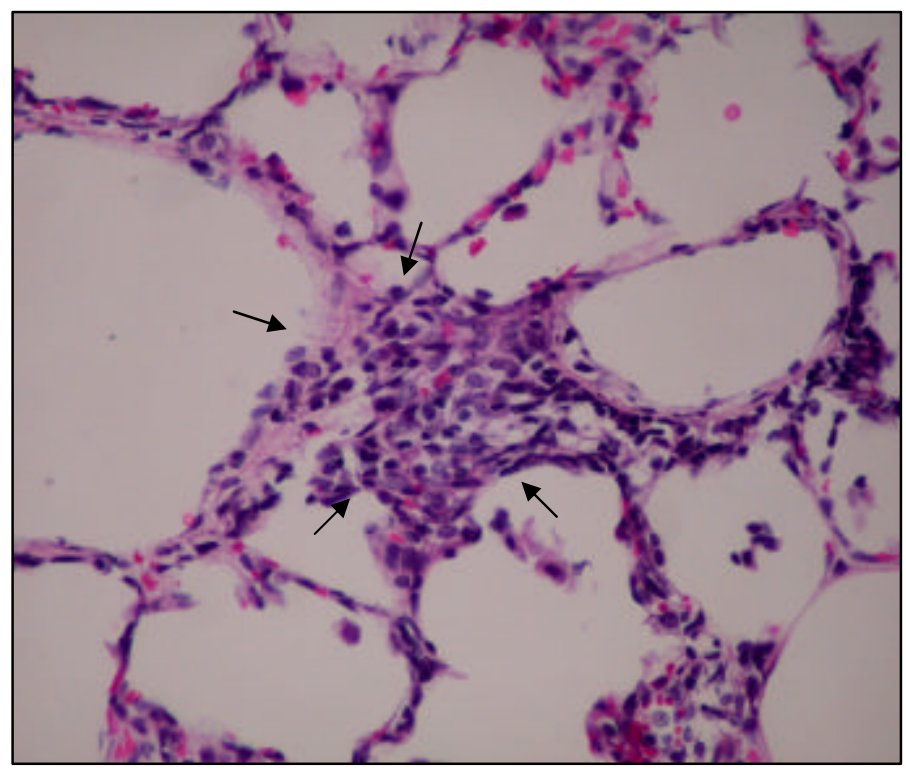

Figura 19: Fotomicrografia de parênquima pulmonar de coelho submetido à injeção intrapleural de TM. Presença de infiltrado linfomononuclear (setas). HE, aumento de 400X.

TM - talco de partículas de tamanhos diversos 
Tabela 15: Avaliação da presença de infiltrado linfomononuclear nos pulmões direito e esquerdo de coelhos submetidos à injeção intrapleural de TP ou de TM (escore de 0 a 3). Comparação com grupo controle.

\begin{tabular}{|c|c|c|}
\hline \multicolumn{3}{|c|}{ Pulmão Direito } \\
\hline Controle & $0,0(0,0-0,0)$ & \\
\hline & TP & $p$ \\
\hline $\begin{array}{l}6 \text { horas } \\
24 \text { horas } \\
48 \text { horas } \\
72 \text { horas } \\
96 \text { horas } \\
\end{array}$ & $\begin{array}{l}0,0(0,0-1,0) \\
0,0(0,0-0,0) \\
2,0(1,5-3,0) \\
1,5(1,0-2,5) \\
1,0(0,5-1,0)\end{array}$ & $\begin{array}{l}0,413 \\
1,000 \\
0,063 \\
0,011 \\
0,114\end{array}$ \\
\hline 96 horas & TM & $\mathrm{p}$ \\
\hline $\begin{array}{l}6 \text { horas } \\
24 \text { horas } \\
48 \text { horas } \\
72 \text { horas } \\
96 \text { horas } \\
\end{array}$ & $\begin{array}{l}0,0(0,0-0,0) \\
0,0(0,0-0,0) \\
1,0(0,0-1,0) \\
0,0(0,0-0,0) \\
2,0(1,3-2,0)\end{array}$ & $\begin{array}{l}1,000 \\
1,000 \\
0,190 \\
1,000 \\
0,057\end{array}$ \\
\hline \multicolumn{3}{|c|}{ Pulmão Esquerdo } \\
\hline \multirow[t]{2}{*}{ Controle } & $0,0(0,0-0,0)$ & \\
\hline & TP & $p$ \\
\hline $\begin{array}{l}6 \text { horas } \\
24 \text { horas } \\
48 \text { horas } \\
72 \text { horas } \\
96 \text { horas }\end{array}$ & $\begin{array}{l}0,0(0,0-0,0) \\
0,0(0,0-0,0) \\
2,0(0,8-2,3) \\
0,5(0,0-1,0) \\
1,0(0,5-1,0)\end{array}$ & $\begin{array}{l}1,000 \\
1,000 \\
0,063 \\
0,343 \\
0,114\end{array}$ \\
\hline 96 horas & TM & $p$ \\
\hline $\begin{array}{l}6 \text { horas } \\
24 \text { horas } \\
48 \text { horas } \\
72 \text { horas } \\
96 \text { horas }\end{array}$ & $\begin{array}{l}0,0(0,0-0,0) \\
0,0(0,0-0,0) \\
0,0(0,0-0,3) \\
0,0(0,0-0,0) \\
0,0(0,0-0,0)\end{array}$ & $\begin{array}{l}1,000 \\
1,000 \\
0,730 \\
1,000 \\
1,000\end{array}$ \\
\hline
\end{tabular}

TP - talco de partículas pequenas, TM - talco de partículas de tamanhos diversos. 
Tabela 16: Avaliação da presença de macrófagos nos pulmões direito e esquerdo de coelhos submetidos à injeção intrapleural de TP ou de TM (escore de 0 a 3). Comparação com grupo controle.

\begin{tabular}{|c|c|c|}
\hline \multicolumn{3}{|c|}{ Pulmão Direito } \\
\hline Controle & $0,0(0,0-0,0)$ & \\
\hline & TP & $p$ \\
\hline $\begin{array}{l}6 \text { horas } \\
24 \text { horas } \\
48 \text { horas } \\
72 \text { horas } \\
96 \text { horas }\end{array}$ & $\begin{array}{l}0,0(0,0-1,0) \\
0,0(0,0-1,0) \\
1,0(1,0-1,0) \\
1,0(1,0-1,0) \\
1,0(1,0-1,0)\end{array}$ & $\begin{array}{l}0,413 \\
0,413 \\
0,016 \\
0,029 \\
0,029\end{array}$ \\
\hline 96 horas & TM & $p$ \\
\hline $\begin{array}{l}6 \text { horas } \\
24 \text { horas } \\
48 \text { horas } \\
72 \text { horas } \\
96 \text { horas }\end{array}$ & $\begin{array}{c}0,5(0,0-1,0) \\
0,0(0,0-0,0) \\
1,0(0,8-1,0) \\
0,0(0,0-0,0) \\
1,0(1,0-1,0)\end{array}$ & $\begin{array}{l}0,025 \\
0,343 \\
1,000 \\
0,063 \\
1,000\end{array}$ \\
\hline \multicolumn{3}{|c|}{ Pulmão Esquerdo } \\
\hline \multirow[t]{2}{*}{ Controle } & $0,0(0,0-0,0)$ & \\
\hline & TP & $p$ \\
\hline $\begin{array}{l}6 \text { horas } \\
24 \text { horas } \\
48 \text { horas } \\
72 \text { horas } \\
96 \text { horas }\end{array}$ & $\begin{array}{l}0,0(0,0-0,0) \\
0,0(0,0-0,0) \\
1,0(1,0-1,0) \\
1,0(0,5-1,0) \\
1,0(1,0-1,0)\end{array}$ & $\begin{array}{l}1,000 \\
0,413 \\
0,016 \\
0,114 \\
0,029\end{array}$ \\
\hline 96 horas & TM & $\bar{p}$ \\
\hline $\begin{array}{l}6 \text { horas } \\
24 \text { horas } \\
48 \text { horas } \\
72 \text { horas } \\
96 \text { horas }\end{array}$ & $\begin{array}{l}0,0(0,0-0,0) \\
0,0(0,0-0,0) \\
0,0(0,0-0,3) \\
0,0(0,0-0,8) \\
0,0(0,0-0,0)\end{array}$ & $\begin{array}{l}1,000 \\
1,000 \\
0,730 \\
0,629 \\
1,000\end{array}$ \\
\hline
\end{tabular}

TP - talco de partículas pequenas, TM - talco de partículas de tamanhos diversos. 
Tabela 17: Avaliação da celularidade nos pulmões direito e esquerdo de coelhos submetidos à injeção intrapleural de TP ou de TM (escore de 0 a 3). Comparação entre os grupos TP e TM.

\begin{tabular}{lccc}
\hline \hline \multicolumn{4}{c}{ Pulmão Direito } \\
\hline \hline \multicolumn{5}{c}{ TP } & TM & $\mathrm{p}$ \\
\hline \hline 6 horas & $0,0(0,0-1,3)$ & $1,0(0,0-2,0)$ & 0,575 \\
24 horas & $0,0(0,0-1,3)$ & $0,0(0,0-0,0)$ & 0,413 \\
48 horas & $2,0(2,0-2,3)$ & $1,0(0,8-2,0)$ & 0,095 \\
72 horas & $2,5(1,5-3,0)$ & $0,0(0,0-0,0)$ & 0,011 \\
96 horas & $2,0(2,0-2,5)$ & $3,0(2,3-3,0)$ & 0,352 \\
\hline \hline \multicolumn{5}{c}{ Pulmão Esquerdo } \\
\hline \hline 6 horas & TP & TM & $\mathrm{p}$ \\
24 horas & $1,0(0,0-2,0)$ & $0,0(0,0-0,5)$ & 0,217 \\
48 horas & $0,0(0,0-1,3)$ & $0,0(0,0-0,0)$ & 0,413 \\
72 horas & $2,0(1,8-2,3)$ & $0,0(0,0-0,3)$ & 0,001 \\
96 horas & $1,0(0,5-1,5)$ & $0,0(0,0-0,8)$ & 0,286 \\
\hline \hline
\end{tabular}

TP - talco de partículas pequenas, TM - talco de partículas de tamanhos diversos.

Tabela 18: Avaliação da presença de infiltrado linfomononuclear nos pulmões direito e esquerdo de coelhos submetidos à injeção intrapleural de TP ou de TM (escore de 0 a 3). Comparação entre os grupos TP e TM.

\begin{tabular}{lccc}
\hline \hline \multicolumn{4}{c}{ Pulmão Direito } \\
\hline \hline & TP & TM & $\mathrm{p}$ \\
\hline \hline 6 horas & $0,0(0,0-1,0)$ & $0,0(0,0-0,0)$ & 0,413 \\
24 horas & $0,0(0,0-0,0)$ & $0,0(0,0-0,0)$ & 1,000 \\
48 horas & $2,0(1,5-3,0)$ & $1,0(0,0-1,0)$ & 0,048 \\
72 horas & $1,5(1,0-2,5)$ & $0,0(0,0-0,0)$ & 0,027 \\
96 horas & $1,0(0,5-1,0)$ & $2,0(1,3-2,0)$ & 0,114 \\
\hline \hline & Pulmão Esquerdo & $\mathrm{p}$ \\
\hline \hline & $\mathrm{TP}$ & $\mathrm{TM}$ & 1,000 \\
\hline \hline 6 horas & $0,0(0,0-0,0)$ & $0,0(0,0-0,0)$ & 1,000 \\
24 horas & $0,0(0,0-0,0)$ & $0,0(0,0-0,0)$ & 0,034 \\
48 horas & $2,0(0,8-2,3)$ & $0,0(0,0-0,3)$ & 0,203 \\
72 horas & $0,5(0,0-1,0)$ & $0,0(0,0-0,0)$ & 0,114 \\
\hline 6 horas & $1,0(0,5-1,0)$ & $0,0(0,0-0,0)$ & \\
\hline \hline
\end{tabular}

TP - talco de partículas pequenas, TM - talco de partículas de tamanhos diversos. 
Tabela 19: Avaliação da celularidade nos pulmões direito e esquerdo de coelhos submetidos à injeção intrapleural de TP ou de TM (escore de 0 a 3). Comparação entre os lados direito e esquerdo.

\begin{tabular}{lccc}
\hline \hline & \multicolumn{2}{c}{ Talco Pequeno } & \\
\hline \hline & Pulmão direito & Pulmão esquerdo & $\mathrm{p}$ \\
\hline \hline 6 horas & $0,0(0,0-1,3)$ & $1,0(0,0-2,0)$ & 0,587 \\
24 horas & $0,0(0,0-1,3)$ & $0,0(0,0-1,3)$ & 1,000 \\
48 horas & $2,0(2,0-2,3)$ & $2,0(1,8-2,3)$ & 0,621 \\
72 horas & $2,5(1,5-3,0)$ & $1,0(0,5-1,5)$ & 0,194 \\
96 horas & $2,0(2,0-2,5)$ & $1,0(1,0-1,0)$ & 0,125 \\
\hline \hline & & & $\mathrm{p}$ \\
\hline \hline & Talco Misto & Pulmão esquerdo & 0,215 \\
24 horas & Pulmão direito & $0,0(0,0-0,5)$ & 1,000 \\
48 horas & $1,0(0,0-2,0)$ & $0,0(0,0-0,0)$ & 0,034 \\
72 horas & $0,0(0,0-0,0)$ & $0,0(0,0-0,3)$ & 0,423 \\
96 horas & $1,0(0,8-2,0)$ & $0,0(0,0-0,8)$ & 0,015 \\
\hline \hline
\end{tabular}

TP - talco de partículas pequenas, TM - talco de partículas de tamanhos diversos.

Tabela 20: Avaliação da presença de capilarite nos pulmões direito e esquerdo de coelhos submetidos à injeção intrapleural de TP ou de TM (escore de 0 a 3). Comparação entre os lados direito e esquerdo.

\begin{tabular}{lccc}
\hline \hline & \multicolumn{2}{c}{ Talco Pequeno } & \\
\hline \hline & Pulmão direito & Pulmão esquerdo & $\mathrm{p}$ \\
\hline \hline 6 horas & $0,0(0,0-1,3)$ & $1,0(0,0-2,0)$ & 0,587 \\
24 horas & $0,0(0,0-1,3)$ & $0,0(0,0-1,3)$ & 1,000 \\
48 horas & $2,0(1,0-2,0)$ & $1,0(0,8-2,0)$ & 0,178 \\
72 horas & $1,0(0,5-2,0)$ & $1,0(0,5-1,5)$ & 0,809 \\
96 horas & $1,0(1,0-1,5)$ & $1,0(1,0-1,0)$ & 1,000 \\
\hline \hline & & Talco Misto & Pulmão esquerdo \\
\hline \hline 6 horas & Pulmão direito & $0,0(0,0-0,5)$ & 1,000 \\
24 horas & $0,5(0,0-1,0)$ & $0,0(0,0-0,0)$ & 1,000 \\
48 horas & $0,0(0,0-0,0)$ & $0,0(0,0-0,3)$ & 0,034 \\
72 horas & $1,0(0,8-2,0)$ & $0,0(0,0-0,8)$ & 0,423 \\
96 horas & $0,0(0,0-0,0)$ & $0,0(0,0-0,0)$ & 0,130 \\
\hline \hline
\end{tabular}

TP - talco de partículas pequenas, TM - talco de partículas de tamanhos diversos. 
Tabela 21: Avaliação da presença de infiltrado linfomononuclear nos pulmões direito e esquerdo de coelhos submetidos à injeção intrapleural de TP ou de TM (escore de 0 a 3). Comparação entre os lados direito e esquerdo.

\begin{tabular}{lccc}
\hline \hline \multicolumn{5}{c}{ Talco Pequeno } \\
\hline \hline & Pulmão direito & Pulmão esquerdo & $\mathrm{P}$ \\
\hline \hline 6 horas & $0,0(0,0-1,0)$ & $0,0(0,0-0,0)$ & 0,178 \\
24 horas & $0,0(0,0-0,0)$ & $0,0(0,0-0,0)$ & 1,000 \\
48 horas & $2,0(1,5-3,0)$ & $2,0(0,8-2,3)$ & 0,178 \\
72 horas & $1,5(1,0-2,5)$ & $0,5(0,0-1,0)$ & 0,194 \\
96 horas & $1,0(0,5-1,0)$ & $1,0(0,5-1,0)$ & 1,000 \\
\hline \hline \multicolumn{5}{c}{ Talco Misto } \\
\hline \hline \\
\hline \hline 6 horas & Pulmão direito & Pulmão esquerdo & $\mathrm{P}$ \\
24 horas & $0,0(0,0-0,0)$ & $0,0(0,0-0,0)$ & 1,000 \\
48 horas & $0,0(0,0-0,0)$ & $0,0(0,0-0,0)$ & 1,000 \\
72 horas & $1,0(0,0-1,0)$ & $0,0(0,0-0,3)$ & 0,178 \\
96 horas & $0,0(0,0-0,0)$ & $0,0(0,0-0,0)$ & 1,000 \\
\hline \hline TP - talco de partículas pequenas, TM - talco de partículas de tamanhos diversos. & $0,0(0,0-0,0)$ & 0,038 \\
\hline
\end{tabular}




\section{DISCUSSÃO}

O papel do talco na resposta inflamatória sistêmica e pulmonar tem sido alvo de vários estudos. As questões referentes ao aparecimento de insuficiência respiratória aguda após a instilação do talco intrapleural ainda não foram totalmente respondidas. Várias são as hipóteses relacionando os fatores inerentes às partículas de talco, sua forma de disseminação sistêmica e pulmonar e a concomitante resposta inflamatória às mesmas. Estudos experimentais e clínicos têm demonstrado a presença de partículas de talco em vários órgãos subseqüentemente à indução de pleurodese $(18,26,46,47,66)$. Outros trabalhos demonstram uma maior difusão de partículas relacionada à dose de talco injetada (16) ou ao diâmetro médio das partículas (44). Froudarakis e cols (67) demonstraram que a resposta inflamatória sistêmica é mais pronunciada em pacientes submetidos à toracoscopia com instilação intrapleural de talco do que naqueles pacientes submetidos somente à toracoscopia, quer seja ela diagnóstica ou terapêutica. Da mesma maneira, estudos clínicos e experimentais têm demonstrado níveis elevados de mediadores inflamatórios, como as citocinas, no soro e no líquido pleural de pacientes ou animais submetidos à indução de pleurodese por talco $(61,62,68,69)$.

Em nosso estudo, a avaliação do perfil inflamatório sérico e pulmonar em resposta à injeção intrapleural dos dois tipos de talco foi realizada através da análise da composição celular, de parâmetros bioquímicos (DHL), de dosagens imunológicas: citocinas inflamatórias (IL8, VEGF) e PCR no sangue e no lavado broncoalveolar associados à 
análise histológica do parênquima pulmonar.

Os tempos pré-definidos neste estudo para a avaliação dos efeitos agudos de injeção intrapleural de talco se basearam nos estudos clínicos conforme citação no quadro 1. Nestes trabalhos, os casos que evoluíram para insuficiência respiratória aguda apresentam descrição de sintomas de desconforto respiratório que se iniciaram de 2 a 96 horas após a instilação intrapleural do talco.

Tanto o talco de partículas pequenas, quanto o talco de partículas de tamanhos diversos, produziu resposta pulmonar e sistêmica aguda. Os níveis séricos de PCR apresentaram-se elevados desde as primeiras 6 horas após a injeção de talco intrapleural, alcançando pico em 24 horas para ambos os grupos (TP e TM). Quanto à análise do VEGF, tanto no LBA quanto no soro, os níveis elevaram-se também nas primeiras 6 horas e mantiveram-se elevados em ambos os grupos. Os níveis de IL-8 no sangue elevaram-se desde as primeiras 6 horas e alcançaram pico em 48 horas, enquanto que no LBA alcançaram pico em 24 horas, mantendo-se elevados em todos os tempos elevados em ambos os grupos. A elevação dos níveis séricos de PCR, VEGF e IL-8 a partir de 6 horas da injeção intrapleural de talco, picos em 24 e 48 horas e queda proporcional nos tempos subseqüentes sugere que a resposta sistêmica é precoce, entretanto, não sustentada.

Os níveis de IL-8 elevaram-se precocemente no lavado broncoalveolar (24 horas) quando comparados aos níveis séricos (48 horas). Resultados semelhantes foram observados por Genofre e cols (71), que avaliaram o comportamento sérico e do líquido pleural de animais com 
injeção intrapleural de talco. Ambos os achados sugerem que a resposta pulmonar antecede a resposta inflamatória sistêmica.

$\mathrm{Na}$ avaliação dos parâmetros inflamatórios séricos e pulmonares (lavado broncoalveolar e histologia pulmonar), observamos uma resposta inflamatória aguda sistêmica e pulmonar mais pronunciada após a utilização do talco de partículas pequenas (TP), quando comparado ao talco de partículas de tamanhos diversos (TM). Os níveis séricos de PCR e os níveis séricos e no LBA de IL-8 foram mais elevados no grupo TP que no grupo TM. Estes achados de resposta inflamatória são semelhantes aos descritos em estudos anteriores (70). Maskell e cols compararam os efeitos da injeção intrapleural de tetraciclina e de talco de partículas pequenas (menores que $10 \mu \mathrm{m}$ ), através da avaliação do "clearence" pulmonar de DTPA (ácido pentético complexado com tecnécio 99m), dos níveis séricos de IL-8 e de proteína C reativa (PCR). Os autores observaram que o talco causou mais alterações pulmonares e sistêmicas que a tetraciclina. Em uma segunda parte deste mesmo estudo, o autor comparou os efeitos da injeção intrapleural de talco de partículas pequenas com a de talco calibrado (a maioria das partículas menores que $10 \mu \mathrm{m}$ foi retirada). Os resultados desse estudo, avaliados através da medida do gradiente de pressão de oxigênio alvéolo-arterial e da PCR, demonstraram uma maior inflamação sistêmica e pulmonar com piora da troca gasosa com a utilização do talco de partículas pequenas.

No presente estudo, os níveis de IL-8 no soro e no LBA foram os principais marcadores deste processo de inflamação sistêmica aguda. Observamos níveis mais elevados de IL-8 e VEGF no lavado 
broncoalveolar à direita quando comparado à esquerda, denotando uma resposta inflamatória aguda mais exacerbada à direita, para ambos os grupos de talco. Estes achados seriam esperados, uma vez que a instilação intrapleural do talco foi à direita e a hipótese é de que as citocinas produzidas no compartimento pleural à direita alcançaram o parênquima pulmonar por contigüidade, somando-se à produção a nível alveolar e sistêmico.

O comportamento destes marcadores inflamatórios foi semelhante em ambos os hemitórax quando comparados através dos resultados obtidos nos lavados broncoalveolares direito e esquerdo. Estes dados sugerem que o extravasamento de mediadores inflamatórios de pleura (primeiro sítio de agressão) possa estimular a produção pulmonar bilateralmente e depois, alcançar o sangue. Essa hipótese explicaria o caso relatado por Gil e cols onde uma paciente submetida à injeção intrapleural de talco com objetivo de pleurodese, evoluiu para insuficiência respiratória e óbito, não tendo sido encontradas partículas de talco em qualquer dos órgãos durante necrópsia (28).

Para que pudéssemos comparar os níveis de IL-8 e VEGF do sangue e do LBA, foi necessária a utilização do fator de correção da diluição do LBA. Após a correção, obtivemos níveis pulmonares mais elevados que os níveis séricos, sugerindo mais uma vez que o pulmão é o órgão principal da resposta inflamatória sistêmica aguda.

As correlações entre os níveis de IL-8 e VEGF em ambos os grupos do estudo e em ambos os hemitórax, refletem uma reação conjunta dos pulmões à agressão pleural à direita. Apesar dos níveis de IL-8 e VEGF 
serem maiores à direita, as correlações sugerem que após a injeção intrapleural os pulmões passam a responder como órgão único à agressão.

Os resultados séricos observados com relação à celularidade, IL-8 e de VEGF, são semelhantes aos observados em estudos prévios como maior resposta inflamatória sistêmica após a injeção intrapleural de talco de partículas pequenas $(61,62)$.

A presença de partículas de talco em tecidos intra e extratorácicos foi objeto de estudo de diversos autores. Ferrer e cols discutem que as partículas pequenas de talco poderiam passar com maior facilidade pelos estomas linfáticos pleurais (diâmetro de 6,2 $\mu \mathrm{m}$ em adultos humanos) alcançando, assim, os vasos linfáticos e depois a circulação sistêmica (45). Desta maneira, a insuficiência respiratória aguda seria causada por uma resposta inflamatória sistêmica e pulmonar após o contato com as partículas de talco. Em nosso estudo, observamos partículas de talco em ambos os pulmões, com os dois tipos de talco, sem diferença significativa entre os grupos. Esses achados sugerem que o provável mecanismo de migração das partículas de talco para os pulmões seja através da circulação sistêmica. Entretanto, cabe ressaltar a limitação do método utilizado para a quantificação das partículas. A quantificação de partículas no sistema digital de análise de imagens não permite a detecção de partículas de talco de diâmetro inferior a $2 \mu \mathrm{m}$. Como estas partículas são mais prevalentes no talco de partículas pequenas, esta quantidade poderia estar subestimada neste grupo, levando a uma conclusão errônea de que a dispersão de partículas é semelhante nos dois grupos.

O número de animais nos grupos de estudo, talvez possa ter 
contribuído para o não alcance metodológico de um padrão histológico que diferenciasse os grupos de estudo. $O$ infiltrado celular do tipo linfomononuclear foi o padrão histológico mais observado nos pulmões dos animais submetidos à injeção intrapleural de TP, refletindo um processo inflamatório mais proeminente e precoce neste grupo. Vargas e cols mostraram que a resposta inflamatória pulmonar precoce foi menor após a administração de talco do que após a administração de nitrato de prata. Entretanto, após um mês, o comportamento celular do parênquima pulmonar era semelhante com os dois agentes utilizados (56). É possível que a sensibilidade de detecção das alterações histológicas empregadas neste estudo não foi suficiente para refletir as alterações inflamatórias que foram observadas no soro e no lavado broncoalveolar.

Quando analisamos esses resultados à luz dos estudos de SDRA, podemos levantar algumas considerações. Segundo Meduri, a maioria dos pacientes com SDRA (independente da causa) apresenta níveis séricos mais elevados de IL-8, IL-1 $\beta$ e IL-6 nas primeiras 24 horas da instalação do quadro $(51,52)$. Os indivíduos que persistem com os níveis séricos elevados destas citocinas geralmente evoluem para óbito, enquanto que aqueles que apresentam redução dos níveis a partir de 48 horas, geralmente evoluem para resolução. A relação entre os níveis de citocinas no LBA e no sangue tende a permanecer elevada nos indivíduos com SDRA, sugerindo ser pulmonar a origem da resposta inflamatória na SDRA. Os tempos de elevação e queda destes marcadores são semelhantes aos achados em nosso estudo. Embora a relação entre os níveis de IL-8 LBA e no sangue tenha permanecido elevada nos tempos 
avaliados no experimento, nenhum animal apresentou sinais ou sintomas compatíveis com SDRA..

Os níveis mais elevados de IL-8 no sangue e no LBA dos animais do grupo TP quando comparados aos do grupo TM nos permitem inferir que o tamanho das partículas de talco influi na resposta inflamatória pulmonar e sistêmica. Os mecanismos pelos quais essa resposta ocorre ainda não estão totalmente esclarecidos e carecem de mais estudos dos mecanismos fisiopatológicos envolvidos.

Por último, é interessante ressaltar que a despeito de uma composição química semelhante entre os dois tipos de talco, o talco de partículas pequenas apresentou uma maior percentagem de ferro em sua constituição $(5,823 \%$ versus $0,687 \%)$. Estudos experimentais utilizando fibras de asbesto, com ferro em sua composição (crocidolita), mostraram aumento na resposta inflamatória e maior dano celular quando comparadas às fibras que não apresentavam ferro em sua composição (crisotila) $(72,73)$. Entretanto, não existem trabalhos na literatura que relacionem uma possível correlação entre a composição química do talco e a resposta inflamatória local ou sistêmica desencadeada após a sua utilização para a indução de pleurodese. Também não há registro na literatura da avaliação da composição química do talco nos estudos que referem uma maior incidência de SDRA com sua utilização. Faz-se necessária uma avaliação deste achado, analisando a resposta inflamatória sistêmica e pulmonar ao talco com maior porcentagem de ferro na sua composição. Da mesma forma é importante avaliar a composição do talco utilizado nos países onde a incidência da SDRA é mais alta. 
Os achados deste estudo, em concordância com outros estudos prévios na literatura, nos permitem sugerir que o talco calibrado com partículas maiores deva ser utilizado na prática clínica, objetivando uma pleurodese mais segura e livre dos efeitos adversos mencionados, fatais em alguns casos. 


\section{CONCLUSÕES}

A maioria dos parâmetros avaliados apresentou níveis mais elevados no sangue e no lavado broncoalveolar dos animais injetados com talco pequeno ou misto quando comparados ao grupo controle, sugerindo uma resposta sistêmica e pulmonar à injeção intrapleural de talco.

Dentre os parâmetros que mostraram diferenças significativas entre os grupos de talco (TP e TM), destacamos o PCR e a IL-8. Ambos os marcadores apresentaram níveis séricos e no lavado broncoalveolar mais elevados no grupo injetado com talco pequeno quando comparado ao grupo injetado com talco misto.

Embora a presença de partículas de talco tenha sido observada na maioria das lâminas de pulmão analisadas, não detectamos diferenças significativas em sua quantidade com relação aos dois tipos de talco (TP e TM) e aos lados pulmonares (direito e esquerdo).

A análise histológica dos pulmões revelou uma tendência a um maior infiltrado celular linfomononuclear nos lados direito e esquerdo dos animais injetados com TP quando comparados aos do grupo TM. Embora outras alterações histológicas tenham ocorrido, elas não diferiram significantemente entre os grupos TP e TM. 


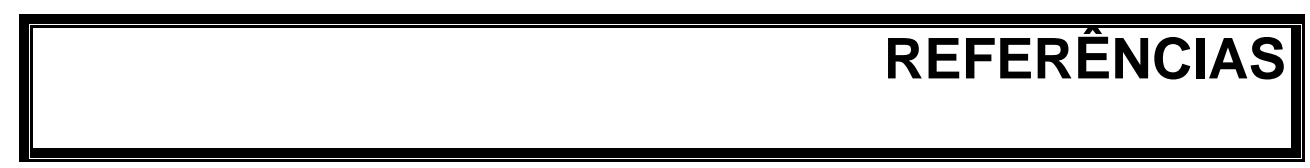




\section{REFERÊNCIAS BIBLIOGRÁFICAS}

1 - Light RW, Vargas FS. Pleural sclerosis for the treatment of pneumothorax and pleural effusion. Lung 1997; 175: 213-23.

2 - Rodriguez-Panadero F, Antony VB. Pleurodesis: state of art. Eur Respir J 1997;10:1648-54.

3 - Light RW. Pleural Diseases, 4th ed Baltimore, MD: Lippincott, Williams \& Wilkins 2001.

4 - Lee YCG, Baumann MH, Maskell NA et al. Pleurodesis practice for malignant pleural effusions in five English-speaking countries. Survey of pulmonologists. Chest 2003; 124: 2229-38.

5 - Kennedy L, Sahn SA. Talc pleurodesis for the treatment of pneumothorax and pleural effusion. Chest 1994; 106: 1215-22.

6 - Kennedy L, Strange C, Ginsberg RJ et al. Pleurodesis using talc slurry. Chest 1994; 106: 342-6.

7 - Zimmer PW, Hill M, Casey $\mathrm{K}$ et al. Prospective randomized trial of talc slurry vs bleomycin in pleurodesis for syntomatic malignant pleural effusions. Chest 1997; 112: 430-4.

8 - Vargas FS, Wang NS, Teixeira LR et al. Corynebacterium parvum versus tetracycline as pleural sclerosing agents in rabbits. Eur Respir $\mathrm{J}$ 1995; 8:2174-7.

9 - Paschoalini MS, Vargas FS, Marchi E et al. Prospective randomized trial of silver nitrate vs talc slurry in pleurodesis for symptomatic malignant pleural effusions. Chest 2005; 128:684-9.

10 - Ong KC, Indumathi V, Raghuram $\mathrm{J}$ et al. A comparative study of 
pleurodesis using talc slurry and bleomycin in the management of malignant pleural effusions. Respirology 2000; 5: 99-103.

11 - Noppen M, Degreve J, Mignolet M et al. A prospective, randomized study comparing the efficacy of talc slurry and bleomycin in the treatment of malignant pleural effusions. Acta Clin Belg 1997; 52-5:258-62.

12 - Diacon AH, Wyser C, Bolliger CT et al. Prospective randomized comparison of thoracoscopic talc poudrage under local anesthesia versus bleomycin instillation for pleurodesis in malignant pleural effusions. Am J Respir Crit Care Med 2000; 162: 1445-9.

13 - Foresti V, Villa A. Corynebacterium parvum pleurodesis. Chest 1995; 107: $291-2$

14 - Walker-Renard PB, Vaughan LM, Sahn SA. Chemical pleurodesis for malignant pleural effusions. Ann Intern Med 1994; 120: 56-64.

15 - Vargas FS, Carmo AO, Teixeira LR et al. A New look at old agents for pleurodesis: nitrogen mustard, sodium hydroxide, and silver nitrate. Current Opinion in Pulmonary Medicine 2000; 6: 281-286.

16 - Montes, JF, Ferrer J, Villarino MA et al. Influence of talc dose on extrapleural talc dissemination after talc pleurodesis. Am J Respir Crit Care Med 2003; 168:348-55.

17 - Antony VB, Loddenkemper R, Astoul P et al. Management of malignant pleural effusions. Am J Respir Crit Care Med 2000; 162: 1987-2001.

18 - Campos JRM, Vargas FS, Werebe EC, et al. Thoracoscopy talc poudrage. A 15-year experience. Chest 2001; 119: 801-6.

19 - Shaw P, Agarwal R. Pleurodesis for malignant pleural effusions. Cochrane Library, Issue 1, 2006. Oxford: Update Software. 
20 - Rinaldo JE, Owens GR, Rogers RM. Adult respiratory distress syndrome following intrapleural instillation of talc. J Thorac Cardiovasc Surg 1983; 85: 523-6.

21 - Bouchama A, Chastre J, Gaudichet A et al. Acute pneumonitis with bilateral peural effusion after talc pleurodesis. Chest 1984; 86:795-97.

22 - Rehse DH, Aye RW, Florence MG. Respiratory failure following talc pleurodesis. Am J Surg 1999; 177(5): 437-40.

23 - Weissberg D, Ben-Zeev I. Talc pleurodesis: experience with 360 patients. Thorac Cardiovasc Surg 1993; 106: 689-695.

24 - Dresler CM, Olak J, Herndon JE et al. Phase III Intergroup study of talc poudrage vs talc slurry sclerosis for malignant pleural effusion. Chest 2005; 127:909-15.

25 - Viallat JR, Rey F, Astoul P et al. Thoracoscopic talc poudrage pleurodesis for malignant effusions: a review of 360 cases. Chest 1996; 110:1387-93.

26 - Campos JRM, Werebe EC, Vargas FS et al. Respiratory failure due to insufflated talc. Lancet 1997; 349: 251-2.

27 - Brant A, Eaton T. Serious complications with talc slurry pleurodesis. Respirology 2001; 6:181-5.

28 - Gill AJ, Mathur MN, Tattersall SF. Systematic response to talc pleurodesis. Coment. Am J Respir Crit Care Med 2004; 169: 1074-5.

29 - Aelony Y. Systematic response to talc pleurodesis. Coment. Am J Respir Crit Care Med 2004; 169:1074-75.

30 - Light RW.Talc for pleurodesis? Chest 2002; 122: 1506-8.

31 - Aelony $\mathrm{Y}$, King, RR, Boutin C. Thoracoscopic talc poudrage in 
malignant pleural effusions. Effective pleurodesis despite low pleural $\mathrm{pH}$. Chest 1998; 113: 1007-12.

32 - Aelony Y, Yao JF. Prolonged survival after talc poudrage for malignant pleural mesothelioma: Case series. Respirology 2005; 10: 649 - 55.

33 - Almind M, Lange $\mathrm{P}$, Viskum K. Spontaneous pneumothorax: comparison of simple drainage, talc pleurodesis, and tetracycline pleurodesis. Thorax 1989; 44: 627-30.

34 - Webb WR, Ozmen V, Moulder PV et al. lodized talc pleurodesis for the treatment of pleural effusions. J Thorac Cardiovasc Surg 1992; 103: 881-6. 35 - Yim APC, Chung SS, Lee TW et al. Thoracoscopic management of malignant pleural effusions. Chest 1996; 109: 1234-8.

36 - Danby CA, Adebonojo SA, Moritz DM. Video-assisted talc pleurodesis for malignant pleural effusions utilizing local anestesia and sedation. Chest $1998 ; 113: 739-42$.

37 - Marom EM, Patz EF, Erasmus JJ et al. Malignant pleural effusion: treatment with small-bore-catheter thoracostomy and talc pleurodesis. Radiology 1999; 210: 277-81.

38 - Cardillo G, Facciolo F, CarboneL et al. Long-term follow-up of videoassisted talc pleurodesis in malignant recurrent pleural effusions. Eur $\mathrm{J}$ Cardiothorac Surg 2002; 21:302-6.

39 - Cardillo G, Carleo F, Giunti R et al. Videothoracoscopic talc poudrage in primary spontaneous pneumothorax: A single-institution experience in 861 cases. J Thorac Cardiovasc Surg 2006; 131: 322-8.

40 - Kolschmann S, Ballin A, Gillisen A. Clinical efficacy and safety of thoracoscopic talc pleurodesis in malignant pleural effusions. Chest 2005; 
128: $1431-5$.

41 - Gasparri R, Leo F, Veronesi G et al. Video-assisted management of malignant pleural effusion in breast carcinoma. Cancer 2006; 106:271-6.

42 - Bernard GR, Artigas A, Brigham KL et al. The American-European consensus conference on ARDS. Definitions, mechanisms, relevant outcomes, and clinical trial coordination. Am J Respir Crit Care Med 1994; 149:818-24.

43 - Ferrer J. Systematic response to talc pleurodesis. Coment. Am J Respir Crit Care Med 2004; 169: 1074-5.

44- Ferrer J, Montes JF, Villarino MA et al. Influence of particle size on extrapleural talc dissemination after talc slurry pleurodesis. Chest 2002; 122: $1018-27$.

45 - Ferrer J, Villarino MA, Tura JM et al. Talc preparations used for pleurodesis vary markedly from one preparation to another. Chest 2001; 119: $1901-1905$.

46 - Werebe EC, Pazetti, Campos JRM et al. Systemic distribuition of talc after intrapleural administration in rats. Chest 1999; 115: 190-193.

47 - Fraticelli A, Robaglia-Schlupp A, Riera $\mathrm{H}$ et al. Distribution of calibrated talc after intrapleural administration. An experimental study in rats. Chest 2002; 122:1737-41.

48 - Takada K, Otsuky Y, Magari S. Lymphatics and pre-lymphatics of the rabbit pericardium and epicardium with special emphasis on particulate absortion and milk spot-like structures. Lymphology 1991; 24: 116-124.

49 - Miserocchi G. Physiology and pathophysiology of pleural fluid turnover. Eur. Respir J. 1997; 10: 219:25. 
50 - Wang QX, Ohtani O, Saitoh M et al. Distribution and ultrastructure of the stomata connecting the pleural cavity with lymphatics in the rat costal pleura. Acta Anat 1997; 158: 255-65.

51 - Meduri GU, Headley S, Kohler G et al. Persistent elevation of inflammatory cytokines preditcts a poor outcome in ARDS. Plasma IL-1 and IL-6 levels are consistent and efficient predictors of outcome over time. Chest 1995; 107:1062-73.

52 - Meduri GU. Kohler G, Headley S et al. Inflammatory cytokines in the BAL of patients with ARDS. Persistent elevation over time predicts poor outcome. Chest 1995; 108:1303-14.

53- Ranieri VM, Suter PM, Tortorella $C$ et al. Effect of mechanical ventilation on inflammatory mediators in patients with acute respiratory distress syndrome: a randomized controlled trial. JAMA 1999; 282:54-61.

54 - Martin TR. Cytokines and lung injury: Searching for useful biomarkers. Crit Care Med 2005; 33: 230-2.

55 - Parsons PE, Eisner MD, Thompson BT et al. Lower tidal volume ventilation and plasma cytokine markers of inflammation in patients with acute lung injury. Crit Care Med 2005; 33:1-6.

56 - Vargas FS, Teixeira LR, Antonangelo $L$ et al. Experimental pleurodesis in rabbits induced by silver nitrate or talc. 1 Year follow-up. Chest 2001; 119:1516-20.

57 - Vargas FS, Teixeira L, Vaz MAC et al. Silver nitrate is superior to talc slurry in producing pleurodesis in rabbis. Chest 2000; 118: 808-13. 58 - Teixeira LR, Vargas FS, Antonangelo L et al. Low concentration silver nitrate pleurodesis in rabbits: optimal concentration for rapid and complete 
sclerosing effect. Lung 2003; 181: 353-9.

59 - Teixeira LR, Vargas FS, Acencio MMP et al. Influence of antiinflammatory drugs (methylprednisolone and diclofenac sodium) on experimental pleurodesis induced by silver nitrate or talc. Chest 2005; 128 : 4041-45.

60 - Genofre EH, Vargas FS, Antonangelo L et al. Ultrastructural acute features of active remodeling after chemical pleurodesis induced by silver nitrate or talc. lung 2005; 183: 197-207.

61 - Marchi E, Vargas FS, Acencio MMP et al. Talc and silver nitrate induce systemic inflammatory effects during the acute phase of experimental pleurodesis in rabbits. Chest 2004; 125: 2268-77.

62 - Marchi E, Vargas FS, Teixeira LR et al. Intrapleural low-dose silver nitrate elicits more pleural inflammation and less systemic inflammation than low dose talc. Chest 2005; 128: 1798-1804.

63 - Rennard SI, Basset G, Lecossier D et al. Estimation of volume of ephitelial lining fluid recovered by lavage using urea as marker of dilution. $J$ Appl Physiol 1986; 60: 532-538.

64 - Hening NR, Tonelli MR, Pier MV et al. Sputum induction as a research tool for sampling the airways of subjects with cystic fibrosis. Thorax 2001; 56: $306-311$

65 - Orphanidou D, Stratakos G, Rasidakis A et al. Adenosine deaminase activity and lysosyme levels in bronchoalveolar lavage fluid in patients with pulmonary tuberculosis. Int J Tuberc Lung Dis 1998; 2(1): 147-152. 66 - Kennedy L, Harley RA, Sahn SA et al. Talc slurry pleurodesis. Pleural fluid and histologic analysis. Chest 1995; 107: 1707-12. 
67 - Froudarakis ME, Klimathianaki M, Pougounias M. Systemic inflammatory reaction after thoracoscopic talc poudrage. Chest 2006;129:356 -361.

68 - van den Heuvel MM, Smit HJM. Barbierato SB et al. Talc-induced inflammation in the pleural cavity. Eur Respir J 1998; 12: 1419-1423.

69 - Nasreen N, Hartman DL, Mohammed KA et al. Tal-induced expression of $\mathrm{C}-\mathrm{C}$ and $\mathrm{C}-\mathrm{X}-\mathrm{C}$ chemokines and intercellular adhesion molecule- 1 in mesothelial cells. Am J Respir Crit Care Med 1998;158: 971-978.

70 - Maskell NA, Lee YG, Gleeson FV et al. Randomized trials describing lung inflammation after pleurodesis with talc of varying particle size. Am $\mathrm{J}$ Respir Crit Care Med 2004; 170: 377-382.

71 - Genofre EH. Avaliação dos efeitos do talco de diferentes tamanhos de partículas na pleurodese experimental [tese]. São Paulo: Faculdade de Medicina da Universidade de São Paulo; 2005.

72 - Choe N, Tanaka S, Kagan E. Asbestos fibers and interleukin-1 upregulate the formation reactive nitrogen species in rat pleural mesothelial cells. Am J Respir Cell Mol Biol 1998; 19:226-236.

73 - Liu W, Ernst JD, Broaddus VC. Phagocytosis of crocidolite asbestos induces oxidative stress, DNA damage, and apoptosis in mesothelial cells. Am J Respir Cell Mol Biol 2000; 23 (3): 371-8. 


\begin{abstract}
ANEXO A
As dosagens de desidrogenase lática $(\mathrm{DHL})$ e de uréia foram realizadas em aparelho bioquímico semi-automatizado Quick Lab (Drake, São Paulo, Brasil), utilizando reagentes da marca Winner Lab (Rosário, Argentina).

A técnica utilizada, para ambos os parâmetros bioquímicos, foi a cinética colorimétrica, com leitura em filtro de $340 \mathrm{~nm}$. A temperatura de análise de $\mathrm{DHL}$ e da uréia foi de $37^{\circ} \mathrm{C}$, com tempo inicial de leitura em 30 segundos. Para o DHL foram realizados 3 intervalos de leitura e para a uréia, 2 intervalos de 60 segundos cada.

O resultado final foi calculado a partir das diferenças de leitura nos intervalos e ajustados através do fator fornecido pelo fabricante.
\end{abstract}




\begin{abstract}
ANEXO B
Para dosagem de IL-8 e VEGF foi utilizado o método ELISA (enzymelinked immunosorbent assay) de captura (R\&D System, Inc., Minneapolis, USA).

Placas com 96 poços (Costar/Corning, Inc., Cambridge, USA) foram sensibilizadas com $100 \mu \mathrm{L}$ de anticorpo monoclonal e incubadas por 18 horas a $4^{\circ} \mathrm{C}$.

Posteriormente a placa foi bloqueada (para evitar ligações inespecíficas) com 300 $\mu \mathrm{L}$ de solução de bloqueio (BSA 2\%) e incubada por 2 horas a $37^{\circ} \mathrm{C}$.

Após o bloqueio, foi adicionado $100 \mu \mathrm{L}$ por poço das amostras e dos padrões diluídos previamente em PBS. Em dois poços foi colocado somente PBS para a caracterização do branco. A placa foi incubada por 18 horas a $4^{\circ} \mathrm{C}$
\end{abstract}

Após incubação, foram adicionados $100 \mu \mathrm{L}$ do anticorpo conjugado (biotinilado) na concentração estabelecida e as placas foram incubadas por 3 horas a $37^{\circ} \mathrm{C}$. Posteriormente, foram adicionados $100 \mu \mathrm{L}$ de Streptavidina HRP (1:250) por poço e incubado por 30 minutos a $37^{\circ} \mathrm{C}$.

A cada etapa a placa foi lavada com tampão de lavagem (PBS + Tween 20) por 6 vezes.

A revelação foi realizada através da adição de $100 \mu \mathrm{L}$ da Solução de Revelação $\left(\mathrm{H}_{2} \mathrm{O}_{2}+\right.$ Tetrametilbenzidina) por poço e incubado de 5 a 60 
minutos a $37^{\circ} \mathrm{C}$ de acordo com cada citocina. A reação foi blo queada acrescentando-se $50 \mu \mathrm{L}$ de $\mathrm{H}_{2} \mathrm{SO}_{4} 30 \%$ por poço, sob agitação lenta.

A leitura foi feita em leitor de ELISA (Power Wave, Bio-tek, USA) utilizando filtro de $450 \mathrm{~nm}$.

Tabela A - Concentrações dos anticorpos utilizados no método ELISA

\begin{tabular}{cccc}
\hline \hline Citocinas & $\begin{array}{c}\text { Anticorpo de } \\
\text { Captura } \\
(\text { Sensibilização) } \\
(\mu \mathrm{g} / \mathrm{mL})\end{array}$ & $\begin{array}{c}\text { Padrões } \\
(\mathrm{pg} / \mathrm{mL})\end{array}$ & $\begin{array}{c}\text { Anticorpo de } \\
\text { Detecção } \\
(\mathrm{ng} / \mathrm{mL})\end{array}$ \\
\hline \hline IL-8 & 4 & $6,25-400$ & 20 \\
VEGF & 0,8 & $15.6-2000$ & 25 \\
\hline \hline
\end{tabular}

IL-8 - Interleucina - 8, VEGF - Fator de crescimento endotelial tumoral 


\section{ANEXO C}

Tabela B - Níveis de IL-8 (pg/mL), VEGF (pg/mL), DHL (U/L) e PCR (mg/L) no sangue e no lavado broncoalveolar de animais do grupo controle e do grupo Sham.

\begin{tabular}{|c|c|c|c|}
\hline \multicolumn{4}{|c|}{ Lavado Broncoalveolar à Direita } \\
\hline & Controle & Controle Sham & $p$ \\
\hline IL-8 & $309,3(241,0-390,7)$ & $4223,2(279,9-461,6)$ & 0,547 \\
\hline VEGF & $560,0(439,7-639,1)$ & $576,0(410,2-649,8)$ & 0,960 \\
\hline $\mathrm{DHL}$ & $1904,7(1368,0-2210,3)$ & $2345,1(1717,6-2378,2)$ & 0,557 \\
\hline \multicolumn{4}{|c|}{ Lavado Broncoalveolar à Esquerda } \\
\hline & Controle & Controle Sham & $p$ \\
\hline IL-8 & $311,8(251,8-315,9)$ & $380,8(158,0-459,4)$ & 0,821 \\
\hline VEGF & $523,7(232,8-698,0)$ & $418,8(418,8-500,1)$ & 0,931 \\
\hline $\mathrm{DHL}$ & $886,7(847,6-1209,5)$ & $704,2(674,8-899,8)$ & 0,261 \\
\hline \multicolumn{4}{|c|}{ Sangue } \\
\hline & Controle & Controle Sham & $p$ \\
\hline IL-8 & $43,6(33,2-78,2)$ & $71,2(65,1-88,1)$ & 0,346 \\
\hline VEGF & $31,3(31,3-33,3)$ & $31,3(31,3-31,3)$ & 0,374 \\
\hline $\mathrm{DHL}$ & $160,0(83,5-375,3)$ & $264,0(206,3-278,3)$ & 0,857 \\
\hline PCR & $12,0(12,0-12,0)$ & $12,0(12,0-21,0)$ & 0,374 \\
\hline
\end{tabular}

IL-8 Interleucina- 8, VEGF - Fator de crescimento endotelial vascular, DHL - Desidrogenase lática, PCR Proteína $\mathrm{C}$ reativa

Tabela C: Total de leucócitos $/ \mathrm{mm}^{3}$ no sangue de coelhos submetidos à injeção intrapleural de TP e TM. Comparação com grupo controle

\begin{tabular}{lcc}
\hline \hline Controle & $8330,0(7775,0-9057,5)$ & \\
\hline \hline & $\mathrm{TP}$ & $\mathrm{P}$ \\
\hline \hline 6 horas & $9185,0(8750,0-9850,0)$ & 0,208 \\
48 horas & $6700,0(5825,0-9157,5)$ & 0,507 \\
72 horas & $7830,0(6837,5-11145,0)$ & 0,808 \\
96 horas & $6750,0(3350,0-8922,5)$ & 0,443 \\
\hline \hline & $10000,0(8860,0-10270,0)$ & 0,169 \\
\hline \hline 6 horas & $\mathrm{TM}$ & 0,765 \\
24 horas & $6680,0(5912,5-13997,5)$ & 1,000 \\
48 horas & $8570,0(6515,0-10585,0)$ & 0,559 \\
72 horas & $9400,0(7530,0-12845,0)$ & 0,110 \\
96 horas & $11080,0(9425,0-12510,0)$ & 0,244 \\
\hline \hline
\end{tabular}

TP - Talco de partículas pequenas, TM - Talco de partículas de tamanhos diversos. 
Tabela D - Total de leucócitos $/ \mathrm{mm}^{3}$ no LBA de coelhos submetidos à injeção intrapleural de TP ou TM. Comparação com o grupo controle.

\begin{tabular}{|c|c|c|}
\hline \multicolumn{3}{|c|}{ Lavado Broncoalveolar à Direita } \\
\hline Controle & $2,4(0,9-2,7)$ & \\
\hline & TP & $\mathrm{p}$ \\
\hline $\begin{array}{l}6 \text { horas } \\
24 \text { horas } \\
48 \text { horas } \\
72 \text { horas } \\
96 \text { horas }\end{array}$ & $\begin{array}{c}10,4(6,8-18,1) \\
4,8(2,2-15,4) \\
1,0(0,8-38,6) \\
14,0(8,0-42,3) \\
3,0(1,8-21,0)\end{array}$ & $\begin{array}{l}0,103 \\
0,183 \\
1,000 \\
0,192 \\
0,375\end{array}$ \\
\hline & $\overline{\mathrm{TTM}}$ & $\overline{\mathrm{p}}$ \\
\hline $\begin{array}{l}6 \text { horas } \\
24 \text { horas } \\
48 \text { horas } \\
72 \text { horas } \\
96 \text { horas }\end{array}$ & $\begin{array}{c}4,0(2,1-5,3) \\
0,3(0,2-1,0) \\
4,4(3,3-45,0) \\
0,4(0,4-6,8) \\
0,2(0,2-2,6)\end{array}$ & $\begin{array}{l}0,204 \\
0,147 \\
0,248 \\
0,393 \\
0,989 \\
\end{array}$ \\
\hline \multicolumn{3}{|c|}{ Lavado Broncoalveolar à Esquerda } \\
\hline Controle & $1,2(0,9-2,0)$ & \\
\hline & $\overline{\mathrm{TP}}$ & $p$ \\
\hline $\begin{array}{l}6 \text { horas } \\
24 \text { horas } \\
48 \text { horas } \\
72 \text { horas } \\
96 \text { horas } \\
\end{array}$ & $\begin{array}{c}5,2(4,1-7,8) \\
5,6(2,1-7,7) \\
1,4(0,5-7,2) \\
4,8(2,4-5,3) \\
5,9(2,0-22,5) \\
\end{array}$ & $\begin{array}{l}0,035 \\
0,137 \\
0,503 \\
0,075 \\
0,196 \\
\end{array}$ \\
\hline & TM & $p$ \\
\hline $\begin{array}{l}6 \text { horas } \\
24 \text { horas } \\
48 \text { horas } \\
72 \text { horas } \\
96 \text { horas }\end{array}$ & $\begin{array}{l}3,0(1,1-9,8) \\
1,7(0,2-6,4) \\
2,1(1,6-2,9) \\
0,3(0,2-2,1) \\
0,2(0,2-0,6)\end{array}$ & $\begin{array}{l}0,393 \\
0,512 \\
0,414 \\
0,904 \\
0,052\end{array}$ \\
\hline
\end{tabular}

TP - Talco de partículas pequenas, TM - Talco de partículas de tamanhos diversos, LBA - lavado broncoalveolar. 
Tabela E: Total de leucócitos $/ \mathrm{mm}^{3}$ no sangue de coelhos submetidos à injeção intrapleural de TP e TM. Comparação entre os grupos TP e TM.

\begin{tabular}{lccc}
\hline \hline & TP & TM & $\mathrm{p}$ \\
\hline \hline 6 horas & $9185,0(8750,0-9850,0)$ & $6680,0(5912,5-13997,5)$ & 0,992 \\
24 horas & $6700,0(5825,0-9157,5)$ & $8570,0(6515,0-10585,0)$ & 0,464 \\
48 horas & $7830,0(6837,5-11145,0)$ & $9400,0(7530,0-12845,0)$ & 0,564 \\
72 horas & $6750,0(3350,0-8922,5)$ & $11080,0(9425,0-12510,0)$ & 0,055 \\
96 horas & $10000,0(8860,0-10270,0)$ & $10700,0(9172,5-12807,5)$ & 0,411 \\
\hline \hline
\end{tabular}

TP - Talco de partículas pequenas, TM - Talco de partículas de tamanhos diversos.

Tabela F: Total de neutrófilos $/ \mathrm{mm}^{3}$ de coelhos submetidos à injeção intrapleural de TP e TM. Comparação com grupo controle.

\begin{tabular}{|c|c|c|}
\hline Controle & $3441,0(2922,0-4161,8)$ & \\
\hline & $\overline{\mathrm{TP}}$ & $p$ \\
\hline $\begin{array}{l}6 \text { horas } \\
24 \text { horas } \\
48 \text { horas } \\
72 \text { horas } \\
96 \text { horas }\end{array}$ & $\begin{array}{l}5509,5(3387,0-6135,0) \\
2900,0(2614,0-4314,3) \\
4161,0(2165,8-4883,3) \\
2295,0(1719,3-3401,5) \\
4387,5(1960,0-4692,0)\end{array}$ & $\begin{array}{l}0,400 \\
0,781 \\
0,799 \\
0,163 \\
0,854\end{array}$ \\
\hline & TM & $p$ \\
\hline $\begin{array}{l}6 \text { horas } \\
24 \text { horas } \\
48 \text { horas } \\
72 \text { horas } \\
96 \text { horas }\end{array}$ & $\begin{array}{l}4008,0(2972,8-5513,5) \\
2994,0(2326,0-3516,5) \\
2025,0(1646,8-3407,5) \\
3878,0(3822,0-4693,8) \\
3756,0(1382,0-5276,8)\end{array}$ & $\begin{array}{l}0,454 \\
0,340 \\
0,264 \\
0,339 \\
0,966\end{array}$ \\
\hline
\end{tabular}

TP - Talco de partículas pequenas, TM - Talco de partículas de tamanhos diversos. 
Tabela G: Total de neutrófilos $/ \mathrm{mm}^{3}$ no sangue de coelhos submetidos à injeção intrapleural de TP e TM. Comparação entre os grupos TP e TM.

\begin{tabular}{lccc}
\hline \hline & TP & TM & p \\
\hline \hline 6 horas & $5509,5(3387,0-6135,0)$ & $4008,0(2972,8-5513,5)$ & 0,682 \\
24 horas & $2900,0(2614,0-4314,3)$ & $2994,0(2326,0-3516,5)$ & 0,486 \\
48 horas & $4161,0(2165,8-4883,3)$ & $2025,0(1646,8-3407,5)$ & 0,226 \\
72 horas & $2295,0(1719,3-3401,5)$ & $3878,0(3822,0-4693,8)$ & 0,029 \\
96 horas & $4387,5(1960,0-4692,0)$ & $3756,0(1382,0-5276,8)$ & 0,829 \\
\hline \hline
\end{tabular}

TP - Talco de partículas pequenas, TM - Talco de partículas de tamanhos diversos.

Tabela H: Valor médio da uréia $(\mathrm{mg} / \mathrm{mL})$ no LBA à direita, LBA à esquerda e no sangue e cálculo do fator de diluição (fator de diluição = uréia sangue / uréia LBA).

\begin{tabular}{lllc}
\hline \hline & LBAD & LBAE & Sangue \\
\hline \hline VM da uréia & 5,15 & 4,34 & 56,56 \\
Fator de diluição & 11,01 & 12,04 & \\
\hline \hline
\end{tabular}

LBA - lavado broncoalveolar 
Tabela I: Níveis de DHL (U/L) no sangue de coelhos submetidos à injeção intrapleural de TP ou TM. Comparação com grupo controle

\begin{tabular}{lcc}
\hline \hline Controle & $160,0(83,5-375,3)$ & \\
\hline \hline & $\mathrm{TP}$ & $\mathrm{p}$ \\
\hline 6 horas & $419,0(346,3-722,3)$ & 0,171 \\
48 horas & $511,0(308,8-1228,8)$ & 0,179 \\
72 horas & $264,0(166,5-383,0)$ & 0,709 \\
96 horas & $171,0(169,5-310,8)$ & 0,889 \\
\hline \hline & $163,0(141,0-227,0)$ & 0,655 \\
\hline \hline 6 horas & $\mathrm{TM}$ & 0,072 \\
24 horas & $545,0(413,8-658,8)$ & 0,269 \\
48 horas & $387,0(225,8-742,0)$ & 0,556 \\
72 horas & $119,0(93,00-182,5)$ & 0,606 \\
96 horas & $140,0(99,5-200,0)$ & 0,638 \\
\hline \hline
\end{tabular}

TP - Talco de partículas pequenas, TM - Talco de partículas de tamanhos diversos, DHL - Desidrogenase lática.

Tabela J: Níveis de DHL (U/L) no sangue de coelhos submetidos à injeção intrapleural de TP ou TM. Comparação entre os grupos TP e TM.

\begin{tabular}{lccc}
\hline \hline & TP & TM & $\mathrm{p}$ \\
\hline \hline 6 horas & $419,0(346,3-722,3)$ & $545,0(413,8-658,8)$ & 0,813 \\
24 horas & $511,0(308,8-1228,8)$ & $387,0(225,8-742,0)$ & 0,382 \\
48 horas & $264,0(166,5-383,0)$ & $119,0(93,00-182,5)$ & 0,183 \\
72 horas & $171,0(169,5-310,8)$ & $140,0(99,5-200,0)$ & 0,301 \\
96 horas & $163,0(141,0-227,0)$ & $140,0(126,0-242,5)$ & 0,893 \\
\hline \hline
\end{tabular}

TP - Talco de partículas pequenas, TM - Talco de partículas de tamanhos diversos, DHL - Desidrogenase lática 
Tabela L: Níveis de DHL (U/L) no LBA de coelhos submetidos à injeção intrapleural de TP ou TM. Comparação com grupo controle.

\begin{tabular}{lcc}
\hline \hline & Lavado Broncoalveolar à Direita & \\
\hline \hline Controle & $1904,7(1368,0-2210,3)$ & $\mathrm{p}$ \\
\hline \hline 6 horas & $\mathrm{TP}$ & 0,707 \\
24 horas & $1948,8(712,9-3735,1)$ & 0,399 \\
48 horas & $2400,2(1032,2-5221,5)$ & 0,571 \\
72 horas & $7585,9(1475,3-13911,1)$ & 0,206 \\
96 horas & $2884,6(1896,5-4448,0)$ & 0,905 \\
\hline \hline & $1607,5(836,8-2235,0)$ & $\mathrm{p}$ \\
\hline \hline 6 horas & $\mathrm{TM}$ & 0,442 \\
24 horas & $1871,7(924,8-5763,7)$ & 0,593 \\
48 horas & $1519,4(1136,8-1910,2)$ & 0,797 \\
72 horas & $2422,2(1070,7-2642,4)$ & 0,462 \\
96 horas & $1684,5(963,4-1874,9)$ & 0,328 \\
\hline \hline & $1684,5(963,4-1874,9)$ & $\mathrm{p}$ \\
\hline \hline Controle & Lavado Broncoalveolar à Esquerda & 0,506 \\
\hline \hline & $886,7(847,6-1209,5)$ & 0,514 \\
\hline \hline 6 horas & TP & 0,267 \\
24 horas & $1382,2(1346,4-1614,7)$ & 0,302 \\
48 horas & $743,3(645,5-1476,8)$ & 0,440 \\
\hline 2 horas & $1004,1(841,1-2180,9)$ & 0,584 \\
\hline 6 horas & $873,7(612,9-2976,4)$ & 0,410 \\
\hline \hline & $1682,2(1039,9-4961,7)$ & 0,824 \\
\hline \hline 6 horas & $1760,4(1007,3-3876,1)$ & $\mathrm{p}$ \\
\hline \hline
\end{tabular}

TP - Talco de partículas pequenas, TM - Talco de partículas de tamanhos diversos, DHL - Desidrogenase lática, LBA - lavado broncoalveolar 
Tabela M: Níveis de DHL (U/L) no LBA de coelhos submetidos à injeção intrapleural de TP ou TM. Comparação entre os grupos TP e TM.

\begin{tabular}{|c|c|c|c|}
\hline \multicolumn{4}{|c|}{ Lavado Broncoalveolar à Direita } \\
\hline & TP & TM & $p$ \\
\hline 6 horas & $1948,8(712,9-3735,1)$ & $1871,7(924,8-5763,7)$ & 0,543 \\
\hline 24 horas & $2400,2(1032,2-5221,5)$ & $1519,4(1136,8-1910,2)$ & 0,205 \\
\hline 48 horas & $7585,9(1475,3-13911,1)$ & $2422,2(1070,7-2642,4)$ & 0,310 \\
\hline 72 horas & $2884,6(1896,5-4448,0)$ & $1684,5(963,4-1874,9)$ & 0,051 \\
\hline 96 horas & $1607,5(836,8-2235,0)$ & $1684,5(963,4-1874,9)$ & 0,429 \\
\hline \multicolumn{4}{|c|}{ Lavado Broncoalveolar à Esquerda } \\
\hline & $\overline{T P}$ & $\overline{\mathrm{TTM}}$ & $p$ \\
\hline 6 horas & $\overline{1004,1(841,1-2180,9)}$ & $821,5(609,6-2653,6)$ & 0,548 \\
\hline 24 horas & $873,7(612,9-2976,4)$ & $991,0(632,4-2014,7)$ & 0,561 \\
\hline 48 horas & $1682,2(1039,9-4961,7)$ & $1147,5(841,1-1998,4)$ & 0,234 \\
\hline 72 horas & $1760,4(1007,3-3876,1)$ & $1382,2(1346,4-1614,7)$ & 0,301 \\
\hline 96 horas & $1232,3(1108,4-1304,0)$ & $743,3(645,5-1476,8)$ & 0,865 \\
\hline
\end{tabular}

TP - Talco de partículas pequenas, TM - Talco de partículas de tamanhos diversos, DHL - Desidrogenase lática, LBA - lavado broncoalveolar

Tabela N: Níveis de DHL (U/L) no LBA de coelhos submetidos á injeção intrapleural de TP ou TM. Comparação entre os lados direito e esquerdo.

\begin{tabular}{|c|c|c|c|}
\hline \multicolumn{4}{|c|}{ Talco Pequeno } \\
\hline & LBAD & LBAE & $p$ \\
\hline 6 horas & $\overline{1948,8(712,9-3735,1)}$ & $\overline{1004,1(841,1-2180,9)}$ & 0,411 \\
\hline 24 horas & $2400,2(1032,2-5221,5)$ & $873,7(612,9-2976,4)$ & 0,188 \\
\hline 48 horas & $7585,9(1475,3-13911,1)$ & $1682,2(1039,9-4961,7)$ & 0,158 \\
\hline 72 horas & $2884,6(1896,5-4448,0)$ & $1760,4(1007,3-3876,1)$ & 0,652 \\
\hline 96 horas & $1607,5(836,8-2235,0)$ & $1232,3(1108,4-1304,0)$ & 0,313 \\
\hline \multicolumn{4}{|c|}{ Talco Misto } \\
\hline & LBAD & LBAE & $p$ \\
\hline$\overline{6 \text { horas }}$ & 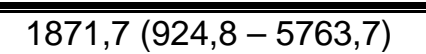 & $\overline{821,5(609,6-2653,6)}$ & 0,289 \\
\hline 24 horas & $1519,4(1136,8-1910,2)$ & $991,0(632,4-2014,7)$ & 0,613 \\
\hline 48 horas & $2422,2(1070,7-2642,4)$ & $1147,5(841,1-1998,4)$ & 0,188 \\
\hline 72 horas & $1684,5(963,4-1874,9)$ & $1382,2(1346,4-1614,7)$ & 0,628 \\
\hline 96 horas & $1684,5(963,4-1874,9)$ & $743,3(645,5-1476,8)$ & 0,169 \\
\hline
\end{tabular}

TP - Talco de partículas pequenas, TM - Talco de partículas de tamanhos diversos, DHL - Desidrogenase lática, LBA - Lavado broncoalveolar. 
Tabela O: Níveis de VEGF ( $\mathrm{pg} / \mathrm{mL})$ no sangue de coelhos submetidos à injeção intrapleural de TP e TM. Comparação entre os grupos TP e TM.

\begin{tabular}{lccc}
\hline \hline & TP & TM & $\mathrm{p}$ \\
\hline \hline 6 horas & $36,3(34,4-42,6)$ & $38,9(35,3-44,6)$ & 0,752 \\
24 horas & $63,7(47,6-79,0)$ & $54,3(52,3-57,5)$ & 0,261 \\
48 horas & $58,6(49,9-63,4)$ & $71,2(45,3-85,2)$ & 0,475 \\
72 horas & $58,3(55,5-71,0)$ & $53,2(44,6-57,6)$ & 0,217 \\
96 horas & $47,0(41,2-66,1)$ & $53,6(47,8-57,8)$ & 0,746 \\
\hline \hline
\end{tabular}

TP - Talco de partículas pequenas, TM - Talco de partículas de tamanhos diversos, VEGF - Fator de crescimento endotelial vascular, LBA - Lavado broncoalveolar

Tabela P: Níveis de VEGF (pg/mL) no LBA de coelhos submetidos à injeção intrapleural de TP ou TM. Comparação entre os grupos TP e TM.

\begin{tabular}{|c|c|c|c|}
\hline \multicolumn{4}{|c|}{ Lavado Broncoalveolar à Direita } \\
\hline & $\overline{\mathrm{TP}}$ & TM & $\bar{p}$ \\
\hline 6 horas & $1984,6(917,9-2143,9)$ & "1393,2 (1155,2 - 1574,0) & 0,534 \\
\hline 24 horas & $3627,0(3184,9-6601,8)$ & $2763,3(1914,5-4683,7)$ & 0,242 \\
\hline 48 horas & $4245,1(3798,1-6543,2)$ & $5256,1(4885,2-6745,1)$ & 0,936 \\
\hline 72 horas & $2218,1(1649,1-3228,8)$ & $2836,7(1922,2-3373,2)$ & 0,983 \\
\hline 96 horas & $1620,6(1001,1-3225,6)$ & $1852,0(1536,2-2143,3)$ & 0,883 \\
\hline \multicolumn{4}{|c|}{ Lavado Broncoalveolar à Esquerda } \\
\hline & $\overline{\mathrm{TP}}$ & $\overline{\mathrm{TM}}$ & $p$ \\
\hline 6 horas & $1277,4(727,0-1870,2)$ & $853,9(738,2-1282,2)$ & 0,364 \\
\hline 24 horas & $3047,3(1987,4-4786,8)$ & $1645,9(1252,4-2374,3)$ & 0,092 \\
\hline 48 horas & $3807,2(3333,2-5859,1)$ & $1645,9(1252,4-2374,3)$ & 0,442 \\
\hline 72 horas & $1464,9(1004,9-2156,9)$ & $3711,5(2715,8-4931,5)$ & 0,834 \\
\hline 96 horas & $1156,2(999,2-1413,4)$ & $1645,9(711,4-2450,9)$ & 0,277 \\
\hline
\end{tabular}

TP - Talco de partículas pequenas, TM - Talco de partículas de tamanhos diversos, VEGF - Fator de crescimento endotelial vascular, LBA - Lavado broncoalveolar 
Tabela Q: Número de partículas de talco nos pulmões direito e esquerdo de coelhos submetidos à injeção intrapleural de TP ou de TM. Comparação entre os grupos TP e TM (partículas $100 \mathrm{~cm}^{2}$ ).

\begin{tabular}{|c|c|c|c|}
\hline \multicolumn{4}{|c|}{ Pulmão Direito } \\
\hline & TP & $\overline{\mathrm{TTM}}$ & $\bar{p}$ \\
\hline $\begin{array}{l}6 \text { horas } \\
24 \text { horas } \\
48 \text { horas } \\
72 \text { horas } \\
96 \text { horas }\end{array}$ & $\begin{array}{c}454,3(281,6-621,6) \\
215,1(151,2-228,9) \\
255,3(74,2-333,4) \\
16,1(15,3-56,2) \\
79,3(31,3-273,9)\end{array}$ & $\begin{array}{c}285,1(154,5-350,2) \\
271,5(219,1-483,1) \\
382,7(150,1-522,3) \\
22,5(10,3-92,5) \\
137,2(50,9-149,1)\end{array}$ & $\begin{array}{l}0,175 \\
0,215 \\
0,339 \\
0,724 \\
0,726\end{array}$ \\
\hline \multicolumn{4}{|c|}{ Pulmão Esquerdo } \\
\hline & TP & TM & $p$ \\
\hline $\begin{array}{l}6 \text { horas } \\
24 \text { horas } \\
48 \text { horas } \\
72 \text { horas } \\
96 \text { horas }\end{array}$ & $\begin{array}{c}412,0(192,0-430,9) \\
295,4(193,7-410,4) \\
282,1(69,1-322,6) \\
9,7(4,9-41,6) \\
15,7(3,9-23,0)\end{array}$ & $\begin{array}{c}43,1(25,7-191,9) \\
31,1(20,0-325,9) \\
456,3(341,8-518,7) \\
18,9(9,9-140,8) \\
37,9(14,3-133,4)\end{array}$ & $\begin{array}{l}0,081 \\
0,528 \\
0,041 \\
0,463 \\
0,317\end{array}$ \\
\hline
\end{tabular}

TP - talco de partículas pequenas, TM - talco de partículas de tamanhos diversos.

Tabela R: Número de partículas de talco nos pulmões de coelhos submetidos à injeção intrapleural de TP e TM. Comparação entre os lados direito e esquerdo (partículas/ $100 \mathrm{~cm}^{2}$ ).

\begin{tabular}{|c|c|c|c|}
\hline \multicolumn{4}{|c|}{ Talco Pequeno } \\
\hline & Pulmão direito & Pulmão esquerdo & $p$ \\
\hline $\begin{array}{l}6 \text { horas } \\
24 \text { horas } \\
48 \text { horas } \\
72 \text { horas } \\
96 \text { horas }\end{array}$ & $\begin{array}{c}454,3(281,6-621,6) \\
215,1(151,2-228,9) \\
255,3(74,2-333,4) \\
16,1(15,3-56,2) \\
79,3(31,3-273,9)\end{array}$ & $\begin{array}{c}412,0(192,0-430,9) \\
295,4(193,7-410,4) \\
282,1(69,1-322,6) \\
9,7(4,9-41,6) \\
15,7(3,9-23,0)\end{array}$ & $\begin{array}{l}0,252 \\
0,281 \\
0,995 \\
0,710 \\
0,340\end{array}$ \\
\hline \multicolumn{4}{|c|}{ Talco Misto } \\
\hline & Pulmão direito & Pulmão esquerdo & $p$ \\
\hline $\begin{array}{l}6 \text { horas } \\
24 \text { horas } \\
48 \text { horas } \\
72 \text { horas } \\
96 \text { horas }\end{array}$ & $\begin{array}{c}285,1(154,5-350,2) \\
271,5(219,1-483,1) \\
382,7(150,1-522,3) \\
22,5(10,3-92,5) \\
137,2(50,9-149,1)\end{array}$ & $\begin{array}{c}43,1(25,7-191,9) \\
31,1(20,0-325,9) \\
456,3(341,8-518,7) \\
18,9(9,9-140,8) \\
37,9(14,3-133,4) \\
\end{array}$ & $\begin{array}{l}0,131 \\
0,040 \\
0,603 \\
0,825 \\
0,413\end{array}$ \\
\hline
\end{tabular}

TP - talco de partículas pequenas, TM - talco de partículas de tamanhos diversos. 
Tabela S: Avaliação de presença de hemorragia nos pulmões direito e esquerdo de coelhos submetidos à injeção intrapleural de TP ou de TM (escore de 0 a 3). Comparação com grupo controle.

\begin{tabular}{|c|c|c|}
\hline \multicolumn{3}{|c|}{ Pulmão Direito } \\
\hline Controle & $0,0(0,0-0,0)$ & \\
\hline & TP & $\bar{p}$ \\
\hline $\begin{array}{l}6 \text { horas } \\
24 \text { horas } \\
48 \text { horas } \\
72 \text { horas } \\
96 \text { horas }\end{array}$ & $\begin{array}{l}0,0(0,0-1,0) \\
0,0(0,0-1,0) \\
0,0(0,0-0,3) \\
0,0(0,0-0,5) \\
1,0(0,5-1,0)\end{array}$ & $\begin{array}{l}0,413 \\
0,413 \\
0,730 \\
0,686 \\
0,114\end{array}$ \\
\hline & TM & $p$ \\
\hline $\begin{array}{l}6 \text { horas } \\
24 \text { horas } \\
48 \text { horas } \\
72 \text { horas } \\
96 \text { horas }\end{array}$ & $\begin{array}{l}0,0(0,0-0,0) \\
0,0(0,0-0,0) \\
1,0(0,8-1,3) \\
0,0(0,0-0,0) \\
0,0(0,0-1,5)\end{array}$ & $\begin{array}{l}1,000 \\
1,000 \\
0,063 \\
1,000 \\
0,629\end{array}$ \\
\hline \multicolumn{3}{|c|}{ Pulmão Esquerdo } \\
\hline Controle & $0,0(0,0-0,0)$ & \\
\hline & TP & $p$ \\
\hline $\begin{array}{l}6 \text { horas } \\
24 \text { horas } \\
48 \text { horas } \\
72 \text { horas } \\
96 \text { horas }\end{array}$ & $\begin{array}{l}0,0(0,0-1,3) \\
0,0(0,0-1,0) \\
0,0(0,0-0,5) \\
0,0(0,0-0,5) \\
0,0(0,0-0,5)\end{array}$ & $\begin{array}{l}0,413 \\
0,413 \\
0,730 \\
0,686 \\
0,686\end{array}$ \\
\hline & $\overline{\mathrm{TM}}$ & $p$ \\
\hline $\begin{array}{l}6 \text { horas } \\
24 \text { horas } \\
48 \text { horas } \\
72 \text { horas } \\
96 \text { horas }\end{array}$ & $\begin{array}{l}0,0(0,0-0,0) \\
0,0(0,0-0,0) \\
0,0(0,0-0,3) \\
0,0(0,0-0,8) \\
0,0(0,0-0,0)\end{array}$ & $\begin{array}{l}1,000 \\
1,000 \\
0,730 \\
0,629 \\
1,000\end{array}$ \\
\hline
\end{tabular}

TP - talco de partículas pequenas, TM - talco de partículas de tamanhos diversos. 
Tabela T: Avaliação de presença de edema nos pulmões direito e esquerdo de coelhos submetidos à injeção intrapleural de TP ou de TM (escore de 0 a 3). Comparação com grupo controle.

\begin{tabular}{|c|c|c|}
\hline \multicolumn{3}{|c|}{ Pulmão Direito } \\
\hline Controle & $0,0(0,0-0,0)$ & \\
\hline & TP & $\bar{p}$ \\
\hline $\begin{array}{l}6 \text { horas } \\
24 \text { horas } \\
48 \text { horas } \\
72 \text { horas } \\
96 \text { horas } \\
\end{array}$ & $\begin{array}{l}0,0(0,0-0,0) \\
0,0(0,0-0,0) \\
0,0(0,0-0,3) \\
0,0(0,0-0,0) \\
0,0(0,0-0,0)\end{array}$ & $\begin{array}{l}1,000 \\
1,000 \\
0,730 \\
1,000 \\
1,000 \\
\end{array}$ \\
\hline & $\overline{\mathrm{TTM}}$ & $\bar{p}$ \\
\hline $\begin{array}{l}6 \text { horas } \\
24 \text { horas } \\
48 \text { horas } \\
72 \text { horas } \\
96 \text { horas }\end{array}$ & $\begin{array}{l}0,0(0,0-0,0) \\
0,0(0,0-0,0) \\
0,0(0,0-0,5) \\
0,0(0,0-0,0) \\
0,0(0,0-1,5)\end{array}$ & $\begin{array}{l}1,000 \\
1,000 \\
0,730 \\
1,000 \\
0,629\end{array}$ \\
\hline \multicolumn{3}{|c|}{ Pulmão Esquerdo } \\
\hline Controle & $0,0(0,0-0,0)$ & \\
\hline & TP & $p$ \\
\hline $\begin{array}{l}6 \text { horas } \\
24 \text { horas } \\
48 \text { horas } \\
72 \text { horas } \\
96 \text { horas }\end{array}$ & $\begin{array}{l}0,0(0,0-0,3) \\
0,0(0,0-0,0) \\
0,0(0,0-0,3) \\
0,0(0,0-0,0) \\
0,0(0,0-0,0)\end{array}$ & $\begin{array}{l}0,730 \\
1,000 \\
0,730 \\
1,000 \\
1,000\end{array}$ \\
\hline & $\overline{\mathrm{TTM}}$ & $p$ \\
\hline $\begin{array}{l}6 \text { horas } \\
24 \text { horas } \\
48 \text { horas } \\
72 \text { horas } \\
96 \text { horas }\end{array}$ & $\begin{array}{l}0,0(0,0-0,0) \\
0,0(0,0-0,0) \\
0,0(0,0-0,0) \\
0,0(0,0-0,0) \\
0,0(0,0-0,0)\end{array}$ & $\begin{array}{l}1,000 \\
1,000 \\
1,000 \\
1,000 \\
1,000\end{array}$ \\
\hline
\end{tabular}

TP - talco de partículas pequenas, TM - talco de partículas de tamanhos diversos. 
Tabela U: Avaliação de presença de trombos nos pulmões direito e esquerdo de coelhos submetidos à injeção intrapleural de TP ou de TM (escore de 0 a 3). Comparação com grupo controle.

\begin{tabular}{lcc}
\hline \hline & Pulmão Direito & \\
\hline \hline Controle & $0,0(0,0-0,0)$ & $\mathrm{p}$ \\
\hline \hline 6 horas & TP & 1,000 \\
24 horas & $0,0(0,0-0,0)$ & 1,000 \\
48 horas & $0,0(0,0-0,0)$ & 0,730 \\
72 horas & $0,0(0,0-0,3)$ & 0,686 \\
96 horas & $0,0(0,0-1,0)$ & 1,000 \\
\hline \hline & $0,0(0,0-0,0)$ & $\mathrm{p}$ \\
\hline \hline 6 horas & TM & 1,000 \\
24 horas & $0,0(0,0-0,0)$ & 1,000 \\
48 horas & $0,0(0,0-0,0)$ & 0,266 \\
72 horas & $0,0(0,0-1,5)$ & 1,000 \\
96 horas & $0,0(0,0-0,0)$ & 1,000 \\
\hline \hline & $0,0(0,0-0,0)$ & $\mathrm{p}$ \\
\hline \hline Controle & Pulmão Esquerdo & 1,000 \\
\hline \hline & $0,0(0,0-0,0)$ & 1,000 \\
\hline \hline 6 horas & 0,0000 \\
24 horas & $0,0(0,0-0,0)$ & 1,000 \\
48 horas & $0,0(0,0-0,0)$ & 1,000 \\
72 horas & $0,0(0,0-0,0)$ & 1,000 \\
96 horas & $0,0(0,0-0,0)$ & 1,000 \\
\hline \hline
\end{tabular}

TP - talco de partículas pequenas, TM - talco de partículas de tamanhos diversos. 
Tabela V: Avaliação da presença de capilarite nos pulmões direito e esquerdo de coelhos submetidos à injeção intrapleural de TP ou de TM (escore de 0 a 3). Comparação entre os grupos TP e TM.

\begin{tabular}{|c|c|c|c|}
\hline \multicolumn{4}{|c|}{ Pulmão Direito } \\
\hline & $\overline{T \text { TP }}$ & $\overline{\mathrm{TTM}}$ & $p$ \\
\hline 6 horas & $0,0(0,0-1,3)$ & $0,5(0,0-1,0)$ & 0,853 \\
\hline 24 horas & $0,0(0,0-1,3)$ & $0,0(0,0-0,0)$ & 0,413 \\
\hline 48 horas & $2,0(1,0-2,0)$ & $1,0(0,8-2,0)$ & 0,397 \\
\hline 72 horas & $1,0(0,5-2,0)$ & $0,0(0,0-0,0)$ & 0,114 \\
\hline 96 horas & $1,0(1,0-1,5)$ & $1,0(1,0-2,5)$ & 0,538 \\
\hline \multicolumn{4}{|c|}{ Pulmão Esquerdo } \\
\hline & TP & $\overline{\mathrm{TTM}}$ & $p$ \\
\hline 6 horas & $1,0(0,0-2,0)$ & $0,0(0,0-0,5)$ & 0,217 \\
\hline 24 horas & $0,0(0,0-1,3)$ & $0,0(0,0-0,0)$ & 0,413 \\
\hline 48 horas & $1,0(0,8-2,0)$ & $0,0(0,0-0,3)$ & 0,095 \\
\hline 72 horas & $1,0(0,5-1,5)$ & $0,0(0,0-0,8)$ & 0,296 \\
\hline 96 horas & $1,0(1,0-1,0)$ & $0,0(0,0-0,0)$ & 0,057 \\
\hline
\end{tabular}

TP - talco de partículas pequenas, TM - talco de partículas de tamanhos diversos.

Tabela X: Avaliação da presença de hemorragia nos pulmões direito e esquerdo de coelhos submetidos à injeção intrapleural de TP ou de TM (escore de 0 a 3). Comparação entre os grupos TP e TM.

\begin{tabular}{|c|c|c|c|}
\hline \multicolumn{4}{|c|}{ Pulmão Direito } \\
\hline & $\overline{\mathrm{TP}}$ & $\overline{\mathrm{TTM}}$ & $p$ \\
\hline 6 horas & $0,0(0,0-1,0)$ & $0,0(0,0-0,0)$ & 0,413 \\
\hline 24 horas & $0,0(0,0-1,0)$ & $0,0(0,0-0,0)$ & 0,413 \\
\hline 48 horas & $0,0(0,0-0,3)$ & $1,0(0,8-1,3)$ & 0,065 \\
\hline 72 horas & $0,0(0,0-0,5)$ & $0,0(0,0-0,0)$ & 0,629 \\
\hline 96 horas & $1,0(0,5-1,0)$ & $0,0(0,0-1,5)$ & 0,900 \\
\hline \multicolumn{4}{|c|}{ Pulmão Esquerdo } \\
\hline & TP & TM & $p$ \\
\hline 6 horas & $0,0(0,0-1,3)$ & $0,0(0,0-0,0)$ & 0,413 \\
\hline 24 horas & $0,0(0,0-1,0)$ & $0,0(0,0-0,0)$ & 0,413 \\
\hline 48 horas & $0,0(0,0-0,5)$ & $0,0(0,0-0,3)$ & 1,000 \\
\hline 72 horas & $0,0(0,0-0,5)$ & $0,0(0,0-0,8)$ & 0,857 \\
\hline 96 horas & $0,0(0,0-0,5)$ & $0,0(0,0-0,0)$ & 0,629 \\
\hline
\end{tabular}

TP - talco de partículas pequenas, TM - talco de partículas de tamanhos diversos. 
Tabela Z: Avaliação da presença de edema nos pulmões direito e esquerdo de coelhos submetidos à injeção intrapleural de TP ou de TM (escore de 0 a 3). Comparação entre os grupos TP e TM.

\begin{tabular}{|c|c|c|c|}
\hline \multicolumn{4}{|c|}{ Pulmão Direito } \\
\hline & TP & 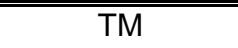 & $p$ \\
\hline $\begin{array}{l}6 \text { horas } \\
24 \text { horas } \\
48 \text { horas } \\
72 \text { horas } \\
96 \text { horas } \\
\end{array}$ & $\begin{array}{l}0,0(0,0-0,0) \\
0,0(0,0-0,0) \\
0,0(0,0-0,3) \\
0,0(0,0-0,0) \\
0,0(0,0-0,0)\end{array}$ & $\begin{array}{l}0,0(0,0-0,0) \\
0,0(0,0-0,0) \\
0,0(0,0-0,5) \\
0,0(0,0-0,0) \\
0,0(0,0-1,5)\end{array}$ & $\begin{array}{l}1,000 \\
1,000 \\
1,000 \\
1,000 \\
0,629 \\
\end{array}$ \\
\hline \multicolumn{4}{|c|}{ Pulmão Esquerdo } \\
\hline & $\overline{\mathrm{TP}}$ & TM & $p$ \\
\hline $\begin{array}{l}6 \text { horas } \\
24 \text { horas } \\
48 \text { horas } \\
72 \text { horas } \\
96 \text { horas }\end{array}$ & $\begin{array}{l}0,0(0,0-0,3) \\
0,0(0,0-0,0) \\
0,0(0,0-0,3) \\
0,0(0,0-0,0) \\
0,0(0,0-0,0)\end{array}$ & $\begin{array}{l}0,0(0,0-0,0) \\
0,0(0,0-0,0) \\
0,0(0,0-0,0) \\
0,0(0,0-0,0) \\
0,0(0,0-0,0)\end{array}$ & $\begin{array}{l}0,730 \\
1,000 \\
0,690 \\
1,000 \\
1,000\end{array}$ \\
\hline
\end{tabular}

TP - talco de partículas pequenas, TM - talco de partículas de tamanhos diversos.

Tabela AA: Avaliação da presença de trombos nos pulmões direito e esquerdo de coelhos submetidos à injeção intrapleural de TP ou de TM (escore de 0 a 3). Comparação entre os grupos TP e TM.

\begin{tabular}{|c|c|c|c|}
\hline \multicolumn{4}{|c|}{ Pulmão Direito } \\
\hline & $\overline{\overline{T P}}$ & $\overline{\overline{T M}}$ & $p$ \\
\hline $\begin{array}{l}6 \text { horas } \\
24 \text { horas } \\
48 \text { horas } \\
72 \text { horas } \\
96 \text { horas } \\
\end{array}$ & $\begin{array}{l}0,0(0,0-0,0) \\
0,0(0,0-0,0) \\
0,0(0,0-0,3) \\
0,0(0,0-1,0) \\
0,0(0,0-0,0)\end{array}$ & $\begin{array}{l}0,0(0,0-0,0) \\
0,0(0,0-0,0) \\
0,0(0,0-1,5) \\
0,0(0,0-0,0) \\
0,0(0,0-0,0)\end{array}$ & $\begin{array}{l}1,000 \\
1,000 \\
0,359 \\
0,629 \\
1,000 \\
\end{array}$ \\
\hline \multicolumn{4}{|c|}{ Pulmão Esquerdo } \\
\hline & TP & $\overline{\mathrm{TTM}}$ & $p$ \\
\hline $\begin{array}{l}6 \text { horas } \\
24 \text { horas } \\
48 \text { horas } \\
72 \text { horas } \\
96 \text { horas }\end{array}$ & $\begin{array}{l}0,0(0,0-0,0) \\
0,0(0,0-0,0) \\
0,0(0,0-0,0) \\
0,0(0,0-0,0) \\
0,0(0,0-0,0)\end{array}$ & $\begin{array}{l}0,0(0,0-0,0) \\
0,0(0,0-0,0) \\
0,0(0,0-0,3) \\
0,0(0,0-0,0) \\
0,0(0,0-0,0)\end{array}$ & $\begin{array}{l}1,000 \\
1,000 \\
0,690 \\
1,000 \\
1,000\end{array}$ \\
\hline
\end{tabular}

TP - talco de partículas pequenas, TM - talco de partículas de tamanhos diversos. 
Tabela BB: Avaliação de macrófagos nos pulmões direito e esquerdo de coelhos submetidos à injeção intrapleural de TP ou de TM (escore de 0 a 3). Comparação entre os grupos TP e TM.

\begin{tabular}{lccc}
\hline \hline & \multicolumn{3}{c}{ Pulmão Direito } \\
\hline \hline 6 horas & $0,0(0,0-1,0)$ & TM & $\mathrm{p}$ \\
24 horas & $0,0(0,0-1,0)$ & $0,5(0,0-1,0)$ & 0,905 \\
48 horas & $1,0(1,0-1,0)$ & $1,0(0,8-1,0)$ & 0,413 \\
72 horas & $1,0(1,0-1,0)$ & $0,0(0,0-0,0)$ & 0,690 \\
96 horas & $1,0(1,0-1,0)$ & $1,0(1,0-1,0)$ & 0,057 \\
\hline \hline & Pulmão Esquerdo & 1,000 \\
\hline \hline 6 horas & $0,0(0,0-0,0)$ & $0,0(0,0-0,0)$ & $\mathrm{p}$ \\
24 horas & $0,0(0,0-0,0)$ & $0,0(0,0-0,0)$ & 1,000 \\
48 horas & $1,0(1,0-1,0)$ & $0,0(0,0-0,3)$ & 0,0313 \\
72 horas & $1,0(0,5-1,0)$ & $0,0(0,0-0,8)$ & 0,352 \\
96 horas & $1,0(1,0-1,0)$ & $0,0(0,0-0,0)$ & 0,057 \\
\hline \hline
\end{tabular}

TP - talco de partículas pequenas, TM - talco de partículas de tamanhos diversos.

Tabela CC: Avaliação de macrófagos nos pulmões direito e esquerdo de coelhos submetidos à injeção intrapleural de TP ou de TM (escore de 0 a 3). Comparação entre os lados direito e esquerdo.

\begin{tabular}{|c|c|c|c|}
\hline \multicolumn{4}{|c|}{ Talco Pequeno } \\
\hline & Pulmão direito & Pulmão esquerdo & $\mathrm{P}$ \\
\hline 6 horas & $0,0(0,0-1,0)$ & $0,0(0,0-0,0)$ & 0,178 \\
\hline 24 horas & $0,0(0,0-1,0)$ & $0,0(0,0-0,0)$ & 1,000 \\
\hline 48 horas & $1,0(1,0-1,0)$ & $1,0(1,0-1,0)$ & 1,000 \\
\hline 72 horas & $1,0(1,0-1,0)$ & $1,0(0,5-1,0)$ & 1,000 \\
\hline 96 horas & $1,0(1,0-1,0)$ & $1,0(1,0-1,0)$ & 1,000 \\
\hline \multicolumn{4}{|c|}{ Talco Misto } \\
\hline & Pulmão direito & Pulmão esquerdo & $\overline{\mathrm{P}}$ \\
\hline 6 horas & $0,5(0,0-1,0)$ & $0,0(0,0-0,0)$ & 0,182 \\
\hline 24 horas & $0,0(0,0-0,0)$ & $0,0(0,0-0,0)$ & 1,000 \\
\hline 48 horas & $1,0(0,8-1,0)$ & $0,0(0,0-0,3)$ & 0,070 \\
\hline 72 horas & $0,0(0,0-0,0)$ & $0,0(0,0-0,8)$ & 0,423 \\
\hline 96 horas & $1,0(1,0-1,0)$ & $0,0(0,0-0,0)$ & 0,250 \\
\hline
\end{tabular}


Tabela DD: Avaliação de hemorragia nos pulmões direito e esquerdo de coelhos submetidos à injeção intrapleural de TP ou de TM (escore de 0 a 3). Comparação entre os lados direito e esquerdo.

\begin{tabular}{lccc}
\hline \hline \multicolumn{5}{c}{ Talco Pequeno } & \\
\hline \hline & Pulmão direito & Pulmão esquerdo & $\mathrm{P}$ \\
\hline \hline 6 horas & $0,0(0,0-1,0)$ & $0,0(0,0-1,3)$ & 0,749 \\
4 horas & $0,0(0,0-1,0)$ & $0,0(0,0-1,0)$ & 1,000 \\
78 horas & $0,0(0,0-0,3)$ & $0,0(0,0-0,5)$ & 1,000 \\
96 horas & $0,0(0,0-0,5)$ & $0,0(0,0-0,5)$ & 1,000 \\
\hline \hline & $1,0(0,5-1,0)$ & $0,0(0,0-0,5)$ & 0,182 \\
\hline \hline & Talco Misto & & \\
\hline \hline 6 horas & Pulmão direito & Pulmão esquerdo & $\mathrm{P}$ \\
24 horas & $0,0(0,0-0,0)$ & $0,0(0,0-0,0)$ & 1,000 \\
48 horas & $0,0(0,0-0,0)$ & $0,0(0,0-0,0)$ & 1,000 \\
72 horas & $1,0(0,8-1,3)$ & $0,0(0,0-0,3)$ & 0,099 \\
96 horas & $0,0(0,0-0,0)$ & $0,0(0,0-0,8)$ & 0,423 \\
\hline \hline TP - talco de partículas pequenas, TM - talco de partículas de tamanhos diversos. & 0,423 \\
\hline
\end{tabular}

Tabela EE: Avaliação de edema nos pulmões direito e esquerdo de coelhos submetidos à injeção intrapleural de TP ou de TM (escore de 0 a 3). Comparação entre os lados direito e esquerdo.

\begin{tabular}{lccc}
\hline \hline \multicolumn{4}{c}{ Talco Pequeno } \\
\hline \hline & Pulmão direito & Pulmão esquerdo & $\mathrm{P}$ \\
\hline \hline & $0,0(0,0-0,0)$ & $0,0(0,0-0,3)$ & 1,000 \\
& $0,0(0,0-0,0)$ & $0,0(0,0-0,0)$ & 1,000 \\
& $0,0(0,0-0,3)$ & $0,0(0,0-0,3)$ & 1,000 \\
& $0,0(0,0-0,0)$ & $0,0(0,0-0,0)$ & 1,000 \\
& $0,0(0,0-0,0)$ & $0,0(0,0-0,0)$ & 1,000 \\
\hline \hline & Talco Misto & \\
\hline \hline 6 horas & Pulmão direito & Pulmão esquerdo & $\mathrm{P}$ \\
24 horas & $0,0(0,0-0,0)$ & $0,0(0,0-0,0)$ & 1,000 \\
48 horas & $0,0(0,0-0,0)$ & $0,0(0,0-0,0)$ & 1,000 \\
72 horas & $0,0(0,0-0,5)$ & $0,0(0,0-0,0)$ & 1,000 \\
96 horas & $0,0(0,0-0,0)$ & $0,0(0,0-0,0)$ & 1,000 \\
\hline \hline & $0,0(0,0-1,5)$ & $0,0(0,0-0,0)$ & 0,423 \\
\hline \hline TP - talco de partículas pequenas, TM - talco de partículas de tamanhos diversos.
\end{tabular}


"Sou-Ihe grato, principalmente, pelo privilégio que me obteve de poder --sem demasia das ilusões, mas reverente --- levantar a voz nesse recinto, como um menino que depõe o seu brinquedo na superfície translúcida de uma água, para a qual a serenidade não é a estagnação, e cujo brilho da face viva nada rouba à projeção poderosa da profundidade".

João Guimarães Rosa 


\section{LISTA DE TABELAS}

